International Scientific-Technical and Production Journal

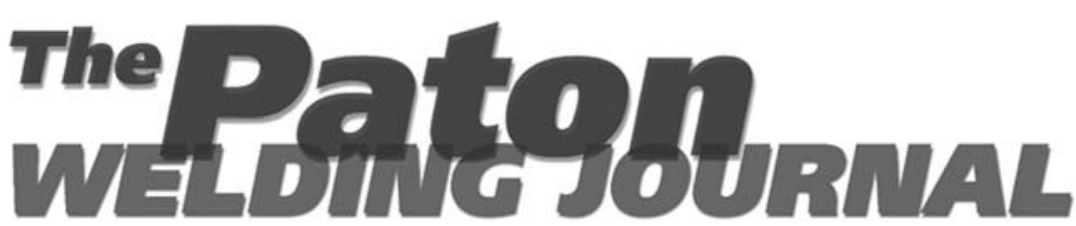

July 2015 No.7

Published since 2000

English translation of the monthly «Avtomaticheskaya Svarka» (Automatic Welding) journal published in Russian since 1948

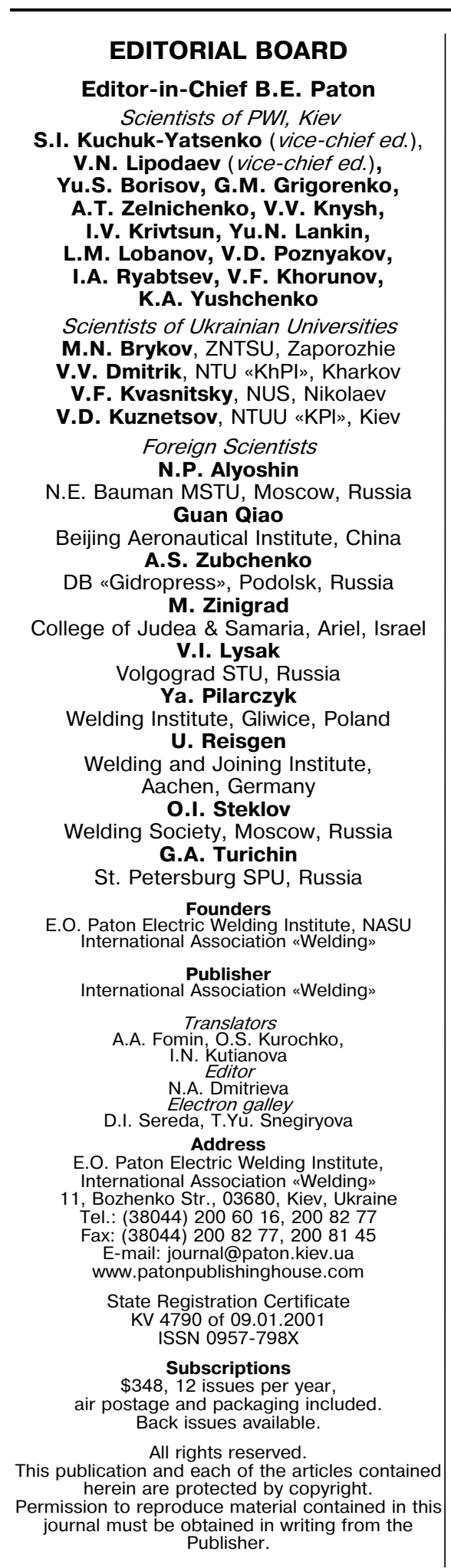

\title{
CONTENTS
}

Company «Plasma-Master Ltd.» is on the way of

innovation development

\section{SCIENTIFIC AND TECHNICAL}

Ustinov A.I., Falchenko Yu.V., Melnichenko T.V., Petrushinets L.V., Lyapina K.V. and Shishkin A.E. Vacuum diffusion welding of stainless steel through porous nickel interlayers

Dmitrik V.V., Sobol O.V., Pogrebnoj M.A. and Syrenko T.A.

Peculiarities of degradation of metal in welded joints of steam pipelines

Poklyatsky A.G., Klochkov I.N. and Motrunich S.I. Some advantages of butt joints of thin wrought aluminium alloys AMg5M and AMg6M produced by FSW, compared to TIG-welded joints

Levchenko O.G. and Bezushko O.N. Thermodynamics of formation of chromium compounds in welding aerosols

Makhlin N.M. and Korotynsky A.E. Asynchronous exciters and stabilizers of arc. Analysis and calculation procedure.

Part 2

\section{INDUSTRIAL}

Kuchuk-Yatsenko S.I., Rudenko P.M., Gavrish V.S., Didkovsky A.V. and Antipin E.V. Converter of frequency and number of phases for flash-butt welding of rails

Krivtsun I.V., Khaskin V.Yu., Korzhik V.N. and Luo Ziyi. Industrial application of hybrid laser-arc welding (Review)

Savulyak V.I., Zabolotny S.A. and Bakalets D.V. Evaluation of strength of joints produced using welding with concurrent brazing

Troitsky V.A. New possibilities of radiation control of quality of welded joints

\section{NEWS}

International Conference «Surfacing - Science,

Production, Prospects» 


\section{COMPANY «PLASMA-MASTER Ltd。» IS ON THE WAY OF INNOVATION DEVELOPMENT}

The R\&P company «Plasma-Master Ltd.» was founded in 1992 by the specialists in the field of technology of welding and surfacing. It has a research and production activity and is specialized on fulfillment of complicated engineering works. The company has several production facilities equipped with advanced welding, surfacing and machining equipment, which in combination with a gained experience of the company specialists allows solving the complicated technical problems. The company staff amounts 40 associates, mainly of research and engineering profile. The company is cooperating with research institutes of Ukraine, first of all with the E.O. Paton Electric Welding Institute of the NAS of Ukraine.

The Editorial Board initiated the interview with Dr. Som A.I., the director of «Plasma-Master Ltd.» company, believing that acquaintance with its effective activity will represent interest to the journal readers.

Dr. Som, the company «Plasma-Master Ltd.» is the recognized leader in Ukraine in the field of plasma-powder surfacing (PPS). How was the company founded? What problems were encountered at the initial stages of its foundation?

As you remember, in the early 1990s the situation in the country was complicated and ambiguous. The disintegration of the Soviet Union, rupture of economic relations and galloping inflation made many people think over: what is next to do? How shall we do? Our activity at the PWI, where I was working by then, had vague prospects. Later, me with a group of young specialists working along with me in the PWI, decided to organize our own company, which was supposed to be more

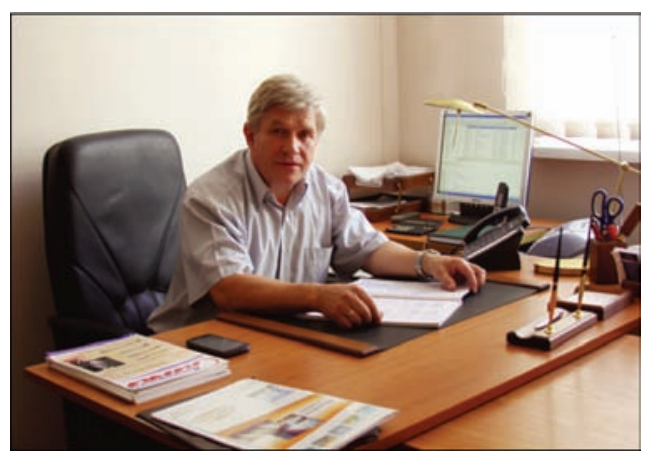
survivable and effective in a rough sea of market relations. The company under the name «Plasma-Master Ltd.» was registered in April, 1992. In the name of the company the word «plasma» implies a source of heating and we were going to work with using the PPS process. At the beginning it was difficult because of the lack of finances, facilities and equipment. But the knowledge and experience gained in the PWI, as well as foreign relations and sponsor assistance, allowed us to get used to the current situation very quickly. And in 1993, we had already delivered the installation for PPS of our own design and separately two new plasmatrons of different design to Germany. This success gave us confidence in our work. Later we encountered another difficulties, life brought also its corrections. Gradually, all the co-founders left the original team, but me, as the director, and the «brand» remained faithful to our business. The company mainly gained its development since 2000, when Ukrainian economy began its gradual revival. At the present time, in spite of objective difficulties, the company remains stable and has broad foreign relations.

What are the main activities of the company?

The basic list of activities is as follows:

- design and manufacture of equipment for PPS as well as technological maintenance;

- design and manufacture of plasmatrons for surfacing of different structures;

- fulfillment of different welding and surfacing works on the orders of industrial enterprises and private entities;

- consulting services on the choice of surfacing equipment and consumables.

Dr. Som, after graduation from the welding faculty of the Kiev Polytechnic Institute you worked 18 years at the PWI, defended thesis for the candidate's degree, became a senior staff scientist. It is interesting, what was the topic of your thesis?

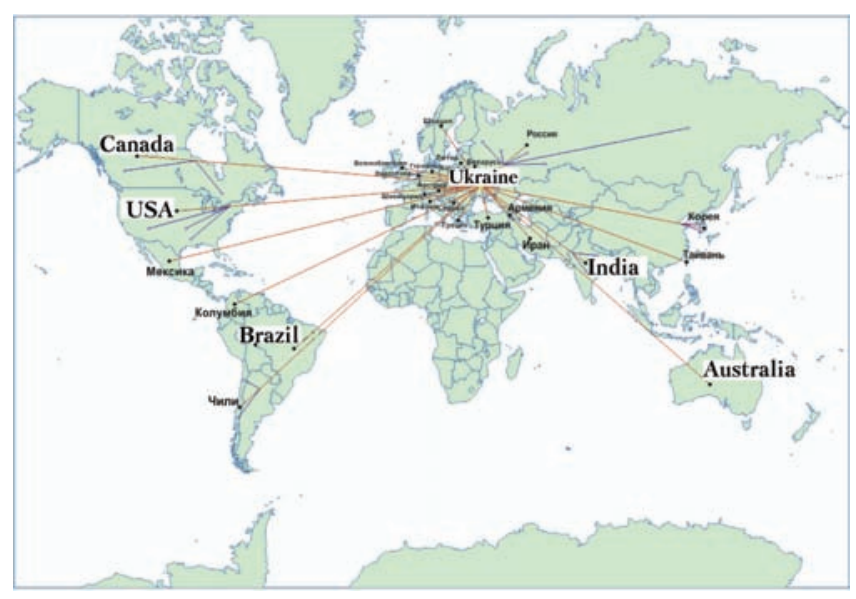

Geography of equipment delivery

The topic of my thesis, which I defended in 1985, directly

related to the development of equipment, consumables and technology of PPS of parts of an intricate shape (screws of extruders).

It turns out that the basis of the future engineering successes was laid already by then. Over the recent years you have multiplied your knowledge and «know-how» in the field of technology and design of equipment for PPS of complex products. In your opinion, what are the prospects in expanding the area of PPS application, including for 3D technology? 

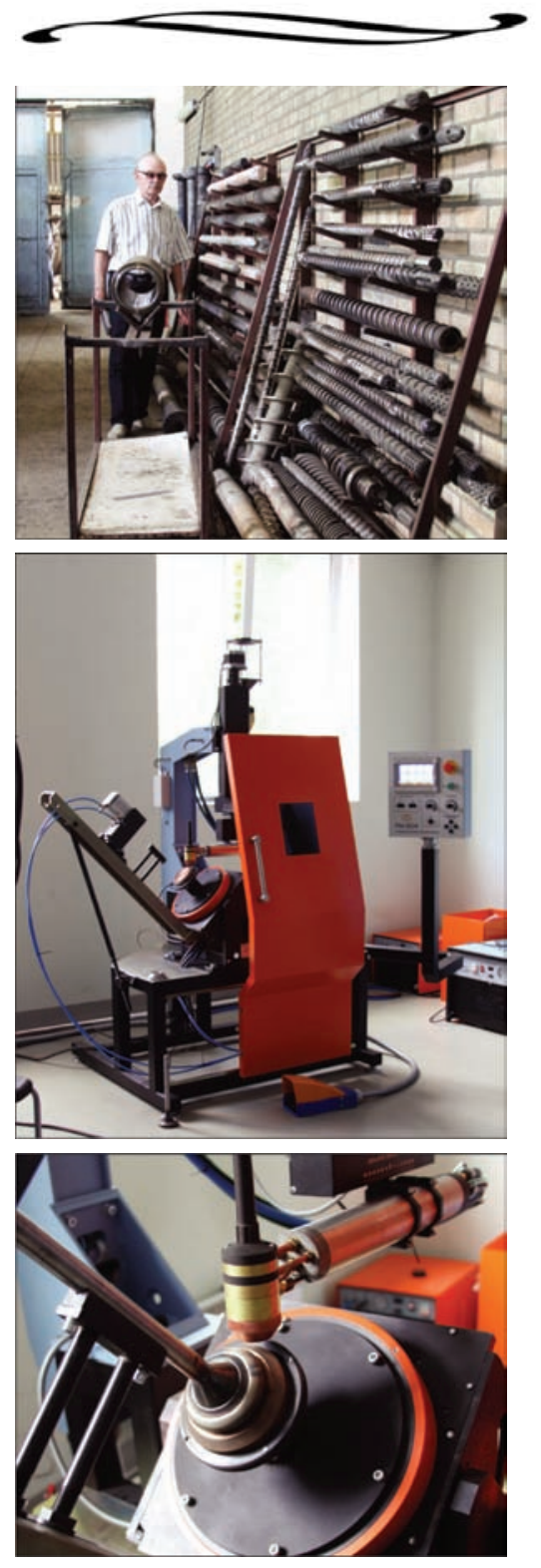
and other complex and critical products using PPS require integrated efforts in designing, engineering, mechanics, technology, materials science, and others. How did you manage to form a professional team for solving such complex problems?

The team was formed gradually through natural selection. The main thing in this work is to inspire the personnel to organize the work properly and to pay everybody a decent salary. It is necessary that people be proud and treasure their workplace. It is not easy in our time but we succeeded in something.

How are the portfolio of orders and such a broad geography of deliveries formed? How is the guaranty and service maintenance provided?

Today, we dispose such a powerful means of communication like the Internet, therefore, it is not difficult to attract potential customers to our products. It is important to respond timely to their inquiry and be able to manufacture and deliver the things shown on the website on time. We deliver the spare parts through the quick mail UPS, DHL or other carriers. A number of installations with a program control have a remote access via the Internet, so it is possible to adjust the working programs and settings without leaving the office. In some countries we have representative partners (USA, Poland, Lithuania, Republic of Korea), who also provide technical support to our customers. The geography of our partners is constantly expanding.

Dr. Som, you are a world-class expert, how do you estimate the directions of further development of plasma-powder surfacing?

This is, first of all, automation process and extension of rational applications. The equipment for PPS can be successfully applied for welding of critical structures using different working gases and shielding environment. It is not difficult to produce powders for this. This represents a very large field for activities.

Interview recorded by $A$. Zelnichenko and $V$. Lipodaev, PWI 


\title{
VACUUM DIFFUSION WELDING OF STAINLESS STEEL THROUGH POROUS NICKEL INTERLAYERS
}

\author{
A.I. USTINOV, Yu.V. FALCHENKO, T.V. MELNICHENKO, L.V. PETRUSHINETS, \\ K.V. LYAPINA and A.E. SHISHKIN \\ E.O. Paton Electric Welding Institute, NASU
}

11 Bozhenko Str., 03680, Kiev, Ukraine. E-mail: office@paton.kiev.ua

\begin{abstract}
Features of formation of permanent joints by diffusion welding through an intermediate interlayer based on porous nickel, produced by vapour phase vacuum deposition (EB PVD) were studied in the case of stainless steel Kh18N10T. It is shown that application of vacuum porous nickel condensates promotes lowering of temperature-force parameters of diffusion welding (welding temperature of $800{ }^{\circ} \mathrm{C}+$ cyclic load with $20 \mathrm{MPa}$ amplitude). Such an influence of the interlayer on the conditions of producing the welded joints is associated with superplastic behaviour of porous nickel and its non-equilibrium structure (small grain size and presence of vacancy type defects). It is established that pore healing in the interlayer is observed and diffusion processes between the interlayer and stainless steel are activated during diffusion welding. This results in formation of a defectfree zone of the joint based on nickel, alloyed with iron and chromium with strength properties only slightly different from those of base metal. 18 Ref., 6 Figures.
\end{abstract}

$\boldsymbol{K} \boldsymbol{e} \boldsymbol{y} \boldsymbol{w} \boldsymbol{o r d} \boldsymbol{s}:$ diffusion welding, stainless steel, intermediate layer, porous nickel interlayer, temperatureforce parameter, foil deformation behaviour

Application of ductile («soft») interlayers, having a low yield point, compared to the material being welded, promotes lowering of temperature and pressure, required to produce permanent joints by the method of vacuum diffusion welding [1]. Interlayer materials used usually are such metals as gold, silver, nickel, copper and aluminium in the form of foils, powders, coatings applied on the surfaces being joined by electroplating or vacuum deposition.

Application of «soft» interlayers in hard material welding is attributable to the fact that the conditions for realization of diffusion welding at relatively low temperature-force parameters of the process are favourable for establishing physical contact of the surfaces being welded and activation of diffusion processes in them. Such an influence of interlayers is related to the fact that their higher ductility, compared to the material being welded, leads to plastic deformation at lower loads, that results in filling of microroughnesses of the surfaces being joined, promoting their plastic deformation due to contact interaction with the interlayer.

It is shown in [2] that stress distribution in the interlayer is non-uniform. In welded joint central part stresses are determined chiefly by the normal component, and at greater distance from the joint center the tangential component becomes larger. Plastic flow of the interlayer un- der the impact of tangential component of stresses creates the necessary conditions to produce permanent joints at minimum temperature-force parameters of the process, predominantly over the contact surface periphery. Equalizing of the conditions for producing joints over the entire surface being welded is achieved at lowering of interlayer material yield point. It is believed that formation of full physical contact over the entire surface being welded, requires plastic deformation of the interlayer by not less than 5-10\% of its initial thickness.

As shown in $[3,4]$ plastic flow of interlayer material can be intensified at certain temperature-force parameters, for instance, by application of «perforated» foil, metal net, etc. as the interlayer.

Producing welded joints through an interlayer during diffusion welding can be promoted also by grain refinement, as with increase of grain boundary density the diffusion processes are greatly accelerated, due to diffusion coefficient being higher by several orders of magnitude along grain boundaries than through the grain bulk [5].

Effectiveness of application of porous highlydispersed materials as interlayers is shown in [6] in the case of ultradispersed powder interlayers, produced by reduction of nickel, copper and co- $^{-}$ balt formates.

Note that application of interlayers is usually accompanied by a change of composition in the joint zone, that can have a negative effect on corrosion and physical properties of the item. To 
reduce such an influence, researchers try to minimize the interlayer thickness. On the other hand, it turned out that such possibilities are limited. This is due to the fact that interlayer yield point rises dramatically with reduction of its thickness.

To lower the yield point of thin foils (10$20 \mu \mathrm{m}$ ), they should be heated up to the temperature, at which interlayer material becomes superductile, and this leads to welding temperature increase. Considering that structural superplasticity is associated with the action of plastic deformation mechanism in the material through grain slipping, factors, promoting the realization of this deformation mechanism, will lead to lowering of the temperature of material transition into superplastic state. Such factors include, primarily, grain refinement and presence of pores.

It is known that thin foils $(10-20 \mu \mathrm{m})$ based on ductile metals can be produced by vacuum deposition from the vapour phase [7], and changing their deposition conditions allows varying grain size and porous structure characteristics [8]. It can be assumed that such a foil structure will promote lowering of the temperature of its transition into superplastic state and decrease of plastic flow stress. Application of such foils as interlayers can ensure lowering temperatureforce parameters of diffusion welding. To study such a possibility, conditions for producing permanent joints by diffusion welding through interlayers based on porous nickel foil, made by EB PVD process, were investigated in this work for the case of stainless steel of Kh18N10T grade.

Conditions to produce permanent joints by diffusion welding without application of an interlayer were the subject of several studies [911]. In [9] it was established that optimal characteristics of welded joints from E10 alloy and $12 \mathrm{Kh} 18 \mathrm{~N} 10 \mathrm{~T}$ steel are achieved at welding temperature of $1100{ }^{\circ} \mathrm{C}$, specific pressure of $15 \mathrm{MPa}$ and soaking time of 10-15 min. In [10] $1 \mathrm{Kh} 18 \mathrm{~N} 9 \mathrm{~T}$ steel welding was performed at $T=$ $=1100{ }^{\circ} \mathrm{C}, P=25 \mathrm{MPa}$, and $10 \mathrm{~min}$ duration.

By the data of [11], to preserve austenitic structure it is recommended to perform welding of steels of $18-8$ type $(18 \% \mathrm{Cr}$ and $8 \% \mathrm{Ni})$ at temperatures below austenite transformation point and to minimize welding time. Proceeding from that, the following welding mode was proposed: $T=1000{ }^{\circ} \mathrm{C}, P=20 \mathrm{MPa}, t=10 \mathrm{~min}$. During welding, metal structure changes due to intragranular and intergranular creep, as well as processes of diffusion nature. Pressure increase essentially increases the creep rate, enhances intergranular creep and grain growth in the joint, that intensifies recrystallization proc- esses. At diffusion welding of austenitic steels, producing joints with optimum properties requires ensuring favourable conditions for recrystallization development, but it should be borne in mind here that excessive grain growth and impurity redistribution lead to lowering of joint impact toughness.

Materials and methods of investigation. Diffusion welding of samples from $12 \mathrm{Kh} 18 \mathrm{~N} 10 \mathrm{~T}$ steel was performed in the free state in vacuum with application of U-394M system, the blockdiagram of which is described in [12]. Welding process parameters were as follows: welding temperature was varied in the range of $T=800-$ $1100{ }^{\circ} \mathrm{C}$, welding duration was $t=5-20 \mathrm{~min}$, welding pressure $P=10-20 \mathrm{MPa}$, vacuum in the working chamber was maintained on the level of $1.33 \cdot 10^{-3} \mathrm{~Pa}$. To intensify establishing of physical contact of the surfaces being joined, in keeping with [13], cyclic application of compressive pressure was applied in a number of cases. Load was applied to the parts by the following scheme: $P=20 \mathrm{MPa}, t=$ $=3 \mathrm{~min}$, unloading to $P=5 \mathrm{MPa}$ with duration $t=1 \mathrm{~min}$. Total cycle number was 5 .

Thin foils of nickel were produced by EB PVD by the procedure described in detail in [14].

Analysis of structural characteristics of foil and welded joints was conducted with application of scanning electron microscope CAMSCAN 4, fitted with a system for energydispersive analysis EDX INCA 200 for local chemical composition of flat samples. For this purpose, transverse sections of foil and welded joints were prepared by a standard procedure with application of grinding-polishing equipment of «Struers» Company. Foil porosity was assessed with application of a computer method of microstructure image analysis.

Deformational behaviour of thin foils during heating under the conditions of continuous tensile loads, the magnitude of which was commensurate with tangential stresses developing in the interlayer during diffusion welding (of the order of $1 / 10$ of applied pressure), was assessed with application of a dylatometric unit fitted with a special device [15].

Mechanical properties of welded joints were assessed by the method of automatic indenting of welded joint cross-sectional plane with recording of the diagram of indenter loading and unloading in Micron-gamma unit [15].

Results and their discussion. Figure 1 shows the characteristic cross-sectional microstructure of porous nickel foil, produced by EB PVD. It is seen that foil microstructure after deposition (Figure 1, $a$ ) is characterized by a columnar grain 


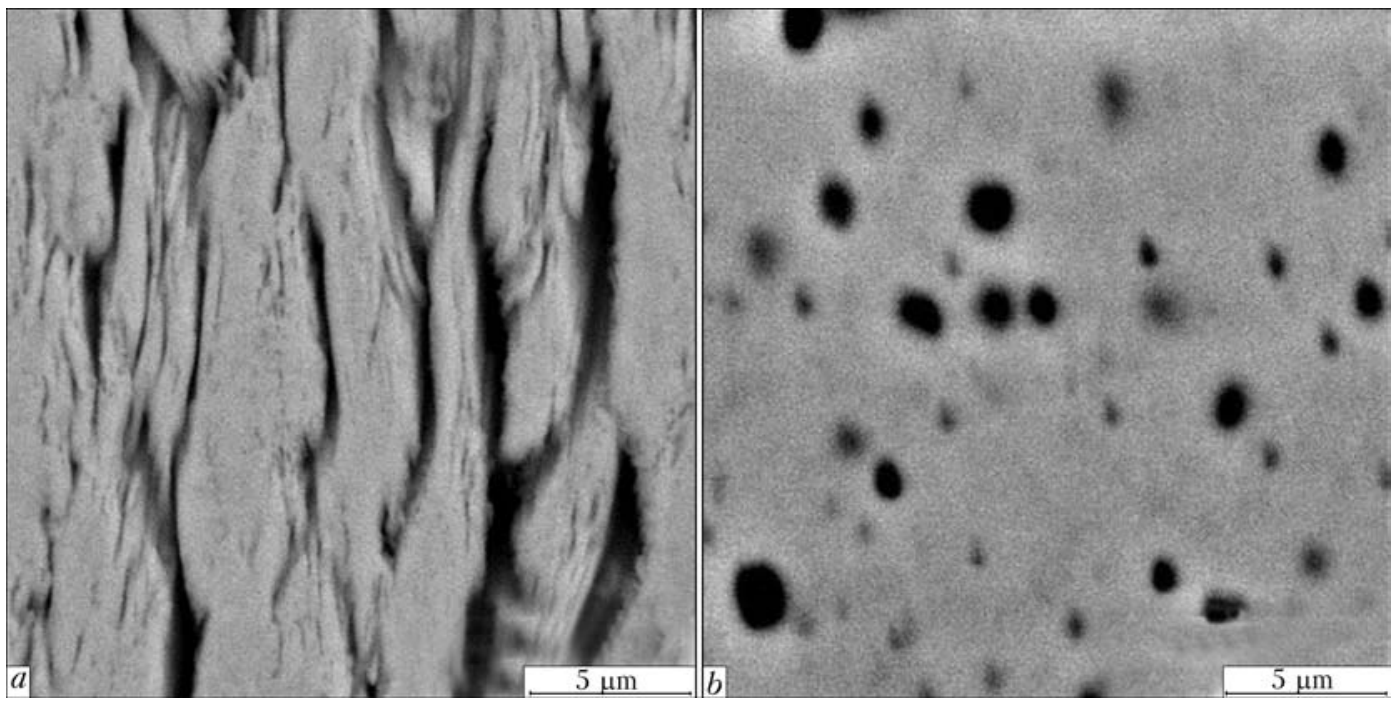

Figure 1. Cross-sectional microstructure of porous nickel foil with 25 vol. $\%$ of pores: $a-$ after deposition; $b-$ after annealing at $600{ }^{\circ} \mathrm{C}$ for $20 \mathrm{~min}$

structure, on the boundary of which elongated open porosity is observed, which runs through the entire thickness of the foil. Low deposition temperature $\left(<0.3 T_{\text {melt }}\right)$ leads to formation of foil in structurally-nonequilibrium state, characterized by elongated grains with cross-section of the order of $2-3 \mu \mathrm{m}$, and increased concentration of vacancies.

Yield point of porous foils was evaluated by the data on their microhardness as $1 / 3 H_{\mu}$ [17]. It turned out that with porosity increase foil yield point at room temperature decreases from $600 \mathrm{MPa}$ for defectfree nickel foil, produced by EB PVD, to $300 \mathrm{MPa}$ for nickel foil with porosity of 25 vol.\%.

Investigations of deformational behaviour of porous nickel foil at heating under the conditions of continuous tensile stresses (of the order of 2-4 MPa) showed that foil plastic flow velocity non-monotonically depends on temperature. As is seen from Figure 2, $a$, foil deformation rate remains on the level of nickel thermal expansion factor (tensile stresses below foil yield point) up to $400-450{ }^{\circ} \mathrm{C}$. At increase of foil temperature, its deformation rate starts growing continuously that is associated with its plastic deformation. In the region of $550-600{ }^{\circ} \mathrm{C}$, dependence of deformation rate on foil temperature becomes exponential that is indicative of its transition into the superplastic state.

Note that during superplastic flow foil structure undergoes qualitative changes - open type porous structure changes to closed type porous structure (Figure 2,b). This is accompanied by reduction of foil porosity from 25 to 18 vol.\%. Here, pores size is also significantly reduced.

Microstructures of porous foil after its annealing at $600{ }^{\circ} \mathrm{C}$ in the free state (without load application) were studied to identify the factors, which have an essential influence on pore evolution during its superplastic flow. It is seen $\left(\mathrm{Fi}^{-}\right.$ gure $1, b$ ) that during annealing structural trans-
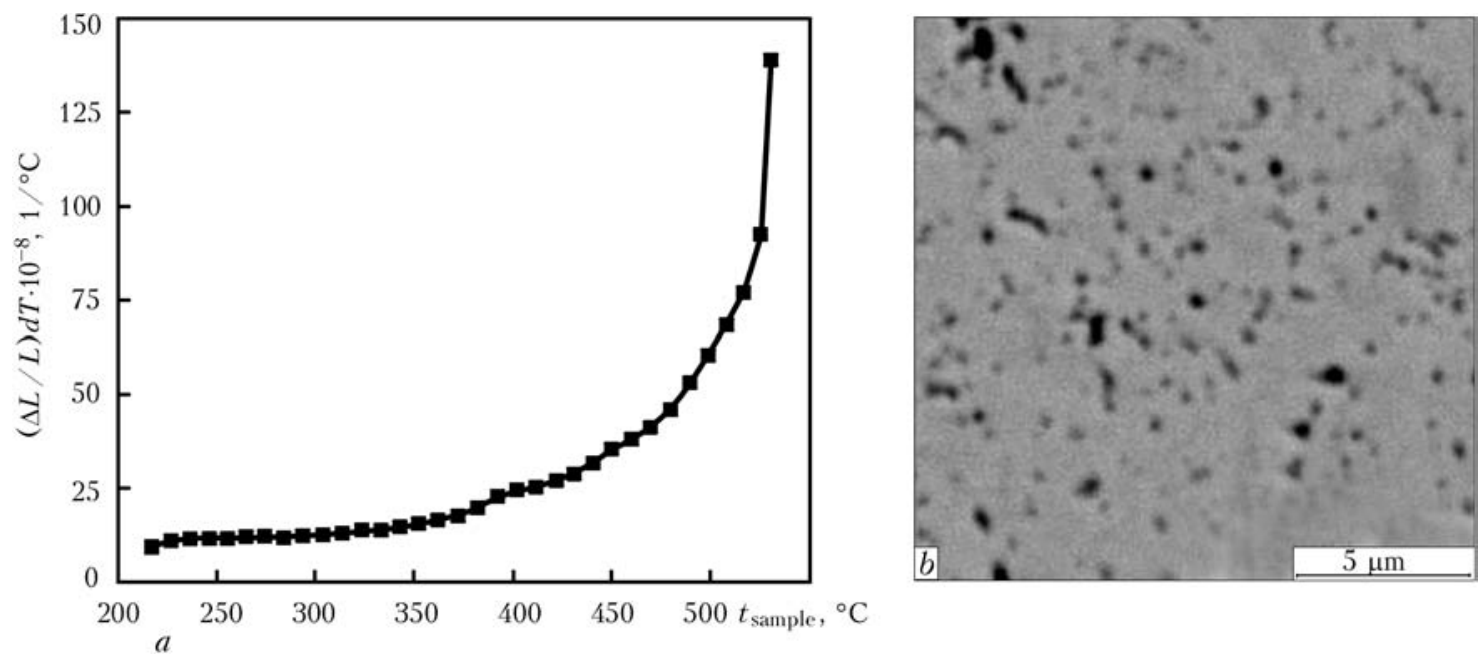

Figure 2. Temperature dependence of nickel foil deformation rate (porosity of 23 vol.\%) at heating under the conditions of continuous tensile stresses of $4 \mathrm{MPa}(a)$, and foil microstructure after its deformation $(b)$ 

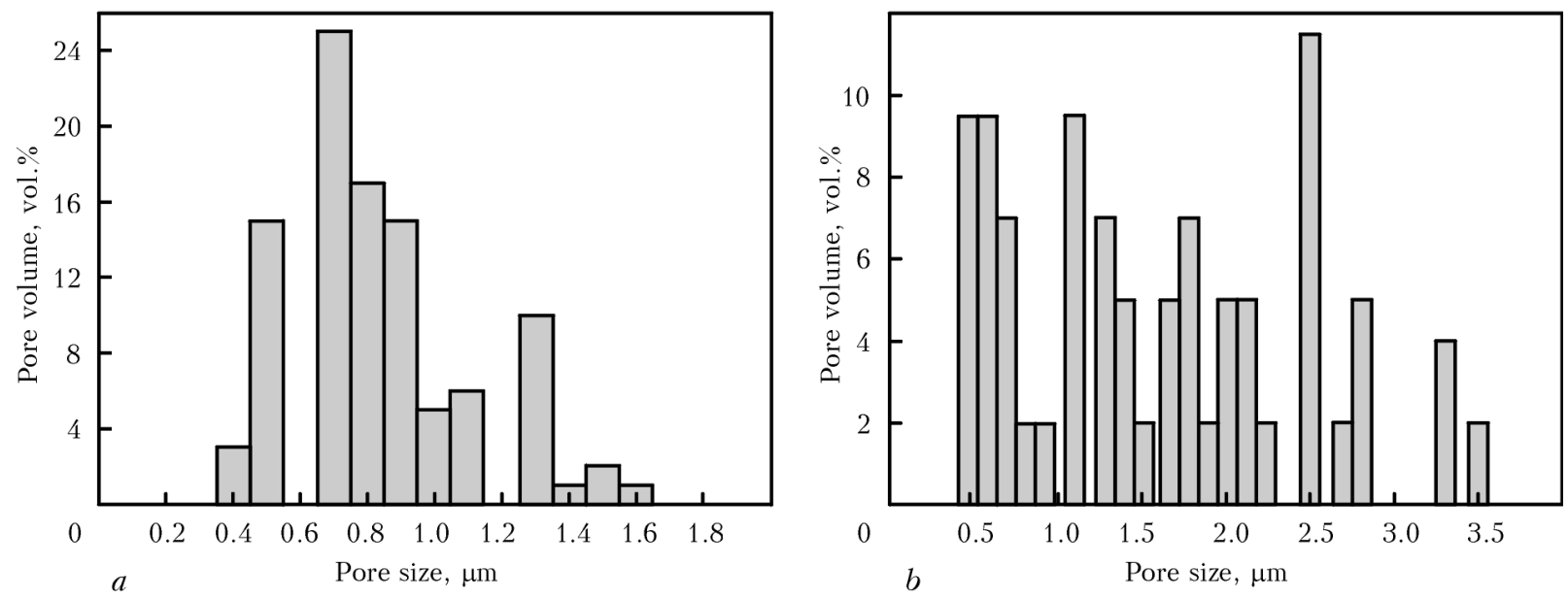

Figure 3. Size distribution of pores in nickel foil after heating up to $600{ }^{\circ} \mathrm{C}$ under the conditions of continuously applied tensile stresses $(a)$ and after annealing at $600{ }^{\circ} \mathrm{C}$ for $20 \mathrm{~min}(b)$

formations run in the foil, which are accompanied by changing of its porous structure: pores become closed and acquire a spherical shape, porosity decreases to 18 vol.\%.

However, unlike foil porous structure after its plastic deformation by superplastic flow mechanism, which is characterized by narrow distribution of pore sizes (Figure 3,a), porous structure of annealed foil has a broader pore distribution by size (from fractions of a micron to several microns) (Figure $3, b$ ). It can be assumed that formation of foil porous structure during its annealing is the consequence of running of various processes in it. Some of them are associated with reduction of free surface of open porosity. This causes its evolution, leading to open pore healing that results in formation of relatively coarse closed porosity. Other processes can be associated with relaxation of excess vacancies, inherent to vacuum condensates produced under temperature conditions, when diffusion mobility of atoms is limited (at $T_{\mathrm{d}}<1 / 3 T_{\mathrm{m}}$, where $T_{\mathrm{d}}$ is the deposition temperature, and $T_{\mathrm{m}}$ is the nickel melting temperature), which are accompanied by their combining into complexes with subsequent transformation into pores. These processes can result in formation of closed pores of relatively small (submicron) size.

Absence of coarse pores in the foil after superplastic flow leads to the assumption that plastic deformation promotes healing of coarse pores, whereas finer pores are preserved. According to [18], pore presence in the material is a prerequisite for realization of its superplastic flow by the mechanism of grain slipping.

Thus, plastic flow of porous nickel foil at relatively low heating temperatures can be related to presence of open porosity and structural changes in foil material, which are due to relaxation of excess vacancies, transformation of open pore structure into closed pore structure, and processes of pore coalescence and healing, that should promote not only lowering of temperature of foil transition into superplastic state, but also intensification of diffusion processes in it.

Figure 4, $a$ shows the microstructure of welded joint of stainless steel samples, produced by the method of diffusion pressure welding at $1100{ }^{\circ} \mathrm{C}$ without application of the interlayer.

It is seen that welded joints, made without the interlayer, are characterized by presence in the joint zone of defects in the form of microdiscontinuities and pores, that results from poor physical contact of the surfaces of samples being welded.

Diffusion welding of stainless steel samples through an interlayer from porous nickel allows lowering welding temperature to $900{ }^{\circ} \mathrm{C}$, and ensuring formation of a defect-free joint zone. Figure $4, b$ shows the microstructure of the zone of a joint produced with application of porous nickel foil $25 \mu \mathrm{m}$ thick. It is seen that there are no defects or discontinuities in the butt joint area. The interface of foil and steel is blurred, that is indicative of diffusion processes running in this zone, and foil surface envelops the steel surface roughness contours. This is an indication of foil plastic deformation under the impact of applied load, and presence of a diffusion zone on the interface of these surfaces points to establishing of physical contact between them and diffusion interaction of the contacting surfaces. Intensive running of diffusion processes in joint zone is also indicated by nickel and iron distribution in the butt joint area (Figure 5, a): elements, included into stainless steel composition $(2.5 \% \mathrm{Fe}$, $1.1 \% \mathrm{Cr})$ are present in nickel interlayer.

Note also the fact that there are no pores in the joint zone. As the processes of atom diffusion from steel into the interlayer and pore healing can be facilitated by foil non-equilibrium struc- 

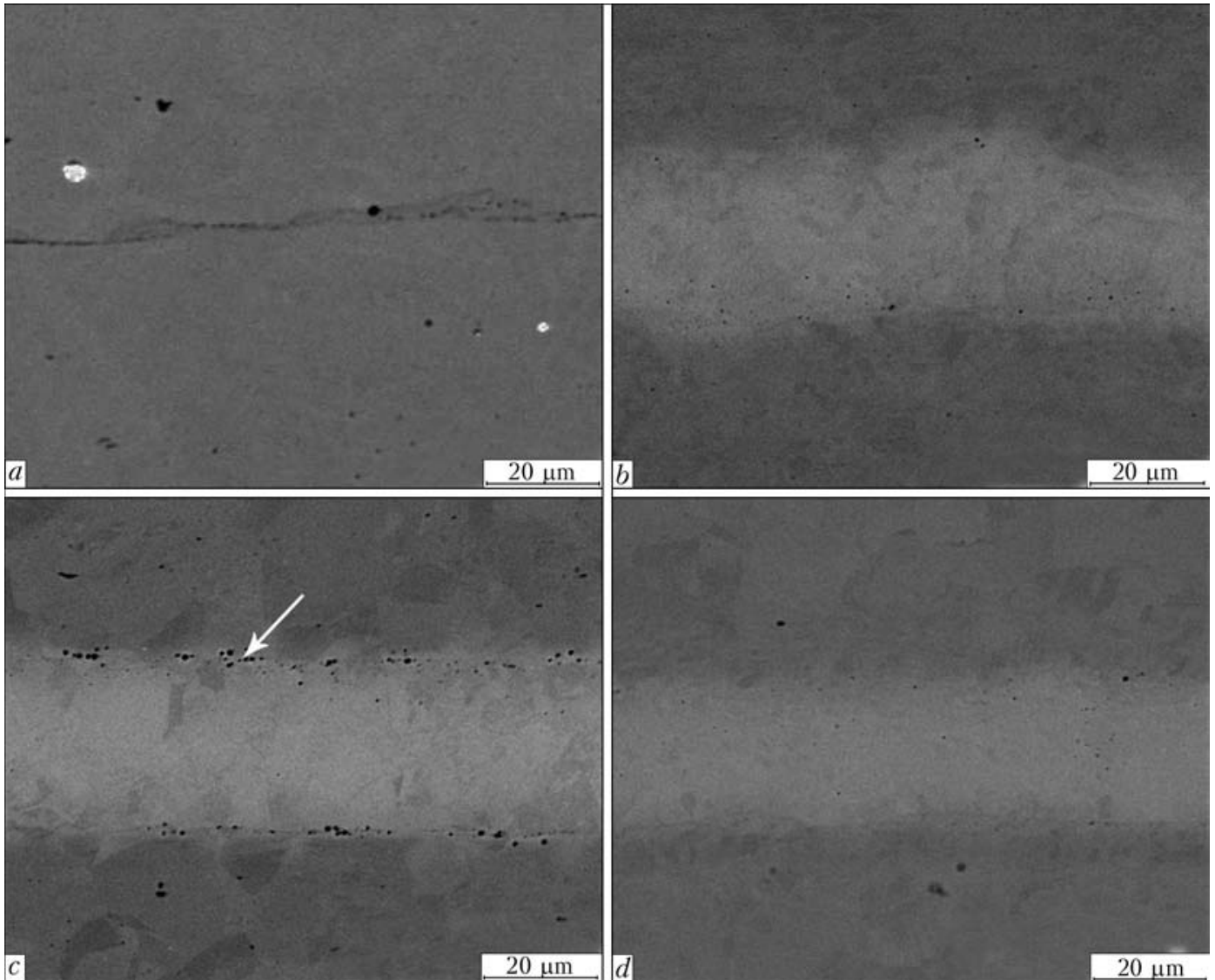

Figure 4. Microstructure of welded joint of stainless steel samples produced by diffusion welding at $T=1100{ }^{\circ} \mathrm{C}, P=$ $=20 \mathrm{MPa}$ without interlayer $(a)$, at $T=900{ }^{\circ} \mathrm{C}, P=20 \mathrm{MPa}$ with application of porous nickel interlayer $(b)$, with application of porous nickel interlayer pre-annealed at $600{ }^{\circ} \mathrm{C}$ for $20 \mathrm{~min}(\mathrm{c})$, in welding at $T=800{ }^{\circ} \mathrm{C}, P=20 \mathrm{MPa}+$ cyclic loading with application of porous nickel interlayer $(d)$

ture due to excess vacancies, diffusion welding of steel samples was performed under similar conditions $\left(T=900{ }^{\circ} \mathrm{C}, P=20 \mathrm{MPa}\right)$ with application of porous nickel foil as interlayer, which was pre-annealed at $600{ }^{\circ} \mathrm{C}$ for $20 \mathrm{~min}$. It is seen that (Figure $4, c$ ) in this case pores and discontinuities (arrow) form on foil/steel interface.

Such a welded joint structure can be the result of both the change of foil porous structure and lower concentration of excess vacancies in it.

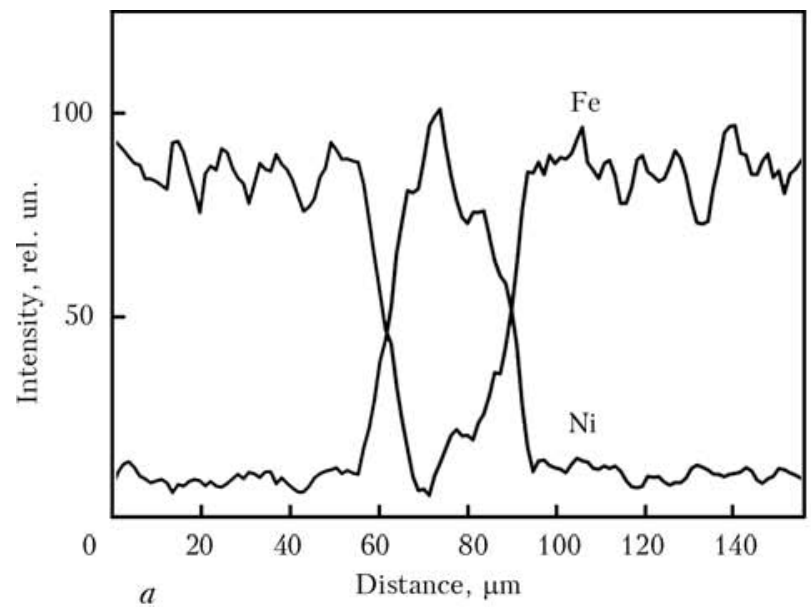

Both the factors can have an influence both on foil superplastic flow under the impact of applied pressure, and on diffusion processes in the joint zone, that, in its turn, influences establishing of physical contact between the surfaces being welded (foil and steel) and their diffusion interaction. Therefore, formation of porous foil with a more equilibrium pore shape and partial relaxation of excess vacancies (by their coales-

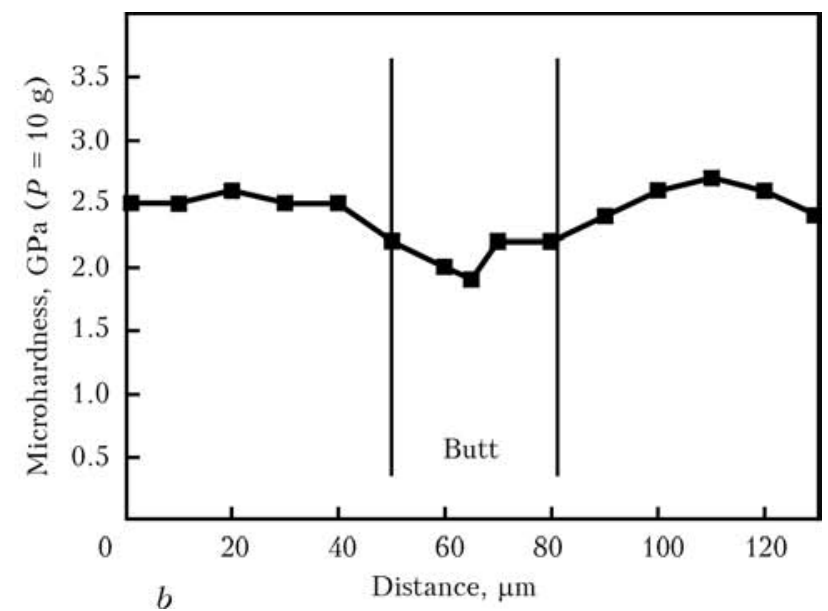

Figure 5. Nickel and iron distribution in the zone of stainless steel joint made by diffusion welding through an interlayer of porous nickel at $T=900{ }^{\circ} \mathrm{C}, P=20 \mathrm{MPa}(a)$, and respective microhardness distribution $(b)$ 


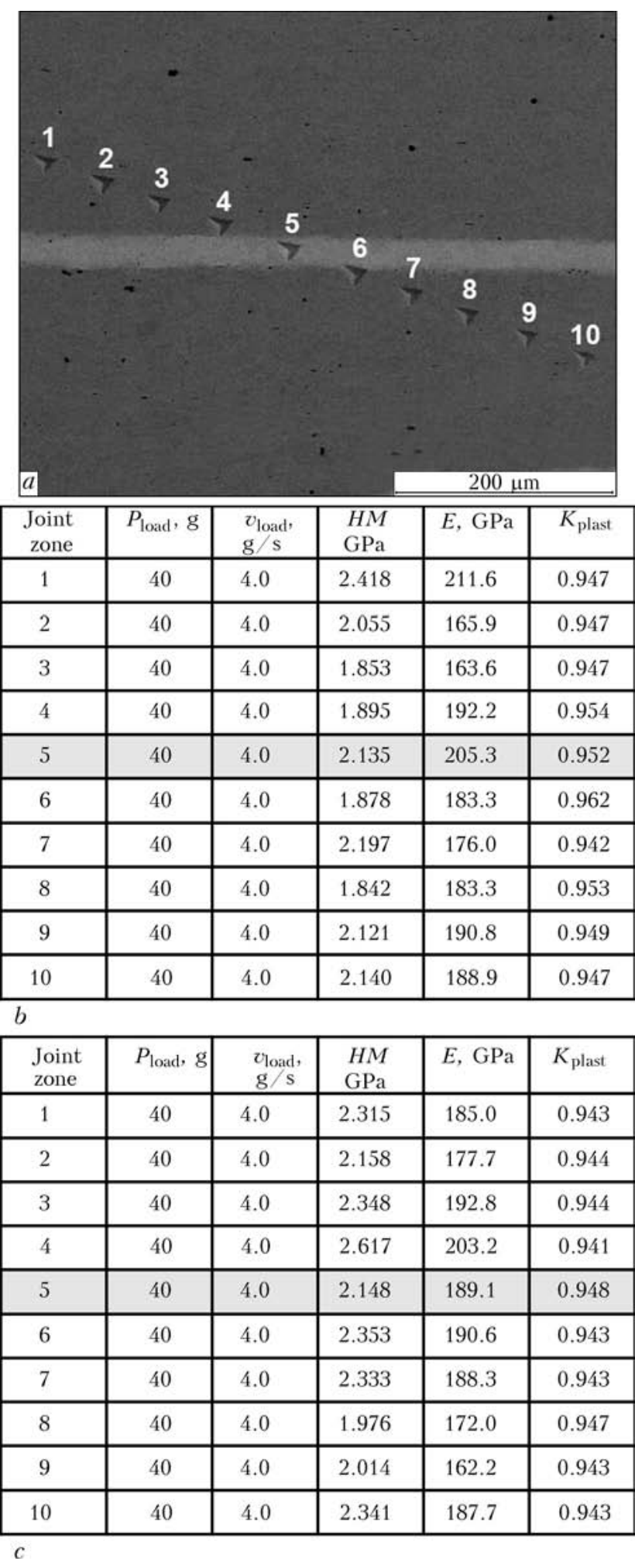

Figure 6. Results of automatic indenting of the zone of stainless steel sample joint produced with application of intermediate foil from porous nickel: $a$ - imprints from indentation; $b-$ welding at $T=900{ }^{\circ} \mathrm{C}, P=20 \mathrm{MPa} ; c-$ welding at $T=800^{\circ} \mathrm{C}, P=20 \mathrm{MPa}+$ cyclic loading; $P_{\text {load }}-$ loading; $v$ - loading rate; $H M$ - Meyer microhardness values; $E$ - Young's modulus; $K_{\text {plast }}$ - plasticity coefficient; highlighted line corresponds to butt joint area in Figure 6, $a$

cence into nanopores) during pre-annealing impairs the weld structure.
Joint mechanical properties were assessed by the method of automatic indentation of the crosssection with application of Micron-gamma instrument at $40 \mathrm{~g}$ load, at indenter loading rate of $4 \mathrm{~g} / \mathrm{s}$. To widen measurement range, indentation was conducted along a line oriented at an angle of $20-25^{\circ}$ to the joint zone (Figure $6, a$ ).

The Table (Figure 6, b) gives measurement results, where the highlighted line shows material properties in the butt joint area. Analysis of measurement results showed that mechanical properties of the joint zone practically do not differ from those of steel. So, a slight lowering of material microhardness was noted in the butt joint area (see Figure 5, $b$ ). Close values of the modulus of elasticity, microhardness and coefficient of plasticity of steel and material in the butt joint area are indicative of formation of a practically equivalent joint.

It turned out that transition from static load during welding to cyclic load (alternative application of loading and unloading) allows additional activation of diffusion processes in the joint zone. As a result, welding temperature can be lowered by $100{ }^{\circ} \mathrm{C}$. Figure $4, d$ shows the microstructure of the zone of the joint produced at $800{ }^{\circ} \mathrm{C}$ under the conditions of cyclic loading. On the other hand, it should noted that lowering of welding temperature somewhat delays the growth of structural elements, namely pores and grains, in the butt joint area.

Thus, it is shown in the case of stainless steel that application of porous nickel foil produced by EB PVD, as an interlayer, allows lowering the temperature-force parameters of diffusion welding, compared to modes of diffusion welding without application of the interlayer.

\section{Conclusions}

Porous structure of nickel foils, produced by vacuum deposition from the vapour phase, is characterized by a low temperature of transition into the superplastic state, that is related not only to presence of open-type porosity, but also to notequilibrium state of foil structure, which can be due to presence of excess vacancies in vacuum condensates.

Application of porous nickel foil as interlayers in diffusion welding of stainless steel allows producing defect-free joints with a small thickness of the butt zone at lower temperature-force parameters of welding (welding temperature of $800{ }^{\circ} \mathrm{C}$, cyclic load with $20 \mathrm{MPa}$ amplitude).

Influence of porous structure of nickel foil on diffusion welding parameters is related to the features of its deformational behaviour, due to 
lowering of the yield point at foil transition into the superplastic state and activation of diffusion processes in the joint zone. Foil plastic flow during welding ensures establishing physical contact of the surface being welded and the interlayer, and relaxation of foil non-equilibrium state activates their diffusion interaction and promotes pore healing.

1. Musin, R.A., Antsiferov, V.N., Kvasnitsky, V.F. (1979) Diffusion welding of heat-resistant alloys. Moscow: Metallurgiva.

2. Bakshi, O.A. (1965) On stress state of soft interlayers in welded joints under tension (compression). Voprosy Svarochn. Proizvodstva: Transact. of ChPI, 33-35, 36.

3. Musin, R.A., Lyamin, Ya.V. (1991) Application of perforated interlayers in diffusion welding. Svarochn. Proizvodstvo, 2, 2-4.

4. Lyamin, Ya.V., Karakozov, E.S., Musin, R.A Method of pressure welding with heating. USSR author's cert. 1463415. Int. Cl. B23 K20/16. Publ. 30.01.89.

5. Bokshtejn, S.Z. (1971) Structure and properties of metal alloys. Moscow: Metallurgiya.

6. Lyushinsky, A.V. (2006) Diffusion welding of dissimilar metals. Moscow: Akademiya.

7. Movchan, B.A. (1998) Inorganic materials deposited from vapor phase in vacuum. In: Modern materials science of 21st century, 318-332. Kiev: Naukova Dumka.

8. Ustinov, A.I., Lyapina, K.V., Melnichenko, T.V. et al. (2008) Influence of substrate temperature on formation of porous structure in stainless steel in case of its deposition with $\mathrm{NaCl}$ and $\mathrm{KCl}$ vapors. Advances in Electrometallurgy, 1, 8-11.

9. Novikov, V.G. (1973) Development of technology of vacuum diffusion welding of electromagnet casings. In: Proc. of 7th All-Union Sci.-Techn. Conf. on Diffusion Vacuum Joining of Metals, Alloys and Nonmetallic Materials, 102-106.

10. Gelman, A.S., Bolshakov, M.V. (1967) Effect of oxide films on joint formation in pressure welding of metals. Svarochn. Proizvodstvo, 10, 23-26.

11. Kozakov, N.F. (1976) Diffusion welding of materials. Moscow: Mashinostroenie.

12. Konyushkov, G.V., Kopylov, Yu.N. (1974) Diffusion welding in electronics. Moscow: Energiya.

13. Ustinov, A.I., Lyapina, K.V., Melnichenko, T.V. (2005) Regularities of stainless steel porous structure formation during its deposition from vapor phase in presence of sodium chloride vapors. Advances in Electrometallurgy, 4, 19-24.

14. Ustinov, A.I., Matvienko, Ya.I., Polishchuk, S.S. et al. (2009) Investigation of phase transformations and plastic deformation at continuous heating of $\mathrm{Al} / \mathrm{Cu}$ multilayer foil. The Paton Welding J., 10, 23-27.

15. Firstov, S.A., Gorban, V.F., Pechkovsky, E.P. et al. (2007) Equation of indentation. Dopovidi NANU, 12, 100-106.

16. Cahoon, J.R., Broughton, W.H., Kutzak, A.R. (1971) The determination of yield strength from hardness measurements. Metallurg. Transact., 2(7), 1979-1983.

17. Kuznetsova, R.I., Bryukhovetsky, V.V., Pojda, V.P. et al. (1995) Mechanism of development of grain boundary pores and local heterogeneity of deformation under superplastic flow conditions. Metallofizika i Nov. Tekhnologii, 17(8), 64-72.

Received 23.03.2015 


\title{
PECULIARITIES OF DEGRADATION OF METAL IN WELDED JOINTS OF STEAM PIPELINES
}

\author{
V.V. DMITRIK ${ }^{1}$, O.V. SOBOL ${ }^{1}$, M.A. POGREBNOJ ${ }^{1}$ and T.A. SYRENKO ${ }^{2}$ \\ ${ }^{1}$ National Technical University «Kharkov Polytechnic Institute» \\ 21 Frunze Str., 61002, Kharkov, Ukraine. E-mail: svarka126@ukr.net \\ ${ }^{2}$ Kharkov Machine-Building College \\ 79 Plekhanovskaya Str., 61068, Kharkov, Ukraine
}

\begin{abstract}
Extension of life of steam pipelines, operated under creep conditions, determines the necessity of evaluation of their damageability and in many respects depends on carbide transformations in metal. The work considers peculiarities of diffusion and structure of carbide phases in metal of welded joints of pearlite steels after long-term operation. It is determined that concentration of coagulating carbide phases $\left(\mathrm{M}_{23} \mathrm{C}_{6}, \mathrm{M}_{7} \mathrm{C}_{3}\right.$ etc. $)$ at the boundaries of $\alpha$-phase grains promotes for nucleation of creep pores and fatigue cracks, that causes brittle fracture of metal of welded joints. 18 Ref., 8 Figures.
\end{abstract}

Key words: steam pipeline welded joints, carbide phases, creep pores, fatigue cracks, damageability, operation life

Running of steam pipelines of Ukrainian HPP makes around 200-300 thousand hours, that for

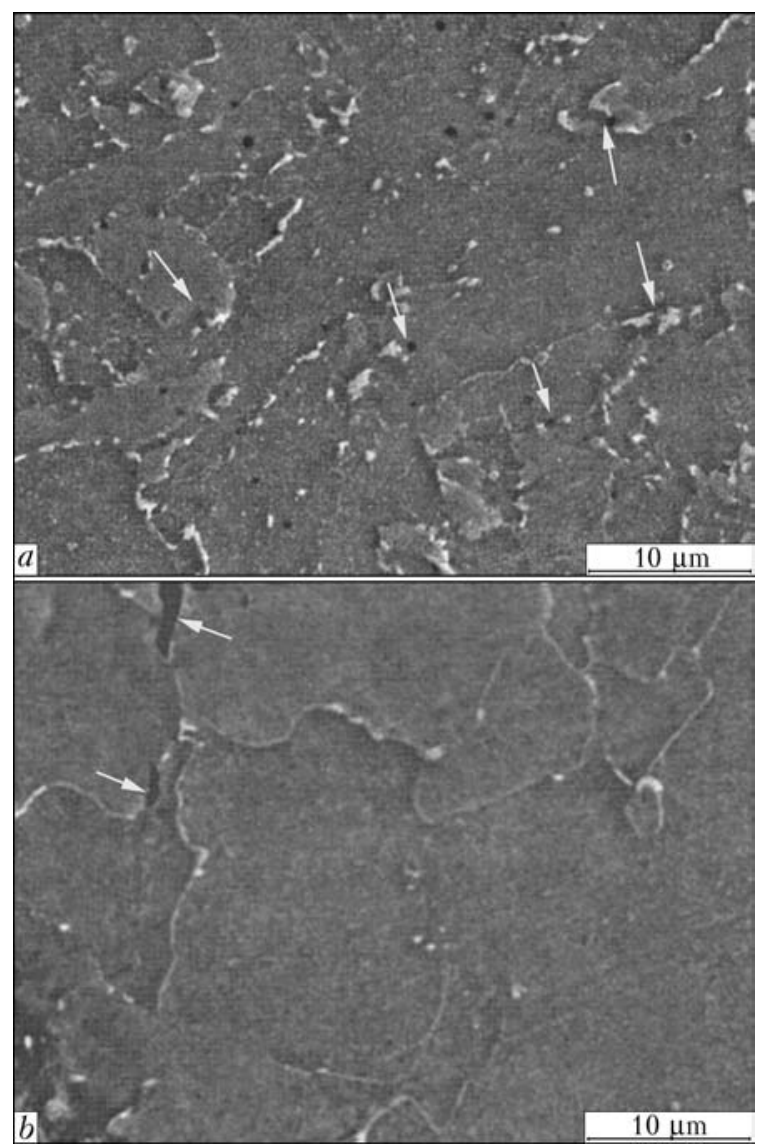

Figure 1. Microstructure of area of HAZ metal overheating of welded joint from steel $12 \mathrm{Kh} 1 \mathrm{MF}: a-$ creep micropores in area of incomplete recrystallization; $b-$ fatigue microcracks; defects are indicated by arrows

(c) V.V. DMITRIK, O.V. SOBOL, M.A. POGREBNOJ and T.A. SYRENKO, 2015 most of them exceeds their design life (including extended) as well as significantly outdo fleet life.

Metal of welded joints of steam pipelines is characterized by structural, chemical and mechanical inhomogeneity, formation of which is promoted by welding heating at their manufacture. Namely, inhomogeneity under conditions of long-term operation provides for more intensive physical-chemical processes in welded joint metal than in the base metal, that, respectively, provokes its degradation and limits the life.

Evaluation of damageability level in welded joints of steam pipelines of long-term operation, which allows specifying their residual life, is of current importance. Investigation of peculiarities of physical-chemical processes, taking place in welded joint metal, is relevant for evaluation.

It is a well-known fact that welded joints of elements of steam conduit channel from $15 \mathrm{Kh} 1 \mathrm{M} 1 \mathrm{~F}$ and $12 \mathrm{Kh} 1 \mathrm{MF}$ steels, being operated under $545-585{ }^{\circ} \mathrm{C}$ temperature and $20-25 \mathrm{MPa}$ pressure [1-7], mostly suffer from damages at long-term running. Transfer of power generating units in cycling operation mode provides for acceleration of their damageability. Damageability of metal of welded joints mainly takes place by creep and fatigue mechanisms, which are forced by corrosion constituent (Figure 1). Damageability by creep mechanism is characterized by formation of nucleation (critical) pores of around $0.03-0.07 \mu \mathrm{m}$ size as well as their coarsening up to $3-7 \mu \mathrm{m}$, further branching and transformation of pores in creep cracks.

The most intensive formation of creep pores is observed in areas of incomplete recrystallization and fusion of HAZ of welded joints in their external, most elongated area. The fatigue cracks 


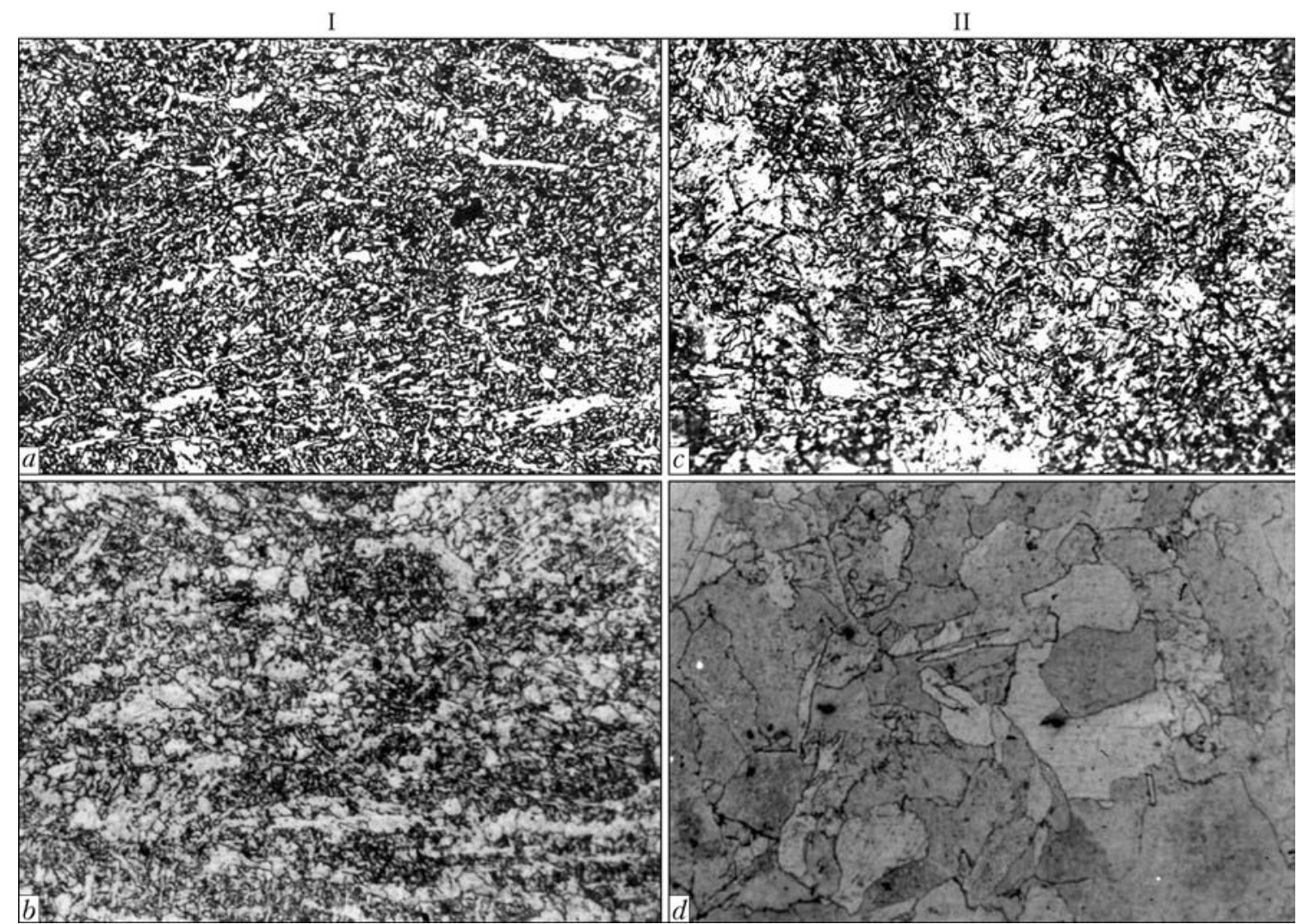

Figure 2. Microstructure $(\times 100)$ of welded joint from steel 15Kh1M1F: $a, c-$ initial structure; $b-$ after $200,000 \mathrm{~h}$ running; $d-280,000$ h; I - weld metal (alloy 09KhMF); II - area of HAZ metal overheating

have the most intensive development in areas of fusion, overheating and incomplete recrystallization of HAZ metal, rarely in weld and base metal. The fatigue cracks are mainly formed on internal surface of welded joints. Damageability of metal of welded joints is to be considered as an effect of its degradation, which is provided by physical-chemical processes and detected by means of examination of its structure as the most reliable parameter.

Structure of welded joints (areas of HAZ, weld and base metals) in process of long-term operation is transformed with different rate in ferrite-carbide mixtures different between themselves (Figure 2). Determination of $\alpha$-phase grain average size; average size of carbides and density of their distribution along the grain body; form, size and distribution of carbides along the grain boundaries; amount of pores and their form, location, average and maximum size as well as specific porosity of metal of welded joints are relevant for evaluation of structure degradation.

Structural changes in welded joints are caused by physical-chemical processes, investigation of which is relevant for reduction of such changes.

Diffusion displacement of atoms of chromium and molybdenum from central zones of $\alpha$-phase crystals in their near-boundary zones [8] takes place under conditions of operating stresses and temperature. Diffusion in inter-grain boundaries, i.e. boundary diffusion, takes place simultaneously at larger rate. Coefficients of boundary and volumetric diffusion are not constant values. Therefore, deviation from Arrhenius law is noted in steam pipeline metal.

Fischer model [9] with introduction of some specifications [10] is more appropriate than other ones for investigation of flows of boundary and volumetric diffusion as separated. Such specifications allow determining dependencies of coagulation of carbides of the 1st group by length. Considering value of diffusion coefficients [8], Fick's equation applicable to boundary diffusion of atoms of chromium and molybdenum is written as:

$$
\left\{\begin{array}{l}
\frac{d(\mathrm{Cr})}{d t}=-\frac{d j_{y}}{d y}-2 \frac{1}{\delta} j_{x}=D_{r} \frac{d^{2}(\mathrm{Cr})}{d y^{2}}+\frac{2 D_{\mathrm{v}}}{\delta} \frac{d(\mathrm{Cr})}{d x} \\
\frac{d(\mathrm{Mo})}{d t}=-\frac{d j_{y}}{d y}-2 \frac{1}{\delta} j_{x}=D_{r} \frac{d^{2}(\mathrm{Mo})}{d y^{2}}+\frac{2 D_{\mathrm{v}}}{\delta} \frac{d(\mathrm{Mo})}{d x}
\end{array}\right.
$$

Here, $\delta$ is the width of grain boundary;

$$
j_{x}=-D_{\mathrm{v}} \frac{d C}{d x},
$$

and similar

$$
j_{y}=-D_{\mathrm{b}} \frac{d C}{d r},
$$


SCIENTIFIC AND TECHNICAL

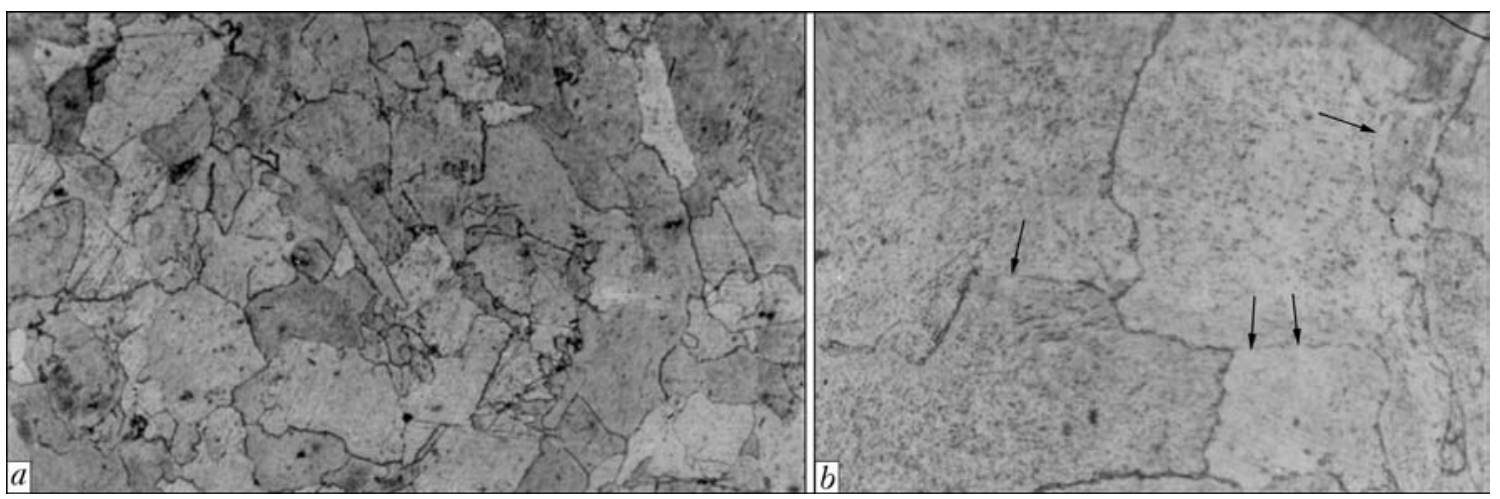

Figure 3. Microstructure of welded joint of main steam line from $15 \mathrm{Kh} 1 \mathrm{M} 1 \mathrm{~F}$ steel (HPP, Energodar city) with life of 180,000 h: $a$ - weld metal (alloy 09KhMF) $(\times 100) ; b$ - area of HAZ metal overheating $(\times 750)$; change of grain boundary structure is indicated by arrows

where $C=\mathrm{Cr}, \mathrm{Mo} ; D_{\mathrm{b}}$ is the coefficient of boundary diffusion; $D_{\mathrm{v}}-$ volumetric one.

Penetration of diffusing atoms of chromium and molybdenum in boundary zone of $\alpha$-phase crystal was determined taking into account $D_{\mathrm{b}}$ and $D_{\mathrm{v}}$ as well as mean displacement square [8].

Resolution of known methods, allowing determining form and size of isolated boundary and volumetric diffusion flows, is not sufficient. Specific near-boundary volume of $\alpha$-phase is resolution captured in use of surface microprobe analysis [11, 12], that, however, allows receiving acceptable results taking into account error. It was determined that $D_{\mathrm{b}} / D_{\mathrm{v}}$ relationship for metal of welded joints lies in $10^{2}-10^{3}$ range and depends on conditions of their operation, chemical composition, structure and other factors. It is determined that energy of activation of boundary diffusion $E_{\mathrm{b}}$ is lower than volumetric one $E_{\mathrm{v}} . E_{\mathrm{b}}$ and $E_{\mathrm{v}}$ are variable values and their relationship makes from 0.40 to 0.72 . Change of intensity of diffusion flows of chromium and molybdenum and, respectively, their energies of activation, is

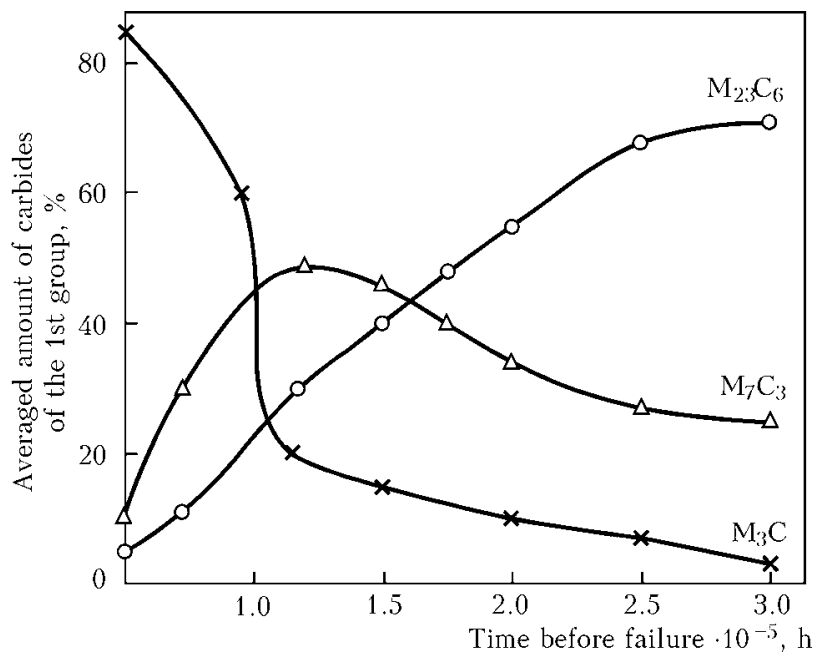

Figure 4. Experimental data on change of amount of carbides of the 1st group in metal of area of HAZ incomplete recrystallization in welded joint of live stem line from steel $12 \mathrm{Kh} 1 \mathrm{MF}$ caused by respective changes of chemical potentials.

It is determined that value of coefficient of chromium boundary diffusion in weld metal structure (alloy 09KhMF) (Figure 3,a) makes $(1.1-2.2) \cdot 10^{-14} \mathrm{~cm}^{2} / \mathrm{s}$, and for structure $\left(\mathrm{Fi}^{-}\right.$ gure $3, b)$ it is $(2.7-3.1) \cdot 10^{-14} \mathrm{~cm}^{2} / \mathrm{s}$. Value of coefficient depends on structure, size and form of grain boundary. $D_{\mathrm{b}}$ value is lower for low-angle boundaries having misorientation not more than $12^{\circ}$ (fine grain structure) in comparison with similar parameters for coarse grain with misorientation more than $15^{\circ} . D_{\mathrm{b}}$ value depends on parameters of operation mode, i.e. temperature, stress, overheating, start-stops as well as duration of welded joint running, their structure and chemical composition. Values of given coefficient are changed under creep conditions, when recrystallization processes at long-term running provide for local change of grain boundaries ( $\mathrm{Fi}-$ gure $3, b$ ).

Concentration profile $\operatorname{Cr}(x, y, t)$ and $\operatorname{Mo}(x$, $y, t)$ are determined with the help of X-ray spectrography as well as surface microprobe analysis. It was determined that level of chrome segregation at running of welded joints of more than $270,000 \mathrm{~h}$ can, for example, make up to $3-5 \%$ $[11,12]$ at boundaries of crystals of $\alpha$-phase and in their near-boundary zones.

Effect of vanadium to carbon relationship [1] has to be taken into account in consideration of structure stability. Carbides $\mathrm{M}_{3} \mathrm{C}, \mathrm{M}_{7} \mathrm{C}_{3}, \mathrm{M}_{23} \mathrm{C}_{6}$ of the 1st group and $\mathrm{Mo}_{2} \mathrm{C}$ and $\mathrm{VC}$ of the $2 \mathrm{nd}$ group are present in metal at $\mathrm{V} / \mathrm{C} \geq 2$.

Peculiarities of carbide phase structure as well as kinetics of their formation and growth are relevant to study for specification of degradation of welded joint metal. Intensity of phase formation as well as their coagulation in structure of weld metal, HAZ areas and base metal had some differences. Identifying of carbides taking into account procedure of study [13] was carried out 
based on results of decoding of microdiffraction images of particles being extracted in replicate from section as well as using method of electronprobe microanalysis on scanning electron microscope JSM-820. The average size between carbides of the 1st and 2nd groups along the $\alpha$-phase grain body was obviously different. Level of difference for areas of HAZ as well as deposited and base metal was also different.

Quantitative change of carbide phases takes place in metal of welded joints during long-term operation. Decrease of $\mathrm{M}_{3} \mathrm{C}$ and increase of $\mathrm{M}_{7} \mathrm{C}_{3}$ carbides [14] are noted at running to $150,000 \mathrm{~h}$. It was determined that further running provides for reduction of $\mathrm{M}_{7} \mathrm{C}_{3}$ and increase of $\mathrm{M}_{23} \mathrm{C}_{6}$ amount (Figure 4).

$\mathrm{X}$-ray structural examination of carbide phases, extracted from welded joint of steam pipeline from $12 \mathrm{Kh} 1 \mathrm{MF}$ steel (running $200,000 \mathrm{~h}$ ), were carried out on X-ray diffraction meter Siemens D-500, which uses powder method for measurements, in monochromatized copper irradiation with graphite monochromator in reflected beam. Difractograms were taken at $10^{\circ} \leq$ $\leq 2 \theta \leq 140^{\circ}$ angle interval with scanning step $0.02^{\circ}$ and pulse accumulation time $75 \mathrm{~s}$ in each point (Figure 5). Identification of phases was carried out in accordance with PDF-4 card index. Rietveld method [15] was used for calculations. Data of works $[16,17]$ were applied as test models of structures of carbide phases.

Letus consider carbide phase structure. Cementite $\mathrm{M}_{3} \mathrm{C}(\mathrm{Fe}, \mathrm{Cr})_{3} \mathrm{C}$ has complex orthorombic lattice with the parameters, A: $a-4.514$; $b-5.079 ; c-6.730$. X-ray analysis determined that chromium can substitute up to $19 \%$ (at.) of iron in $\mathrm{M}_{3} \mathrm{C}$ (structure of welded joint from steel $15 \mathrm{Kh} 1 \mathrm{M} 1 \mathrm{~F})$. ( $\mathrm{Fe}, \mathrm{Cr})_{3} \mathrm{C}$ is formed at local concentration of chromium from 1.0 to $2.5 \%$. No atoms of molybdenum were found in $\mathrm{M}_{3} \mathrm{C}$. Increase of chromium concentration more than $2.5 \%$ promotes for formation of trigonal carbide $(\mathrm{Fe}, \mathrm{Cr})_{7} \mathrm{C}_{3}$, having hexagonal lattice of the following parameters, A: $a-4.523 ; c-13.98$. $\mathrm{M}_{7} \mathrm{C}_{3}$ precipitates were of spherical or polyhedrous form, melting temperature $1669{ }^{\circ} \mathrm{C}$ and density $6.92 \mathrm{~g} / \mathrm{cm}^{3} . \mathrm{M}_{7} \mathrm{C}_{3}$ carbide is formed in steels $15 \mathrm{Kh} 1 \mathrm{M} 1 \mathrm{~F}$ and $12 \mathrm{Kh} 1 \mathrm{MF}$ at tempering (730-750 $\left.{ }^{\circ} \mathrm{C}, 3-5 \mathrm{~h}\right)$ as well as resulting from $\left(\mathrm{M}_{3} \mathrm{C}+\mathrm{C}\right) \rightarrow \mathrm{M}_{7} \mathrm{C}_{3}$ reaction in process of their long-term operation.

Cubic carbide $\mathrm{M}_{23} \mathrm{C}_{6}$ (5-7 \%) appears together with $\mathrm{M}_{7} \mathrm{C}_{3}$ after tempering. $\mathrm{M}_{7} \mathrm{C}_{3}$ has high capability to dissolution of iron atoms that is provided by intensive exchange reactions between $\alpha$-phase crystals and $\mathrm{M}_{7} \mathrm{C}_{3}$, resulting to

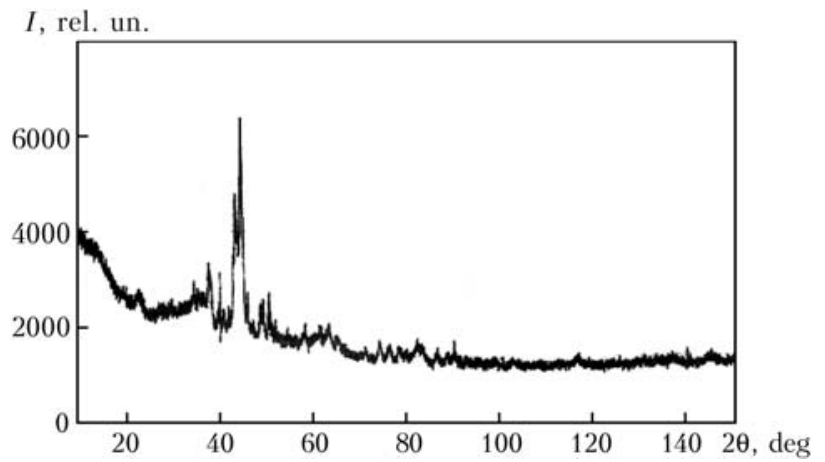

Figure 5. Experimental X-ray pattern of $\mathrm{M}_{23} \mathrm{C}_{6}$ carbide phase

$\mathrm{M}_{7} \mathrm{C}_{3}$ coagulation via lattice building-up. $\mathrm{M}_{23} \mathrm{C}_{6}$ carbides are formed at presence of local chromium concentration more than $3 \%$ (running of welded joints $130,000-150,000 \mathrm{~h}$ ) by means of $\mathrm{M}_{7} \mathrm{C}_{3} \rightarrow$ $\rightarrow \mathrm{M}_{23} \mathrm{C}_{6}$ reaction. They have complex structure representing itself face-centered cube of 10.64 A parameters (Figure 6).

$\mathrm{X}$-ray pattern (see Figure 5) shows that $\mathrm{M}_{23} \mathrm{C}_{6}$ carbide has significant level of crystalline lattice deformation. Significant widening of reflexes is observed. It is promoted by reduced size of crystallites and presence of microdeformations.

Investigation of phases using line-diagrams and PDF-4 card showed that cards of carbide $\mathrm{M}_{23} \mathrm{C}_{6}$ (28-646) and $\mathrm{M}_{3} \mathrm{C}$ ( $\alpha$-modification, cohenite, card 34-1) give the best correlation with experimentally observed image. It should be noted that some lines of experimental X-ray patterns did not correspond to card index data.

Determination of parameters [15] was carried out for phases studied by Rietveld method. It was verified that external distance between atoms in tetrahedral units is more than lattice parameter for $30-40 \%$. Tetrahedral ribs between cubes significantly exceed length of cube ribs. Local amorphism of $\mathrm{M}_{23} \mathrm{C}_{6}$ lattice is noted that

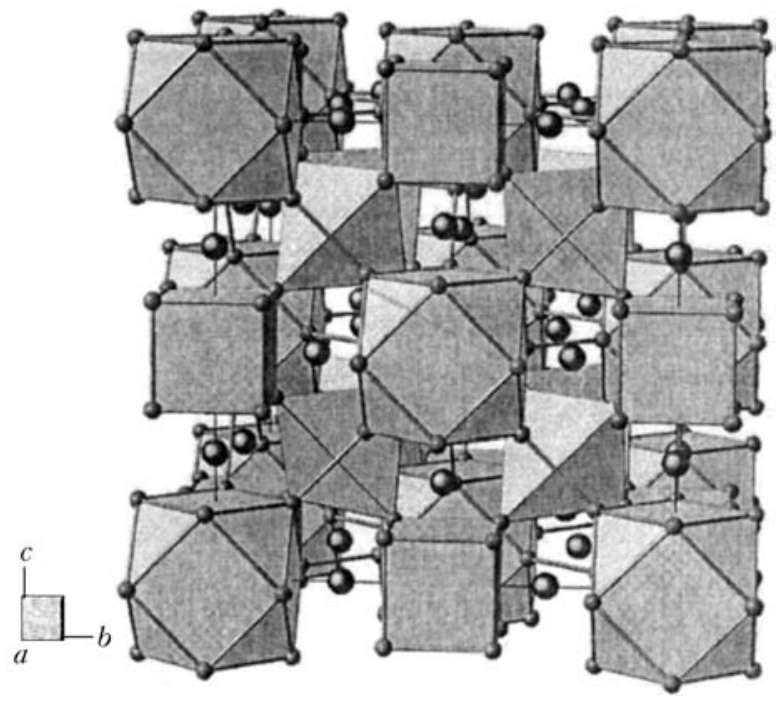

Figure 6. Model of face-centered lattice of $\mathrm{M}_{23} \mathrm{C}_{6}$ carbide 


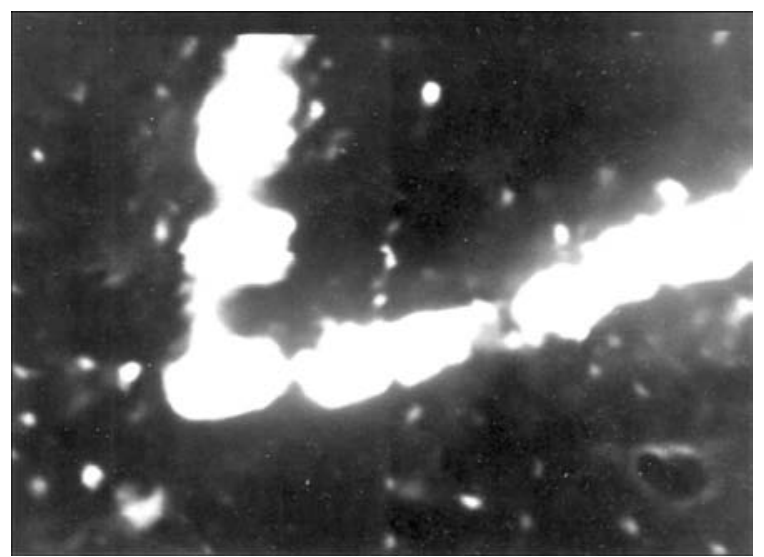

Figure 7. Demonstration of coalescence of $\mathrm{M}_{23} \mathrm{C}_{6}$ carbides at boundaries of $\alpha$-phase grains $(\times 7500)$

is, possibly, related with its building-up in process of coagulation by means of coalescence. The cube (Figure 6) includes 92 atoms of chromium and molybdenum as well as 24 atoms of carbon. It was determined that after $150,000 \mathrm{~h}$ of running atoms of molybdenum, having more affinity to carbon than atoms of chromium, displace them from $\mathrm{M}_{23} \mathrm{C}_{6}$ lattice points and atoms of chromium again react to form of $\alpha$-phase crystal. $\mathrm{M}_{23} \mathrm{C}_{6}$ density makes $6.97 \mathrm{~g} / \mathrm{cm}^{2}$.

Tendency to increase of amount of $\mathrm{VC}$ carbides is noted in metal of welded joints of long operation. Such an increase is promoted by release of carbon due to $\mathrm{M}_{7} \mathrm{C}_{3} \rightarrow \mathrm{M}_{23} \mathrm{C}_{6}$ reaction. Superfine vanadium carbide has cubic lattice of 4.154.16 A parameters, its density is $5.36 \mathrm{~g} / \mathrm{cm}^{3}$. VC is primarily formed in weld metal after tempering $\left(730-750{ }^{\circ} \mathrm{C}\right)$. Vanadium carbide has fiber form, effectively brakes dislocation movement that reduces creep effect. It was determined that VC carbides remain stable and do not coagulate in welded joint running up to $300,000 \mathrm{~h}$. Such a stability is promoted by low rate of exchange reactions between $\mathrm{VC}$ carbides and $\alpha$-phase crystals, since atoms of iron do not dissolve in VC.

It can be shown that welded joints from $12 \mathrm{Kh} 1 \mathrm{MF}$ steel have better heat resistance properties in process of long-term operation $\left(t_{\text {run }}>\right.$ $>270,000 \mathrm{~h}, T_{\text {op }} \leq 454^{\circ} \mathrm{C}$ ) under creep conditions than welded joints from steel $15 \mathrm{Kh} 1 \mathrm{M} 1 \mathrm{~F}$. Welded joints from steel $12 \mathrm{Kh} 1 \mathrm{MF}$ are less damaged by creep pores than joints from steel 15Kh1M1F.

Small amount of $\mathrm{Mo}_{2} \mathrm{C}$ was found in metal of welded joints from studied steels. It is a wellknown fact that $\mathrm{Mo}_{2} \mathrm{C}$ has hexagonal closepacked lattice with parameters, A: $a-3.022$; $c-4.724$. Melting temperature of $\mathrm{Mo}_{2} \mathrm{C}$ is $2000{ }^{\circ} \mathrm{C}$ and its density $9.18 \mathrm{~g} / \mathrm{cm}^{3}$. Molybdenum carbide has high stability in welded joint running to $300,000 \mathrm{~h}$, that is explained

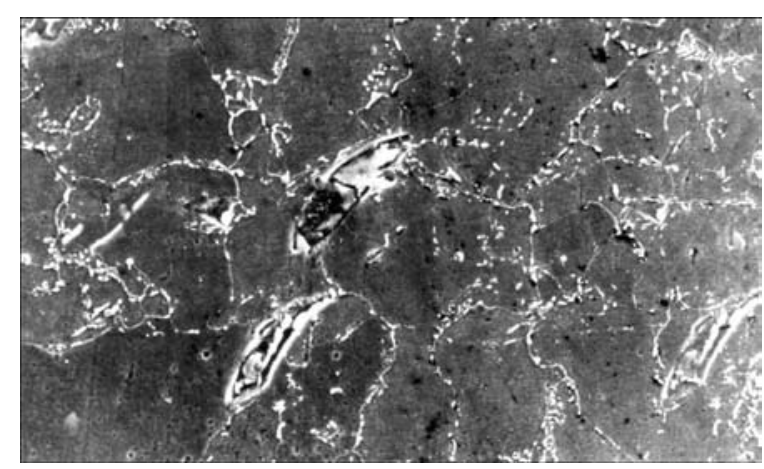

Figure 8. Microstructure $(\times 2000)$ of welded joint metal with creep pores and cracks

by its capability to dissolve iron and other elements of studied steels in small amount not more than $7 \%$.

Carbides' coagulation promotes for increase of spread of their concentrated location taking place due to building-up of their crystalline lattice, that is provoked by boundary diffusion (to larger extent) and volumetric (to lower extent) (Figure 7). $\mathrm{M}_{23} \mathrm{C}_{6}$ carbides form intermittent chains along the boundaries of $\alpha$-phase grains $[12,18]$. Creep pores are nucleated close to such carbides, transforming in crack in process of their development (Figure 8) [4, 11, 18].

Presence of carbide chains along the $\alpha$-phase grain boundaries promotes for reduction of interatomic cohesive forces, that provides also nucleation of fatigue cracks developing by creep mechanism.

It was determined that concentration of carbides has some variations in areas of HAZ metal as well as weld and base metals. Difference of carbide distribution along the $\alpha$-phase grain body and their boundaries is also noted. For example, structure of area of HAZ metal incomplete recrystallization in boundary zones and at boundaries (welded joints from steel $15 \mathrm{Kh} 1 \mathrm{M} 1 \mathrm{~F}$, running 276,000 h) included mostly $\mathrm{M}_{23} \mathrm{C}_{6}$ carbides (approximately $70 \%$ ), $\mathrm{M}_{7} \mathrm{C}_{3}$ carbides (around $20 \%$ ) and the rest was $\mathrm{M}_{3} \mathrm{C}, \mathrm{Mo}_{2} \mathrm{C}$ and $\mathrm{VC}$. $\alpha$-phase grains of $\mathrm{M}_{23} \mathrm{C}_{6}$ carbides made around $50 \%$ in central zone.

It was determined that studied physicalchemical processes, providing degradation of metal of welded joints of steam pipelines after their running more than $200,000 \mathrm{~h}$, promote $10-$ $20 \%$ decrease of mechanical properties of joints $[1-7,12,18]$.

\section{Conclusions}

1. Peculiarities of diffusion and structure of carbide phases in metal of welded structures of longterm operation from heat-resistant pearlite steels 
were found, that allowed specifying mechanism of its degradation.

2. It was determined that concentration of coagulating carbide phases (mainly $\mathrm{M}_{23} \mathrm{C}_{6}$ and $\mathrm{M}_{7} \mathrm{C}_{3}$ ) at boundaries of $\alpha$-phase grains promotes for nucleation of creep pores and fatigue cracks, providing damageability of metal of welded joints by creep mechanism.

1. Gladshtejn, V.I. (2007) Influence of running up to 350,000 hours on service characteristics and structure of cast body parts of turbines and fittings. Metallovedenie $i$ Term. Obrab. Metallov, 4, 24-32.

2. Khromchenko, F.A., Kalugin, R.N. (2004) Calculation-experimental method for evaluation of residual life of welded joints in steam pipelines. The Paton Welding J., 5, 6-11.

3. Rezinskaya, V.F., Grin, E.A. (2013) Current problems of safety assurance of heat-mechanic equipment in prolongation of its service life. Teploenergetika, $\mathbf{1}$, 17-24.

4. Dmitrik, V.V., Bartash, S.N. (2014) Peculiarities of degradation of metal of welded joints in steam pipelines of heat power plants. The Paton Welding J., 6/7, 29-30.

5. Sirotyuk, A.M., Kapty, O.V., Dmitrakh, I.M. et al. (2013) Expert system for evaluation of structural element fracture of pipelines of heat-and-power engineering system. Metody ta Prylady Kontr. Yakosti, 2, 126-136.

6. Trubachyov, V.M., Kamenskaya, N.I. (2012) Methods for evaluation of microdamageability of metal of steam pipelines in long-term operation of thermal power plant. Metallovedenie i Term. Obrab. Metallov, 8, 49-54.

7. Danyushevsky, I.A., Kupry, E.B., Malkin, M.R. et al. (2008) Evaluation of residual life taking into account microdamageability. Teploenergetika, 2, 12-17.
8. Dmitrik, V.V., Syrenko, T.A. (2012) To the mechanism of diffusion of chromium and molybdenum in the metal of welded joints of steam pipelines. The Paton Welding J., 10, 20-24.

9. Bokshtejn, B.S. (1978) Diffusion in metals. Moscow: Metallurgiya.

10. Gottshtajn, G. (2011) Physico-chemical principles of materials science. Moscow: BINOM.

11. Dmitrik, V.V., Baumer, V.N. (2007) Carbide phases and damageability of welded joints in long-term service. Metallofizika, Nov. Tekhnologii, 7, 937-947.

12. Dmitrik, V.V., Syrenko, T.A. (2010) Specifics of temper brittleness of steam pipeline welded joints. Energosberezhenie. Energetika. Energoaudit, 4, 2935.

13. Lashko, N.F., Zaslavskaya, L.V., Kozlova, M.N. et al. (1978) Physico-chemical and phase analysis of steels and alloys. Moscow: Metallurgiya.

14. Lanskaya, K.A. (1969) Heat-resistant steels. Moscow: Metallurgiya.

15. Rafaja, D., Lengauer, W., Ettmayer, P. et al. (1998) Rietveld analysis of the ordering in V8C7. J. Alloys and Compounds, 3, 60-62.

16. Fruchart, D., Chaudouet, P., Fruchart, R. (1984) Etudes structurales de composes de type cementite: effet de l'hydrogene sur $\mathrm{Fe}_{3} \mathrm{C}$ suivi par diffraction electronique spectrometrie moessbauer sur $\mathrm{FeCo}_{2} \mathrm{~B}$ et $\mathrm{Co} 3 \mathrm{~B}$ dopes au $57 \mathrm{Fe}$. J. Solid State Chemistry, 51, 246-252.

17. Rodriguez-Carvajal, J., Rossnel, T. (1988) Full Prof. 98 and Win PLOTR: New Windows 95/NT applications for diffraction. Commission for Powder Diffraction, International Union of Crystallography Newsletter 20, 5-8, 159

18. Dmitrik, V.V., Tsaryuk, A.K., Konyk, A.I. (2008) Carbide phases and damageability of welded joints of steam pipelines under creep conditions. The Paton Welding J., 3, 28-32.

Received 18.02.2015 


\title{
SOME ADVANTAGES OF BUTT JOINTS OF THIN WROUGHT ALUMINIUM ALLOYS AMg5M AND AMg6M PRODUCED BY FSW, COMPARED TO TIG-WELDED JOINTS
}

\author{
A.G. POKLYATSKY, I.N. KLOCHKOV and S.I. MOTRUNICH \\ E.O. Paton Electric Welding Institute, NASU \\ 11 Bozhenko Str., 03680, Kiev, Ukraine. E-mail: office@paton.kiev.ua
}

\begin{abstract}
Comparative studies were performed of microstructure, degree of softening, ultimate strength, crack initiation and propagation susceptibility and fatigue resistance of welded joints of wrought aluminium alloys AMg5M andAMg6M $1.8 \mathrm{~mm}$ thick, produced by nonconsumable-electrode argon-arc welding and friction stir welding, as well as of the levels of residual longitudinal stresses developing in them. It is shown that application of FSW enables formation of permanent joint with minimum level of stress concentration in weld-to-base metal transition areas, and allows avoiding defects in the form of pores, oxide film macroinclusions and hot cracks in welds due to metal melting and solidification in fusion welding. Intensive plastic deformation of metal results in formation of a uniform disoriented structure under the tool shoulder and in the weld nugget with grain size of 3-4 $\mu \mathrm{m}$ and disperse (not more than $1 \mu \mathrm{m}$ ) phase precipitates, and grain elongation and distortion in the direction of plasticized metal displacement occur in the adjacent areas. This leads to increase of metal hardness in the joint zone, sample ultimate strength at uniaxial tension, their fatigue strength and lowering of crack initiation and propagation susceptibility. Lowering of temperature of welded edges heating leads to lowering of maximum level of residual longitudinal stresses in welded joints by $25 \%$, compared to TIG welding. 16 Ref., 8 Figures.
\end{abstract}

$\boldsymbol{K} \boldsymbol{e} \boldsymbol{y} \boldsymbol{w} \boldsymbol{O} \boldsymbol{r} \boldsymbol{d} \boldsymbol{s}:$ friction stir welding, aluminium alloys, hardness, microstructure, ultimate strength, fatigue

Semi-finished products in the form of sheets, plates, strips, extruded panels, shape sections, rods, forgings, stampings, etc. from strong and ductile wrought aluminium alloys AMg5 and $\mathrm{AMg} 6$ are widely used in fabrication of variouspurpose welded structures operating at temperatures from -190 up to $+70{ }^{\circ} \mathrm{C}[1]$. Permanent joints in most cases are produced by various methods of fusion welding, at which the weld forms as a result of melting of a certain volume of materials being joined and filler wire in a common weld pool and their subsequent solidification in shielding gas atmosphere. This leads to structural transformations in the weld metal and areas adjacent to it, as well as formation of defects in the form of pores, oxide film macroinclusions and hot cracks, resulting in lowering of welded joint physico-mechanical properties [2-4].

Metal melting in the zone of weld formation can be avoided and properties of semi-finished products used to produce weldments can be preserved to a maximum degree at application of solid-phase friction stir welding (FSW) [5, 6]. Aluminium alloy heating at friction in the welding zone just to its plastic state, intensive mixing,

(c) A.G. POKLYATSKY, I.N. KLOCHKOV and S.I. MOTRUNICH, 2015 deformation in a limited volume and its compaction by tool working surfaces result in formation of a finely-dispersed structure in the weld, and less softening of base metal (BM) in the HAZ than in fusion welding. This provides an increase of ultimate strength of such joints at uniaxial tension and their fatigue strength at cyclic loads, as well as lowering of residual stresses and deformations [7-14].

The objective of this work is determination of the advantages of butt joints of sheet wrought aluminium alloys AMg5M and AMg6M, produced by FSW, compared to those made by TIG welding.

Studies were performed on $1.8 \mathrm{~mm}$ sheets of aluminium alloys $\mathrm{AMg} 5 \mathrm{M}$ and $\mathrm{AMg} 6 \mathrm{M}$. Butt joints were produced by TIG welding at the speed of $20 \mathrm{~m} / \mathrm{h}$ at the current of 135-140 A with application of MW-450 system («Fronius», Austria), using $1.6 \mathrm{~mm}$ welding wires SvAMg5 and SvAMg6. FSW process was performed in laboratory unit developed at PWI with application of a special tool with a conical tip and shoulder of $12 \mathrm{~mm}$ diameter [15] with $1420 \mathrm{rpm}$ rotation speed and $12 \mathrm{~m} / \mathrm{h}$ linear displacement speed. The width of welds produced by nonconsumable electrode was $6.5 \mathrm{~mm}$ on average, and of those welded by FSW - $3.5 \mathrm{~mm}$ (at about $12 \mathrm{~mm}$ 
width of the thermomechanical impact zone (TMIZ) from the weld face side).

Sections were cut out of the produced welded joints to study their structure and samples with $15 \mathrm{~mm}$ gauge width were prepared to determine their ultimate strength at uniaxial tension to GOST 6996-66. Width of sample gauge part for fatigue resistance determination was equal to $25 \mathrm{~mm}$. Sample mechanical testing was performed in all-purpose servohydraulic system MTS 318.25. Cyclic testing was conducted under axial loads by sinusoidal cycle with coefficient $R_{\sigma}=0.1$ and $15 \mathrm{~Hz}$ frequency up to complete failure of samples. A series of 5-7 similar samples was tested under the same conditions. Experimental data of fatigue testing were processed by linear regression analysis methods generally accepted for investigations of this kind. Results of performed testing were used to plot for each sample series based on established limited fatigue limits the respective fatigue curve - regression line in coordinates of $2 \sigma_{\mathrm{a}}-\lg N\left(2 \sigma_{\mathrm{a}}\right.$ is the stress range, equal to doubled value of cycle stress amplitude).

Fracture resistance characteristics of BM and welds were determined on Kahn samples with a $\operatorname{sharp}(R=0.1 \mathrm{~mm})$ notch, providing crack initiation at relatively low energy level using an all-purpose RU-5 testing machine. The notch was located so that its tip coincided with weld axis. For each sample the ultimate strength and specific work of crack propagation at simultaneous bending and tension were determined, using load-deformation diagrams derived during their testing [16].

Metal hardness was measured on face side of scraped welded joints. Degree of metal softening in the joint zone was evaluated in ROCKWELL instrument at load $P=600 \mathrm{~N}$. Structural features of welded joints were assessed in optical electron microscope MIM-8.

Residual longitudinal stresses in welded joints were determined by experimental method based on metal cutting up. Relieved residual stresses due to welding heating were calculated by the magnitude of deformation of metal induced as a result of its cutting up, using the respective formulas of the theory of elasticity (Hooke's law).

Performed studies demonstrated that weld dimensions at FSW are smaller and its shape differs favourably from that of TIG weld (Figure 1). It does not have weld reinforcement formed in $\mathrm{fu}^{-}$ sion welding due to filler wire application or back bead due to application of a substrate with formed groove. This allows avoiding any significant stress concentration in areas of weld-to-base
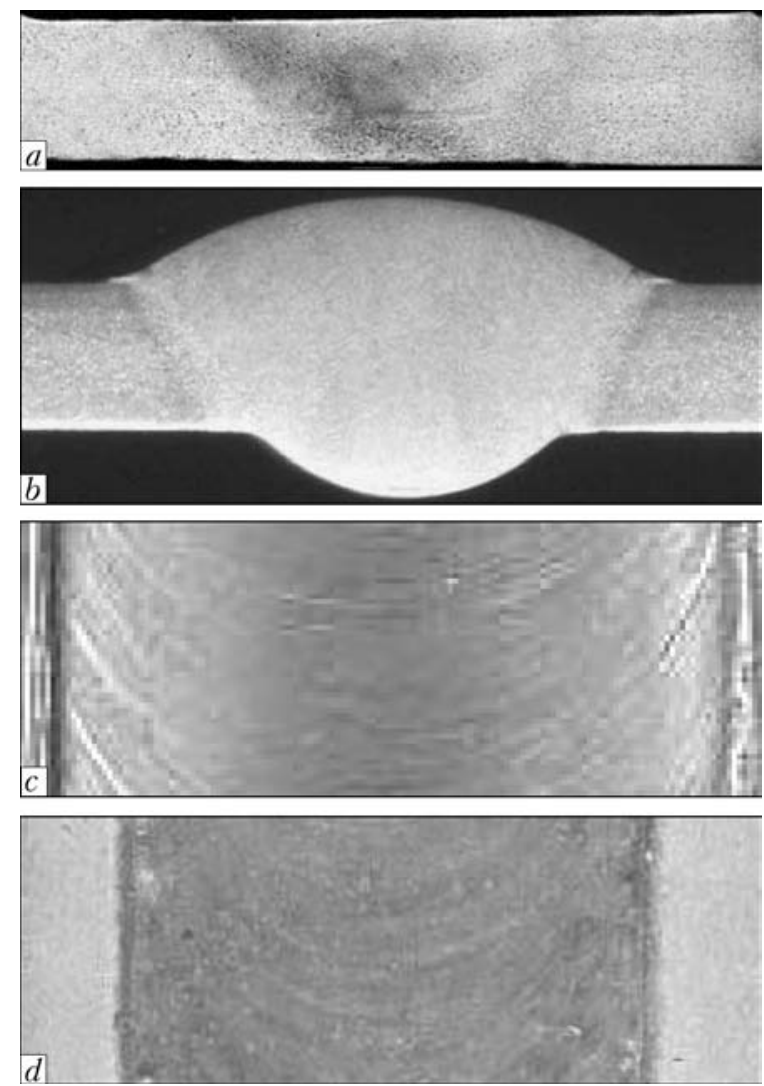

Figure 1. Cross-sections $(a, b)$ and appearance of weld face surface $(c, d)$ on $1.8 \mathrm{~mm}$ alloy AMg6M, produced by FSW $(a, c)$ and TIG welding $(b, d)$

metal transition, adversely affecting the operational and service life characteristics of the joints.

Moreover, formation of a permanent joint in the solid phase without melting of edges being welded allows avoiding their oxidation during welding. Intensive deformation and mixing of plasticized metal promotes mechanical softening and dispersion of initial oxide film on them, forming instantly on aluminium alloys. Therefore, FSW welds do not have any defects in the form of oxide film macroinclusions, quite often forming in TIG welding of aluminium-magnesium alloys (Figure 2). Absence of molten metal, in which hydrogen solubility rises abruptly, allows avoiding additional welding zone saturation by it due to this gas migration from adjacent surface layers of metal. Now, mixing and compacting of metal being welded in the joint zone ensures for-

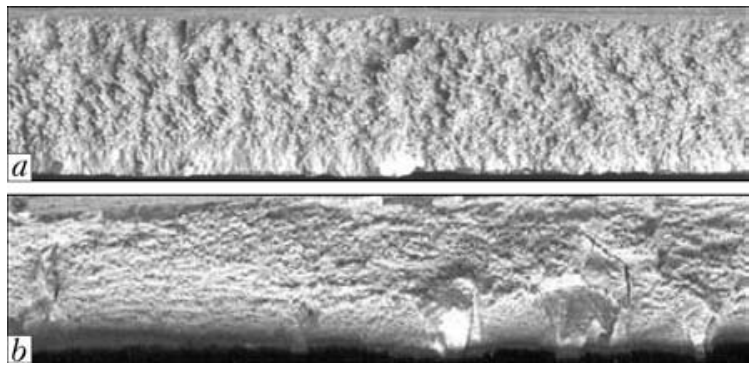

Figure 2. Longitudinal fractures of welds of $1.8 \mathrm{~mm}$ alloy AMg6M produced by FSW ( $a$ ) and TIG welding (b) 
SCIENTIFIC AND TECHNICAL

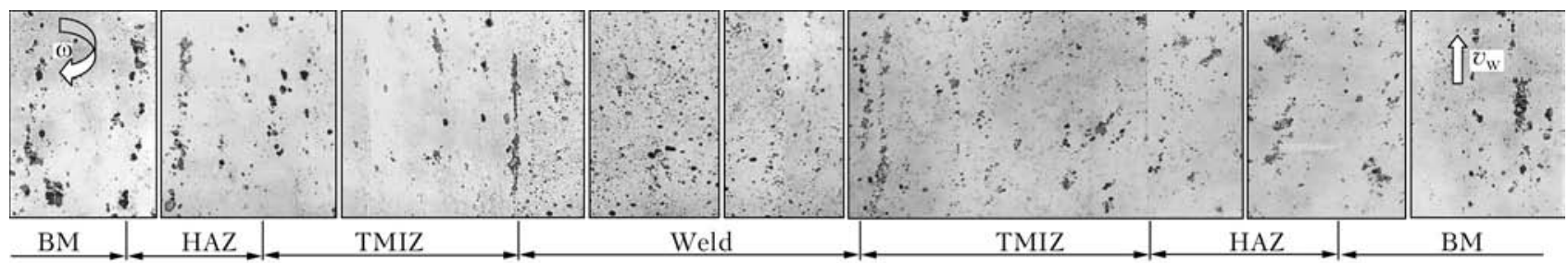

Figure 3. Microstructure $(\times 400)$ of surface areas of BM and FS-welded joint of AMg6M alloy, in the metal of HAZ, TMIZ and weld from the tool advancing (left) and retreating side (right)

mation of pore-free welds. As in FSW the processes of metal melting and solidification are absent, and the weld forms in the solid phase, it allows totally avoiding formation of the most dangerous and inadmissible defects in critical structures in the form of hot cracks appearing during solidification of molten metal in the sites of clusters of low-melting eutectic inclusions.

The process of permanent joint formation at FSW is a combination of a whole range of interconnected phenomena, including intensive local heat evolution on friction surfaces and cooling of small metal volumes in a closed space under high pressure, displacement of metal heated up to plastic state by a complex trajectory, plastic deformation in metal microvolumes, recrystallization, diffusion, mechanical crushing of component particles, intensive displacement of dislocations, instant formation of a permanent joint behind the tool, etc., that exactly determines the structural features of its various areas.

Microstructural studies showed that displacement of sufficiently thin $(0.1-0.2 \mathrm{~mm})$ layer of plasticized metal by tool shoulder surface, occurring during FSW, leads to an essential change of its structural condition - grain deformation, reorientation and refinement (Figure 3). Grains adjacent to metal being mixed are elongated and distorted in the direction of its mixing. From tool advancing side they are located practically parallel to the butt. Directly under the tool shoulder grain refinement occurs, but their clear orientation is absent.

Intensive displacement of plasticized metal by tool shoulder working surfaces across the entire thickness of edges being welded leads to formation of specific joint structure (Figure 4). In the weld central part (nugget) dynamic recrystallization results in formation of fine-crystalline weld metal structure. So, in weld nugget, the size of grains having a practically globular shape does not exceed $4 \mu \mathrm{m}$, and that of dispersed phase precipitates is not more than $1 \mu \mathrm{m}$, that is 5 to 7 times smaller than in BM. In TMIZ at the boundary of weld-to-base metal transition coarser grains $\left(6^{-7} \mu \mathrm{m}\right)$ are also found in addition to fine ones, the coarser grains being elongated in the direction of plasticized metal displacement. In HAZ metal, not subjected to deformational impact, grain size is equal to $10-15 \mu \mathrm{m}$.

TIG welds of these alloys are characterized by a mixed dendritic structure consisting of columnar and equiaxed grains typical for aluminiummagnesium alloys in as-cast condition. Equiaxed dendrites of about $25 \mu \mathrm{m}$ size form in weld central part. Near the zone of weld fusion with BM the laminated dendritic structure is more pronounced, with extended phase precipitates along these grain boundaries.

Intensive plastic deformation of metal in the zone of permanent joint formation in FSW not only promotes its structure refinement, but also leads to its deformational strengthening ( $\mathrm{Fi}^{-}$ gure 5). So, in the central part of welds of $\mathrm{AMg} 5 \mathrm{M}$ alloy metal hardness is on the level of $H R B 84$, and in the zones of its transition to $\mathrm{BM}$ it is equal to $H R B$ 83. Here, minimum hardness of metal ( $H R B$ 78) is observed in the HAZ, whereas at TIG welding in the weld central part metal hardness does not exceed $H R B$ 76, and in the zones of its fusion with BM - HRB 78 . Therefore, samples of joints of AMg5M alloy made by TIG welding with filler wire SvAMg5, with removed reinforcements and back beads fail through weld metal at uniaxial tension and have the ultimate strength on the level of $300 \mathrm{MPa}$. Samples of such joints with weld reinforcement fail through BM, similar to samples produced by FSW. Their ultimate strength is about $320 \mathrm{MPa}$.

Fracture of samples of AMg6M alloy welded joints produced by TIG method using filler wire Sv-AMg6 without weld reinforcements and back beads also runs through weld metal, and their ultimate strength does not exceed $325 \mathrm{MPa}$, while in similar sample with weld reinforcement, failing in the zone of weld fusion with $\mathrm{BM}$, this value is on the level of $345 \mathrm{MPa}$, similar to samples made by FSW, which fail through BM.

Load-deformation diagrams, derived at testing samples of BM and welded joints of $\mathrm{AMg} 6 \mathrm{M}$ alloy at their simultaneous bending and tension, are indicative of sufficiently high level of their ductility, as crack initiation at stress raiser tip occurs smoothly (Figure 6). Ultimate strength 

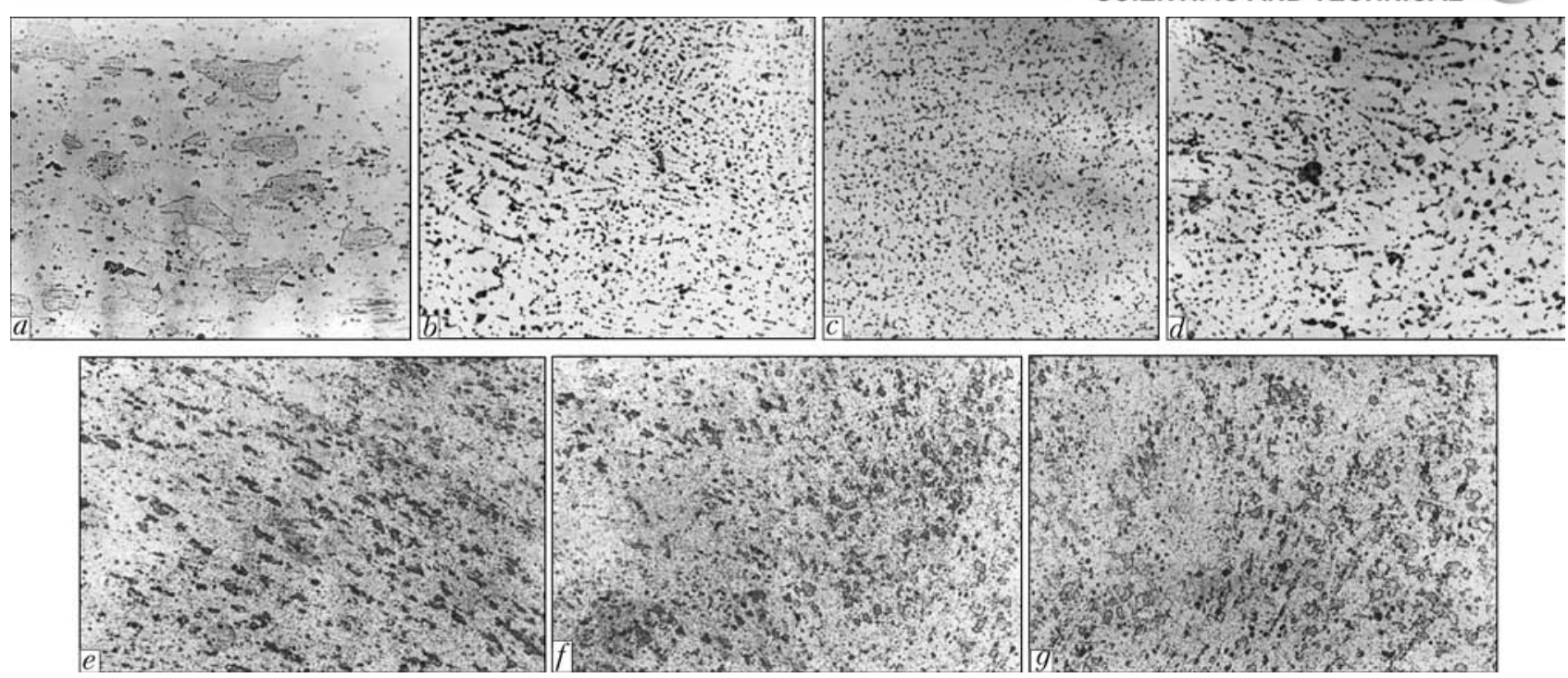

Figure 4. Microstructure $(\times 400)$ of BM $(a)$ and welded joints of AMg5M alloy produced by TIG method with filler wire SvAMg5 ( $b, d-$ zone of weld fusion with BM; $c-$ weld) and FSW ( $e-$ TMIZ from the advancing side; $f-$ weld nugget; $g-$ from retreating side)

of BM samples here is on the level of $415 \mathrm{MPa}$. Propagation of the crack initiating at sharp notch tip in TIG-welded samples occurs through weld metal. Ultimate strength of such a weld is lower compared to $\mathrm{BM}$, and is equal to $361 \mathrm{MPa}$. At testing of samples welded by FSW, the crack shifts to the zone of weld transition to BM, and their ultimate strength is on the level of $436 \mathrm{MPa}$. Crack propagation at testing of produced FSW samples also occurs slower than in BM. So, specific work of crack propagation in weld metal of such samples is on the level of $8.8 \mathrm{~J} / \mathrm{cm}^{2}$, whereas for BM of AMg6M alloy this value is equal to $5.7 \mathrm{~J} / \mathrm{cm}^{2}$, and for welds made by fusion welding it is $4.7 \mathrm{~J} / \mathrm{cm}^{2}$.

Fractographic analysis of fracture surfaces of FS-welded joint samples is indicative of ductile nature of weld fracture. Small pits with thin ridges are clearly visible in the weld central part at the tip of the raiser in the form of a sharp notch. Finely-dispersed weld structure provides a greater total length of grain boundaries that

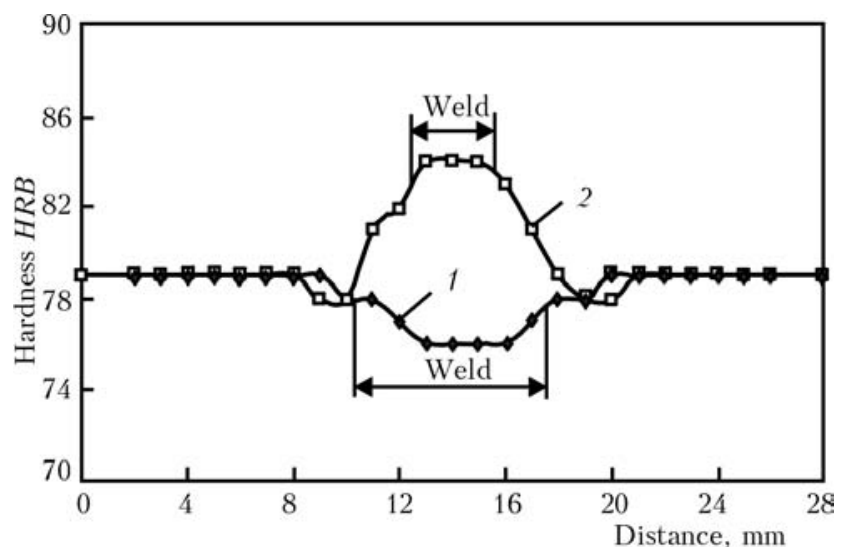

Figure 5. Hardness distribution in welded joints of $1.8 \mathrm{~mm}$ alloy AMg5M produced by TIG welding (1) and FSW (2) prevents an abrupt increase of stress concentration and hinders propagation of the main crack through weld metal. Therefore, increase of tensile load leads to the crack shifting into the zone of weld-to-BM transition, the fractograph of which reveals small flat areas of the relief, indicative

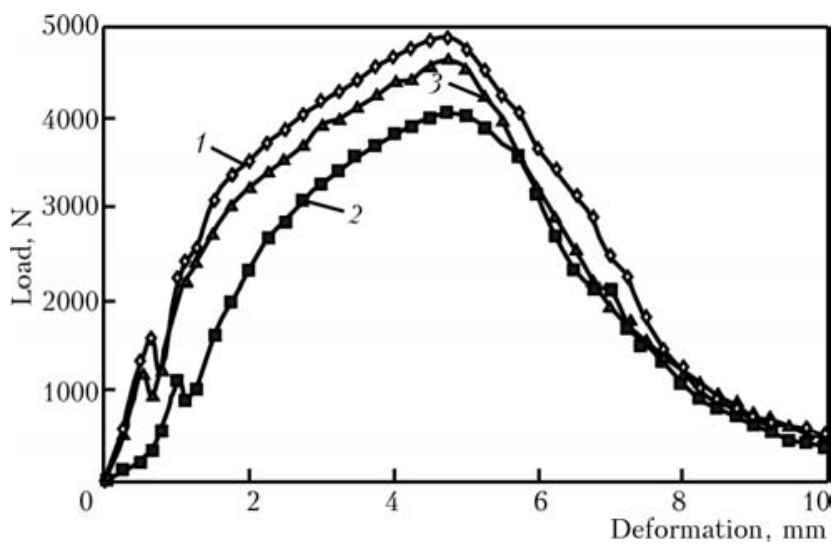

Figure 6. Load-deformation diagrams derived at testing samples of BM and welded joints of alloy AMg6M: 1 FSW; 2 - TIG welding; 3 - BM

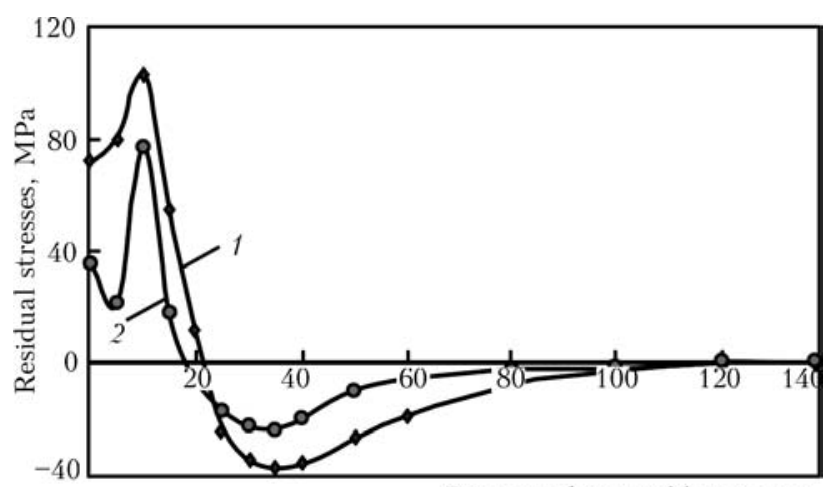

Distance from weld axis, $\mathrm{mm}$

Figure 7. Distribution of residual longitudinal stresses in welded joints of $1.8 \mathrm{~mm}$ alloy AMg6M produced by TIG welding (1) and FSW (2) 

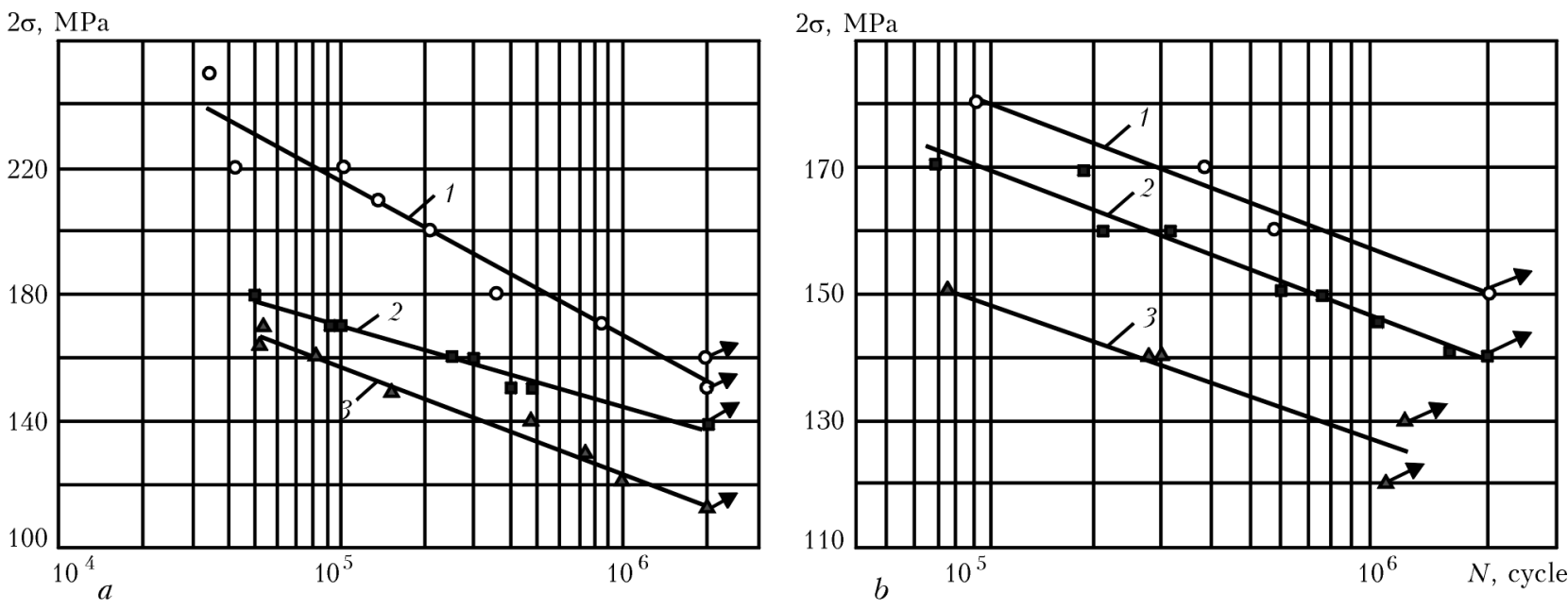

Figure 8. Fatigue curves of BM and welded joints of aluminium alloys $\operatorname{AMg} 6 \mathrm{M}(a)$ and $\operatorname{AMg} 5 \mathrm{M}(b) 1.8 \mathrm{~mm}$ thick at stress cycle asymmetry $R_{\sigma}=0.1$

of appearance of brittle fracture indications. However, prevalence of a homogeneous finelydispersed metal structure with uniform distribution of fine phase inclusions provides a higher level of metal strength even in this zone, compared to welds produced by fusion welding.

Performed research showed that lowering of metal heating temperature in the zone of permanent joint formation at FSW is favourable for the level of residual stresses resulting from nonuniform distribution of thermal field in it. So, at TIG welding maximum magnitude of residual longitudinal tensile stresses at $10 \mathrm{~mm}$ distance from weld axis is on the level of $103 \mathrm{MPa}$ ( Figure 7 ). In weld center these stresses are equal to $72 \mathrm{MPa}$. At about $22 \mathrm{~mm}$ distance from weld axis they drop to zero, which is followed by development of compressive stresses with maximum magnitude of $38 \mathrm{MPa}$ at $35 \mathrm{~mm}$ distance from weld axis. In welded joints made by FSW, maximum magnitude of tensile stresses is just $78 \mathrm{MPa}$. Here, their magnitude in weld center is on the level of $36 \mathrm{MPa}$ that is 2 times smaller than at TIG welding. Accordingly, maximum magnitude of residual compressive stresses at $35 \mathrm{~mm}$ distance from weld axis drops to $23 \mathrm{MPa}$.

Results of experimental studies of fatigue resistance of welded joints in aluminium alloys $\mathrm{AMg} 6 \mathrm{M}$ and $\mathrm{AMg} 5 \mathrm{M}$ produced in the solid phase by FSW demonstrated that their fatigue limit based on $2 \cdot 10^{6}$ stress cycles is equal to $85-95 \%$ of respective $\mathrm{BM}$ values, and practically reaches the level of the conditional fatigue limit values (Figure 8). In its turn, fatigue resistance of TIGwelded joints is markedly inferior in the entire fatigue life range based on $1 \cdot 10^{5}-2 \cdot 10^{6}$ stress cycles. Fatigue life of FSW joints is up to 10 times higher, compared to joints made by TIG welding, and their limited fatigue life based on $10^{6}$ stress cycles is higher by $15-20 \%$. The main cause for lower fatigue life of TIG-welded joints, chiefly, is the high concentration of acting stresses, due to weld geometrical features.

\section{Conclusions}

1. At FSW of aluminium alloys AMg5M and AMg6M intensive plastic deformation of metal under the tool shoulder and in weld nugget results in formation of a uniform disoriented structure with grain size of 3-4 $\mu \mathrm{m}$ and dispersed (not more than $1 \mu \mathrm{m}$ ) phase precipitates. In the zones of weld transition to BM elongation of some grains to $6-$ $7 \mu \mathrm{m}$ and their distortion in the direction of plasticized metal displacement take place.

2. FSW application ensures formation of permanent joint with minimum level of stress concentration in the areas of weld-to-base metal transition, and allows avoiding defects in welds in the form of pores, oxide film macroinclusions and hot cracks due to melting and solidification of metal in fusion welding.

3. At FSW of heat-hardenable alloys AMg5M and $\mathrm{AMg} 6 \mathrm{M}$, owing to strain hardening of metal due to its grain refinement, metal hardness in the joint zone becomes higher, whereas in fusion welding metal hardness in this zone decreases as a result of formation of cast coarse-grained dendritic weld structure. Therefore, ultimate strength of FSW samples at uniaxial tension is by $20 \mathrm{MPa}$ higher than that of samples without weld reinforcements and back beads, welded by TIG process. Fracture resistance values of samples at their simultaneous bending and tension are indicative of a higher resistance of joints, produced in the solid phase, to crack initiation and propagation.

4. Owing to weld formation in the solid phase at temperatures lower than those in fusion weld- 
ing, maximum level of tensile residual longitudinal stresses in welded joints of AMg5M alloy produced by FSW is by $25 \%$ lower than at TIG welding.

5. Effectiveness of FSW process application instead of TIG welding for fabrication of structures operating at alternating loads from aluminium alloys $\mathrm{AMg} 5 \mathrm{M}$ and $\mathrm{AMg} 6 \mathrm{M}$ has been substantiated experimentally by determination of fatigue resistance characteristics. It is shown that fatigue life of butt joints produced by FSW is much higher than that of joints made by TIG welding, and their limited fatigue life based on $2 \cdot 10^{6}$ stress cycles practically reaches the level of $\mathrm{BM}$ sample fatigue life, while being by 30 to $40 \%$ lower for TIG-welded joints.

1. Beletsky, V.M., Krivov, G.A. (2005) Aluminium al loys (composition, properties, technology, application): Refer. Book. Ed. by I.N. Fridlyander. Kiev: KOMINTEX.

2. Rabkin, D.M., Lozovskaya, A.V., Sklabinskaya, I.E. (1992) Metals science of welding of aluminium and its alloys. Kiev: Naukova Dumka.

3. Mashin, V.S., Poklyatsky, A.G., Fedorchuk, V.E. (2005) Mechanical properties of aluminium alloys in consumable and nonconsumable electrode arc welding. The Paton Welding J., 9, 39-45.

4. Poklyatsky, A.G. (2001) Peculiarities of formation of oxide film macroinclusions in weld metal of aluminium alloys (Review). Ibid., 3, 36-38.

5. Klimenko, Yu.V. Method of friction welding of metals. USSR author's cert. 195846. Int. Cl. B23K 35 /02. Fill. 09.11.1965. Publ. 04.05.1967.
6. Thomas, W.M., Nicholas, E.D., Needham, J.C. et al Friction stir butt welding. Int. pat. appl. PCT / GB 92 02203; GB pat. appl. 9125978.8. Publ. 1991.

7. Shibayanagi, T. (2007) Microstructural aspects in friction stir welding. J. Japan Inst. of Light Metals, 9, 416-423.

8. Pietras, A., Zadroga, L. (2003) Rozwoj metody zdrzewania tarciowego z mieszaniem materialu zgrzeiny (FSW) i mozliwosci jej zastosowania. Biul. Instytutu Spawalnictwa w Gliwicach, 5, 148-154.

9. Sato, Y. (2002) Relationship between mechanical properties and microstructure in friction stir welded Al alloys. J. JWS, 8, 33-36.

10. Larsson, H., Karlsson, L., Svensson, L. (2000) Friction stir welding of AA5083 and AA6082 aluminium alloys. Svetsaren, 2, 6-10.

11. Kluken, A., Ranes, M. (1995) Aluminium bridge constructions - Welding technology and fatigue properties. Ibid., 3, 13-15.

12. Ericsson, M., Sandstrom, R. (2003) Influence of melting speed on the fatigue of friction stir welds, and comparison with MIG and TIG. Int. J. Fatigue, 25, 1379-1387

13. Lanciotti, A., Vitali, F. (2003) Characterization of friction welded joints in aluminium alloy 6082-T6 plates. Welding Int., 8, 624-630.

14. Jata, K.V., Sankaran, K.K., Ruschau, J.J. (2000) Friction stir welding effects on microstructure and fatigue of aluminum alloy 7050-T7451. Metallurg. Transact. A, 31, 2181-2192.

15. Ishchenko, A.Ya., Poklyatsky, A.G. Tool for friction stir welding of aluminium alloys. Pat. 54096 Ukraine. Int. Cl. B23K 20/12. Fill. 30.04.2010. Publ. 25.10.2010.

16. Poklyatsky, A.G. (2011) Resistance of welds on thinsheet aluminium alloys to initiation and propagation of service cracks. The Paton Welding J., 10, 5-9.

Received 23.03.2015 


\title{
THERMODYNAMICS OF FORMATION OF CHROMIUM COMPOUNDS IN WELDING AEROSOLS
}

\author{
O.G. LEVCHENKO and O.N. BEZUSHKO \\ E.O. Paton Electric Welding Institute, NASU \\ 11 Bozhenko Str., 03680, Kiev, Ukraine. E-mail: office@paton.kiev.ua
}

\begin{abstract}
Thermodynamic investigations of probability of formation of toxic chromium compounds in the composition of aerosols formed during arc welding of high-alloy steels using coated electrodes were carried out. The probability of proceeding of chemical reactions, resulting in formation of toxic chromium compounds in welding aerosols, was determined. It is shown that in the zone of welding arc in the temperature range from 1100 to $3000 \mathrm{~K}$, the formation of hexavalent chromium oxide is low probable. The calculations established that adding of titanium, silicon, manganese and aluminum into the composition of welding electrodes prevents formation of $\mathrm{CrO}_{3} .9$ Ref., 1 Table, 3 Figures.
\end{abstract}

Keywords: welding aerosols, harmful substances, thermodynamics, probability, chemical reactions, hexa valent chromium

The energy, released in the near-electrode zone of welding arc, is consumed not only for melting of materials, but also for their evaporation, resulting in formation of welding aerosol (WA) contaminating the air of working zone. Until now the processes of WA formation have been little studied because of the complex physical, chemical, physico-chemical and other processes running in the zone of welding arc. For developers of welding consumables the determination of possibility of reducing the chromium content in the composition of WA in arc welding of high-chromium-nickel steels represents a special interest.

As is known [1] in WA the chromium may be presented in trivalent state in the form of $\mathrm{Cr}_{2} \mathrm{O}_{3}$, and in hexavalent one in the form of $\mathrm{CrO}_{3}$ and also in the form of chromates and dichromates of potassium and sodium $\left(\mathrm{K}_{2} \mathrm{CrO}_{4}, \mathrm{~K}_{2} \mathrm{Cr}_{2} \mathrm{O}_{7}\right.$, $\mathrm{Na}_{2} \mathrm{CrO}_{4}, \quad \mathrm{Na}_{2} \mathrm{Cr}_{2} \mathrm{O}_{7}$ ). According to GOST 12.1.005-88 the maximum allowable concentration in the air of working zone regulated for trivalent chromium is $1 \mathrm{mg} / \mathrm{m}^{3}$, and that for hexavalent one is $0.01 \mathrm{mg} / \mathrm{m}^{3}$, i.e. hexavalent chromium may cause a harmful effect on the human body 100 times higher than trivalent chromium. Accordingly, hexavalent chromium refers to the harmful substances of the first class of hazard (extremely dangerous), and trivalent to the third class (moderately dangerous). Thus, during welding of $\mathrm{Cr}-\mathrm{Ni}$ steels the determining toxic component of WA is hexavalent chromium.

The aim of the work is the evaluation of probability and conditions of formation of chromium oxides in the composition of WA.

(C) O.G. LEVCHENKO and O.N. BEZUSHKO, 2015

To determine the probability and conditions of the reaction equilibrium the Gibbs thermodynamic function was used [2]. Changes of isobaric potential under standard conditions at a preset temperature are determined by equation (1)

$$
\Delta G_{\mathrm{t}}^{0}=\Delta H_{\mathrm{t}}^{0}-T \Delta S_{\mathrm{t}}^{0},
$$

where $\Delta H_{\mathrm{t}}^{0}, T \Delta S_{\mathrm{t}}^{0}$ are the values of enthalpy and entropy change at the temperature $T$, respectively.

The product $T \Delta S$, called a bound energy, reflects that part of the system energy, which cannot be transformed into useful work. Since the enthalpy represents a full energy reserve, the difference $\Delta H^{0}-T \Delta S^{0}$ reflects that part of energy which can be transformed into a useful work in the direction of system motion to equilibrium. Since the energy reserve is reduced here, i.e. $G_{2}<$ $<G_{1}$, then at an arbitrary running of the process $\Delta G^{0}=G_{1}-G_{2}<0$. The more $\Delta G^{0}$ decreases, the more irreversible running the process is towards the formation of reaction products.

To calculate the $\Delta G^{0}$ reactions, proceeding in welding zone at high temperatures, the approximate method [3] was used, which consists in the fact that during calculation of $\Delta G^{0}$ the enthalpy and entropy, characteristic for the reaction, are taken as being independent of temperature and those which change only as a result of their aggregate or polymorphic transformations. This is justified by the fact that the value $\Delta G^{0}$ is determined for evaluation of thermodynamic probability of reaction and degree of its moving away from equilibrium or for comparison of probability of several reactions that can occur in the same system. A small error obtained in the calculations here does not essentially affect the results of thermodynamic analysis. The calculation equations in this case are the following: 


$$
\begin{gathered}
\Delta H_{\mathrm{t}}^{0}=\Delta H_{\mathrm{t}}^{0} \pm L_{1} \pm L_{2} \pm \ldots \pm L_{n}, \\
\Delta S_{\mathrm{t}}^{0}=\Delta S_{298}^{0} \pm L_{1} / T_{1} \pm L_{2} / T_{2} \pm \ldots \pm L_{n} / T_{n},
\end{gathered}
$$

where $L_{1}, L_{2}, L_{n}$ are the corresponding values of conversion heat, $\mathrm{kJ} /$ mole; $T_{1}, T_{2}, T_{n}$ are the temperatures of phase transformations of reaction participants, K.

Due to the accepted assumption, not only the calculation of $\Delta G$ is simplified, but it is also possible to provide a simple and graphical expression of dependence $\Delta G_{t}$ on the temperature. If transformations of reaction participants are absent, the dependence is expressed in a straight line, and if present, the dependence $\Delta G_{\mathrm{t}}=f(T)$ takes the form of a broken line with bends at transformation temperatures.

The change of enthalpy in the temperature range as well as corresponding phase transformations has the following form:

$$
\begin{gathered}
\Delta H_{\mathrm{t}}^{0}=\Delta H_{\mathrm{t}}^{298}+\int_{298}^{T_{1}} \Delta C_{P 1} d T \pm L_{1}+ \\
+\int_{T_{1}}^{T_{2}} \Delta C_{P 2} d T \pm L_{2}+\ldots+\int_{T_{n}}^{T} \Delta C_{P(n+1)} d T,
\end{gathered}
$$

where $\Delta C_{P 1}, \Delta C_{P 2}, \Delta C_{P(n+1)}$ is the change of the specific heat in the course of reaction for various temperature ranges, $\mathrm{J} /(\mathrm{K} \cdot \mathrm{mole})$.

The entropy provides a key for determination of probability or improbability of thermodynamic process. The change of entropy during heating of substance from room temperature to $T$, and also at the phase and aggregate change of state of substance is the following:

$$
\begin{gathered}
\Delta S_{\mathrm{t}}^{0}=\Delta S_{298}^{0}+\int_{298}^{T_{1}} \frac{\Delta C_{P 1} d T}{T} \pm \frac{L_{1}}{T_{1}}+ \\
+\int_{T_{1}}^{T_{2}} \frac{\Delta C_{P 2} d T}{T} \pm \frac{L_{2}}{T_{2}}+\ldots+\int_{T_{n}}^{T} \frac{\Delta C_{P(n+1)} d T}{T},
\end{gathered}
$$

where $T_{1}, T_{2}, T_{n}$ is the temperature of polymorphous transformations, melting and boiling, respectively.

In case of equilibrium reaction the ratio of product of concentrations of the reaction products to product of concentrations of the starting substances is a constant value at a fixed temperature, which is called the equilibrium constant. Thus, the equilibrium constant depends only on temperature: $K=$ $=f(T)$. The equations for calculation of equilibrium constant of reaction are obtained by transformation of Van't Hoff equation [4]:

$$
\Delta G^{0}=-R T \ln K,
$$

where $R=8.314 \mathrm{~J} /($ mole $\cdot \mathrm{K})$;

$$
\ln K=-\Delta G^{0} / R T=-\left(\Delta H_{\mathrm{t}}^{0}-T \Delta S_{\mathrm{t}}^{0}\right) / R T .
$$

After replacement of the natural logarithm to the decimal one and substitution of numerical value of the gas constant $R$, we shall obtain

$$
\lg K=-\Delta H_{\mathrm{t}}^{0} / 19.1 T+\Delta S_{\mathrm{t}}^{0} / 19.1 .
$$

Having determined the change of enthalpy and entropy in the course of the reaction at a specified temperature, it is possible to calculate the equilibrium constant of the reaction.

To analyze the composition of WA, in particular, the type of chromium compounds, which may be formed in welding of alloyed $\mathrm{Cr}-\mathrm{Ni}$ steels, chemical reactions were considered, and results of thermodynamic calculations of these eight reactions are given in the Table.

In the considered cases $\Delta H_{3000}^{0}$ has a negative value, i.e. these reactions are exothermic and accompanied by heat release. Moreover, the entropy $\Delta S^{0}$ of reactions $3,4,5,7,8>0$, i.e. they proceed spontaneously, and the entropy of reactions $1,2,6<0$, which proves the impossibility of their spontaneous occurrence.

For the conditions of arc welding (at constant pressure $P=$ const) heat release (transfer) (randomly from the hot body to the cold one) is possible due to changes in enthalpy of the system $Q=\Delta H$. Moreover, it must be remembered that the enthalpy and entropy have extensive properties, i.e. they depend on the amount of substance [5].

As was noted above, to determine the probability and conditions of reaction equilibrium (in this case at $P=$ const) the Gibbs thermodynamic function $\Delta G_{\mathrm{t}}^{0}=f(T)$ was used. For reactions specified in the Table the graphic dependencies of given function were obtained (Figure 1).

In the thermodynamic system being under the constant pressure, only those processes occur randomly, which are accompanied by decrease in isobaric potential of the system, i.e. of all the possible list of chemical interactions between substances, included into the base metal and welding electrode, those reactions are possible, which would result in reduction of thermodynamic potential. Those reactions will proceed the most intensively, in which the absolute value of decrease in isobaric potential is the highest: $\left|\Delta G_{t}\right|=\max$.

Chemical affinity of substances increases their capacity to interact with formation of new substances. Obviously, that the more energy must be spent (to perform the work) to destroy the chemical bond, the higher is the value of chemical 
SCIENTIFIC AND TECHNICAL

Results of calculation of thermodynamic parameters for reactions that may proceed in the arc gap at $3000 \mathrm{~K}$

\begin{tabular}{|c|c|c|c|c|}
\hline $\begin{array}{c}\text { Number } \\
\text { of reaction }\end{array}$ & Chemical reaction & $\Delta H_{3000}^{0}, \mathrm{~kJ}$ & $\Delta S_{3000}^{0}, \mathrm{~J} / \mathrm{K}$ & $\Delta G_{3000}^{0}, \mathrm{~J}$ \\
\hline 1 & $4 \mathrm{Cr}+3 \mathrm{O}_{2}=2 \mathrm{Cr}_{2} \mathrm{O}_{3}$ & -3774.8 & -1043.62 & $-643,940$ \\
\hline 2 & $2 \mathrm{Cr}+3 \mathrm{O}_{2}=2 \mathrm{CrO}_{3}$ & -1546.486 & -920.1 & $1,213,514$ \\
\hline 3 & $4 \mathrm{CrO}_{3}=2 \mathrm{Cr}_{2} \mathrm{O}_{3}+3 \mathrm{O}_{2}$ & -594.918 & 802.6565 & $-3,002,890$ \\
\hline 4 & $2 \mathrm{CrO}_{3}+3 \mathrm{Mn}=3 \mathrm{MnO}^{2} \mathrm{Cr}_{2} \mathrm{O}_{3}$ & -1878.804 & 19.742 & $-1,938,030$ \\
\hline 5 & $4 \mathrm{CrO}_{3}+3 \mathrm{Mn}=3 \mathrm{MnO}_{2}+2 \mathrm{Cr}_{2} \mathrm{O}_{3}$ & -2820.458 & 69.84 & $-3,029,978$ \\
\hline 6 & $4 \mathrm{CrO}_{3}+3 \mathrm{Si}=3 \mathrm{SiO}_{2}+2 \mathrm{Cr}_{2} \mathrm{O}_{3}$ & -4257.198 & -57.439 & $-4,084,881$ \\
\hline 7 & $4 \mathrm{CrO}_{3}+3 \mathrm{Ti}=3 \mathrm{TiO}_{2}+2 \mathrm{Cr}_{2} \mathrm{O}_{3}$ & -2919.148 & 473 & $-4,88$ \\
\hline 8 & $2 \mathrm{CrO}_{3}+2 \mathrm{Al}=\mathrm{Al}_{2} \mathrm{O}_{3}+\mathrm{Cr}_{2} \mathrm{O}_{3}$ & -2283.639 & 1.024 & $-286,711$ \\
\hline
\end{tabular}

affinity. On the other hand, it is also clear that the more energy is released (or absorbed) during formation of chemical bond, the stronger is this bond. Consequently, the necessary condition for the process of interaction of substances is the reduction of isobaric potential of the system as a result of reaction. The absolute value of isobaric potential according to the module $\left|\Delta G_{t}\right|$ determines the value of chemical affinity, and the sign indicates the direction of chemical reaction:

$\Delta G_{\mathrm{t}}<0-$ direct reaction proceeds;

$\Delta G_{\mathrm{t}}>0$ - reverse reaction proceeds;

$\Delta G_{\mathrm{t}}=0-$ reaction is in equilibrium.

The stated regularities are true for the case when pure substances come into interaction [6].

Reaction $2 \mathrm{Cr}+3 \mathrm{O}_{2}=2 \mathrm{CrO}_{3}$ has a positive value of Gibbs energy at $3000 \mathrm{~K}$ (see Figure 1). This means that the reaction proceeds in reverse direction: $2 \mathrm{CrO}_{3}=2 \mathrm{Cr}+3 \mathrm{O}_{2}$, i.e. despite the fact that the oxidation reaction of elementary chromium must proceed according to its chemical properties, in this case in the zone of welding arc the temperature conditions are created being unfavorable for formation of hexavalent chromium.

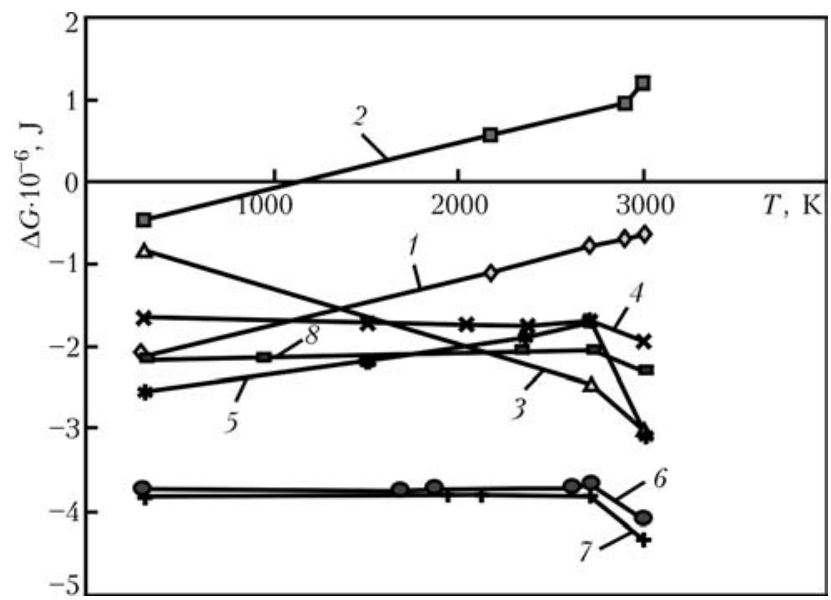

Figure 1. Graphical representation of probability of chemical reactions (numbers of curves correspond to the numbers of chemical reactions in the Table)
From the results of calculations (see Figure 1) it is seen that the most probable reactions at the change of temperature from 298 to $3000 \mathrm{~K}$ will be reactions 7 and 6 (see the Table). They evidence that the presence of such metals as titanium and silicon in the composition of welding consumables contributes to restoration of oxide of hexavalent chromium $\mathrm{CrO}_{3}$ to trivalent one $\mathrm{Cr}_{2} \mathrm{O}_{3}$. The probability of proceeding reactions 1 and 2 decreases with increase in temperature and reaching equilibrium they will proceed in the reverse direction. The curves of Gibbs energy of reactions 4 and 8 are almost parallel to each other and have a direct dependence on temperature, moreover, the probability of reaction 8 is higher than that of 4 . The latter evidences that manganese and aluminum, as well as titanium and silicon, promote restoration of hexavalent chromium oxide to trivalent oxide.

According to results of calculations it is obvious that all the considered chemical reactions (see the Table) in the range of temperatures from 298 to $3000 \mathrm{~K}$ have a high thermodynamic probability of their proceeding except of reaction 2 . At the same time if in the process of welding an elementary chromium is taken out beyond the arc gap and during decrease in temperature to $1100 \mathrm{~K}$ it is not oxidized, then at decrease of temperature lower than $1100 \mathrm{~K}$, although with low probability, the reaction of its oxidation $2 \mathrm{Cr}+3 \mathrm{O}_{2}=2 \mathrm{CrO}_{3}$ can proceed

Moreover, the results of experimental investigations [7, 8] showed that hexavalent chromium is present in the composition of WA in welding of high-alloyed steels using coated electrodes. This is explained by the fact that it is represented in WA in the form of potassium and sodium chromates $\left(\mathrm{K}_{2} \mathrm{CrO}_{4}, \mathrm{~K}_{2} \mathrm{Cr}_{2} \mathrm{O}_{7}, \mathrm{Na}_{2} \mathrm{CrO}_{4}\right.$, $\mathrm{Na}_{2} \mathrm{Cr}_{2} \mathrm{O}_{7}$ ), the formation of which is significantly affected by the content in coating of welding electrodes of alkali metal oxides $\mathrm{K}_{2} \mathrm{O}$ and $\mathrm{Na}_{2} \mathrm{O}[9]$. 


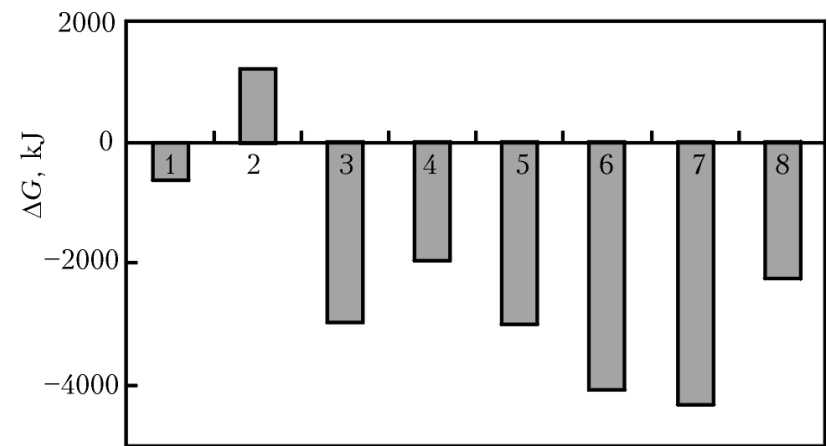

Figure 2. Change of isobaric potential of probability of chemical reactions at $3000 \mathrm{~K}$ (here and in Figure 3, digits numbers of reactions)

Analysis of thermodynamics of chemical reactions, given in the Table, allows concluding that the probability of reaction 1 of formation of chromium oxide with increase in temperature is almost reduced to zero. Reaction 2 has the lowest probability in forward direction. It is likely that at the temperature of more than $1100 \mathrm{~K}$, it will proceed in reverse direction, i.e. with decomposition of $\mathrm{CrO}_{3}$ to $\mathrm{Cr}$ and $\mathrm{O}_{2}$. Reaction 3 is likely in the given range of temperatures and has a symmetrical reflection of reaction 2 curve. This evidences that that most likely $\mathrm{CrO}_{3}$ will decay into $\mathrm{Cr}_{2} \mathrm{O}_{3}+\mathrm{O}_{2}$, but not into $\mathrm{Cr}+\mathrm{O}_{2}$. Reactions 4 and 8 have almost parallel curves, moreover, the probability of reaction 4 is a little bit higher.

Reactions 6 and 7 have the highest probability in a given range of temperatures. Reaction 5 is interesting by the fact that with increase in temperature to $2713 \mathrm{~K}$ its probability decreases, and after melting of chromium oxide $\mathrm{Cr}_{2} \mathrm{O}_{3}$ the curve has a sharp inclination in the negative direction (see Figure 1), i.e. it has a high probability at high temperatures.

We shall note that breaks in the plots of Gibbs function evidence of change in the aggregate state of final component of chemical reaction.

To compare the probability of proceeding the considered chemical reactions at the maximum temperature $(3000 \mathrm{~K})$, the histograms (Figures 2 and 3 ) are plotted. According to Figure 2 it is seen that reactions 1 and $3-8$ have a negative isobaric potential. This means that they proceed in the forward direction. At $3000 \mathrm{~K}$ reactions 7 and 6 are the most intensive. Reaction 2 does not proceed in the forward direction, it is only possible in the following form: $2 \mathrm{CrO}_{3}=2 \mathrm{Cr}+3 \mathrm{O}_{2}$. In this case, it is quite obvious that the formed elementary chromium will be oxidized in the course of reaction 1 .

From the results given in Figure 3, it is seen that at constant temperature (in this case $3000 \mathrm{~K}$ ) reactions $1-8$ will proceed, wherein reactions 7 and

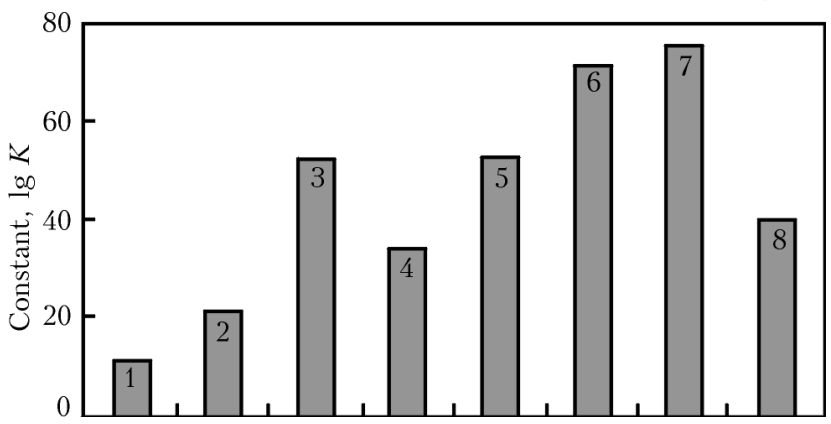

Figure 3. Equilibrium constants of chemical reactions at $3000 \mathrm{~K}$

6 will be the most intensive. The results of calculations of equilibrium constant prove that at $3000 \mathrm{~K}$ the mentioned chemical reactions can proceed almost completely. The direction of their proceeding is indicated by the sign of isobaric potential (see Figure 2).

\section{Conclusions}

1. The calculations of thermodynamic characteristics of probability of proceeding the chemical reactions of chromium oxides formation in arc welding showed that in the zone of welding arc in the temperature range from 1100 to $3000 \mathrm{~K}$ the hexavalent chromium compounds are not formed.

2 . The calculations of thermodynamic characteristics confirmed that adding of titanium, silicon, manganese and aluminum into the composition of welding electrodes can prevent the formation of hexavalent chromium oxide. At $3000 \mathrm{~K}$ the ability of these metals to prevent the formation of hexavalent chromium is increased in the following order: aluminum, manganese, silicon, titanium.

1. (1982) Researches on the origin and the characteristics of chromium in stainless steel welding fumes: IIW Doc. II-A-563-82.

2. Kokh, B.A. (1975) Principles of thermodynamics of welding thermal processes. Leningrad: Sudostroenie.

3. Rykalin, N.N. (1951) Calculations of thermal processes in welding. Moscow: Mashgiz.

4. Filippov, S.I. (1967) Theory of metallurgical processes. Moscow: Metallurgiya.

5. Devero, O.F. (1986) Problems of metallurgical thermodynamics. Moscow: Metallurgiya.

6. Bernadsky, I.I. (1978) Theory of metallurgical processes. Kiev: Vysshaya Shkola.

7. Yushchenko, K.A., Levchenko, O.G., Bulat, A.V. et al. (2007) Sanitary and hygienic characteristics of covered electrodes for welding high-alloy steels. The Paton Welding J., 12, 35-38.

8. Yushchenko, K.A., Bulat, A.V., Levchenko, O.G. et al. (2009) Effect of composition of base metal and electrode covering on hygienic properties of welding fumes. Ibid., 7, 44-48.

9. Pokhodnya, I.K., Gorpenyuk, V.N., Milichenko, S.S. et al. (1990) Metallurgy of arc welding: Processes in arc and melting of electrodes. Kiev: Naukova Dumka.

Received 18.03.2015 


\title{
ASYNCHRONOUS EXCITERS AND STABILIZERS OF ARC. ANALYSIS AND CALCULATION PROCEDURE. Part 2
}

\author{
N.M. MAKHLIN ${ }^{1}$ and A.E. KOROTYNSKY ${ }^{2}$ \\ ${ }^{1}$ State Enterprise «Researh Engineering Center of Welding and Control «Power Engineering» \\ of E.O. Paton Electric Welding Institute, NASU \\ 11 Bozhenko Str., 03680, Kiev, Ukraine. E-mail: electro@paton.kiev.ua \\ ${ }^{2}$ E.O. Paton Electric Welding Institute, NASU \\ 11 Bozhenko Str., 03680, Kiev, Ukraine. E-mail: office@paton.kiev.ua
}

\begin{abstract}
Issues of analysis of processes in electronic voltage boosters of asynchronous type with series circuit of main or pilot arcs are considered. They have configuration of forming circuit, in which capacitive storage and inductance of primary winding of pulse step-up transformer have series connection, and switching key of the circuit is parallel. Part 2 of the work provides for the results of analysis of circuits of increased voltage pulse generators, forming asynchronous exciters and stabilizers of arcing. Description is given to circuit solutions and issues of analysis of charge-discharge circuit of asynchronous exciters and stabilizers of arcing, built based on method of resonant pumping, are reflected. Analysis of processes in the circuit of asynchronous exciters and stabilizers of arcing is carried out using solutions of the equations known in theoretical electrical engineering. Engineering procedure is proposed based on these solutions for calculation of main components in functional assemblies of asynchronous exciters and stabilizers of arcing and recommendations of selection of their element base are given. 29 Ref., 2 Tables, 6 Figures.
\end{abstract}

Keywords: arc and plasma welding, asynchronous exciters and stabilizers of arc, generator of increased voltage pulses, pulse transformer, cores, ferrites, sprayed iron, device for input of high-voltage pulses, resonant pumping

Efficiency of contact-free methods for initiation of stationary arc discharge by ionizing of interelectrode gap due to injection of pulses of high or increased voltage in it mainly depends on method of input of these pulses in arc circuit and parameters of high-voltage pulses, generated by special voltage booster-exciters and stabilizers of arc. Series of works, for example [1-5], are dedicated to structural design of such electronic devices and their circuit design. However, issues of analysis of electromagnetic processes in functional assemblies of such devices and procedures of their calculation are considered in insufficient for practice volume. Work [6] bridges this gap to some extent. It is dedicated to circuit design, analysis and procedure for calculation of electronic voltage boosters with independent alternating voltage supply (mainly of industrial frequency) with series circuit of main or pilot arc. Work [7] studies the issues of circuit design, analysis and procedure for calculation of charging devices (CD) of asynchronous exciters and stabilizers of arc (AESA), made based on key scheme with dosing reactor or voltage multiplier (VM) designed by Cockcroft-Walton scheme. Moreover, similar issues concerning such important functional assembly of AESA as generator of increased voltage pulses (GVP), which is imbedded

(c) N.M. MAKHLIN and A.E. KOROTYNSKY, 2015 in AESA regardless the method of realizing or CD scheme, have fragment representation in known references up to the present time. This promotes for some difficulties in development and designing of AESA. Significant difficulties appear in development and designing of AESA, based on application resonant pumping method for charge of GVP capacitive storage, due to absence of woks providing the results of analysis of processes in circuits of similar devices and procedure for calculation of their assemblies and units.

Aim of the present work lies in analysis of processes in GVP, imbedded in AESA, as well as in functional assemblies of AESA, based on method of resonant pumping, using for analysis the methods of investigation of linear circuits known in theoretical electrical engineering, making recommendations on calculation and selection of components of devices of this group following the results of their analysis and experience of development, manufacture and practical application.

Peculiarities of analysis and calculation of GVP. Principle of AESA operation is based on periodic charging of GVP capacitive storage and its further discharge via primary winding of pulse step-up transformer, which secondary winding injectes pulses of high or increased voltage in the circuit of main or pilot arc [1, 2, 7].

Figure 1, $a$ shows a structural-functional scheme of AESA with CD based on key scheme with dosing reactor or CD based on VM and series circuit of direct or alternating current arc. Basic variant of GVP of such AESA represents 
itself series $L C$-ringing circuit including capacitive storage $C_{\mathrm{c}}$, inductance $L_{\mathrm{c}}$ (inductance of primary winding $I$ of pulse step-up transformer $T V 1)$ and semiconductor switching element $\mathrm{K}$ (key) with control circuit 1.

Formation of increased voltage pulses in GVP circuit is carried out due to transition process taking place at periodic turn-on of semiconductor key K. Calculation equivalent scheme, shown in Figure 2, $a$, can be used for analysis of transition process in GVP circuit. At that the following assumptions, which virtually have no effect on analysis quality, are reasonable to take into account:

1) $R_{\mathrm{k}}=R_{\mathrm{k} . \mathrm{d}}+E S R_{C}+R_{L}+R_{\text {c.w }}$, where $\mathrm{R}_{\mathrm{k} . \mathrm{d}}$ is the dynamic resistance of turn-on key $\mathrm{K} ; E R S_{C}$ is the equivalent series active resistance of GVP capacitive storage; $R_{L}$ is the active resistance of primary winding of pulse step-up transformer $T V 1 ; R_{\text {c.w }}$ is the active resistance of GVP connecting wires;

2) inductance $L_{\mathrm{c}}$ of primary winding $I$ of pulse step-up transformer $T V 1$ is linear, equal to initial one and does not depend on current passing in it;

3) $\tau_{\text {trans }}<<T_{i}$, where $\tau_{\text {trans }}$ is the duration of transition process; $T_{i}$ is the period of turn-on frequency of semiconductor key $\mathrm{K}$;

4) $R_{\mathrm{c}} / 2 L_{\mathrm{c}}<1 / \sqrt{L_{\mathrm{c}} C_{\mathrm{c}}}$

5) $U_{\text {out }}=U_{L} W_{2} / W_{1}$, where $U_{\text {out }}$ is the output voltage of AESA (voltage on secondary winding of pulse step-up transformer $T V 1$ ); $U_{L}$ is the voltage on $L_{\mathrm{c}}$ inductance; $W_{1}$ and $W_{2}$ are the number of turns of primary and secondary winding of pulse step-up transformer $T V 1$, respectively.

Transition process under non-zero initial conditions in $R_{\mathrm{c}} C_{\mathrm{c}} L_{\mathrm{c}}$-circuit with preliminary charged capacity for $u_{C}$ voltage on GVP capacitive storage considering made assumptions is described by known differential equation of the second order $[8,9]$

$$
L C \frac{d^{2} u_{C}}{d t^{2}}+R C \frac{d u_{C}}{d t}+u_{C}=U_{C 0},
$$

where $U_{C 0}=U_{C y}$ is the steady-state capacitive storage voltage (at $t \rightarrow \infty, d u_{C} / d t=0$ and $i_{C}(t)=$ $=0$ ), i.e. capacitive storage voltage $C_{\mathrm{c}}$ directly before semiconductor key $\mathrm{K}$ turn-on.

Solutions of equation (1) can be represented in form of expressions by entering designations $R / 2 L=\delta, 1 / L C=\beta_{0}^{2} \beta=\sqrt{\beta_{0}^{2}-\delta^{2}}$ and considering made assumption $\beta_{0}^{2}>\delta^{2}$ :

$$
\begin{gathered}
i_{C}=-\frac{U_{C 0}}{\beta L} \sin \beta t e^{-\beta t}, \\
u_{C}=U_{C 0} \frac{\beta_{0}}{\beta} \cos (\beta t-\gamma) e^{-\delta t},
\end{gathered}
$$

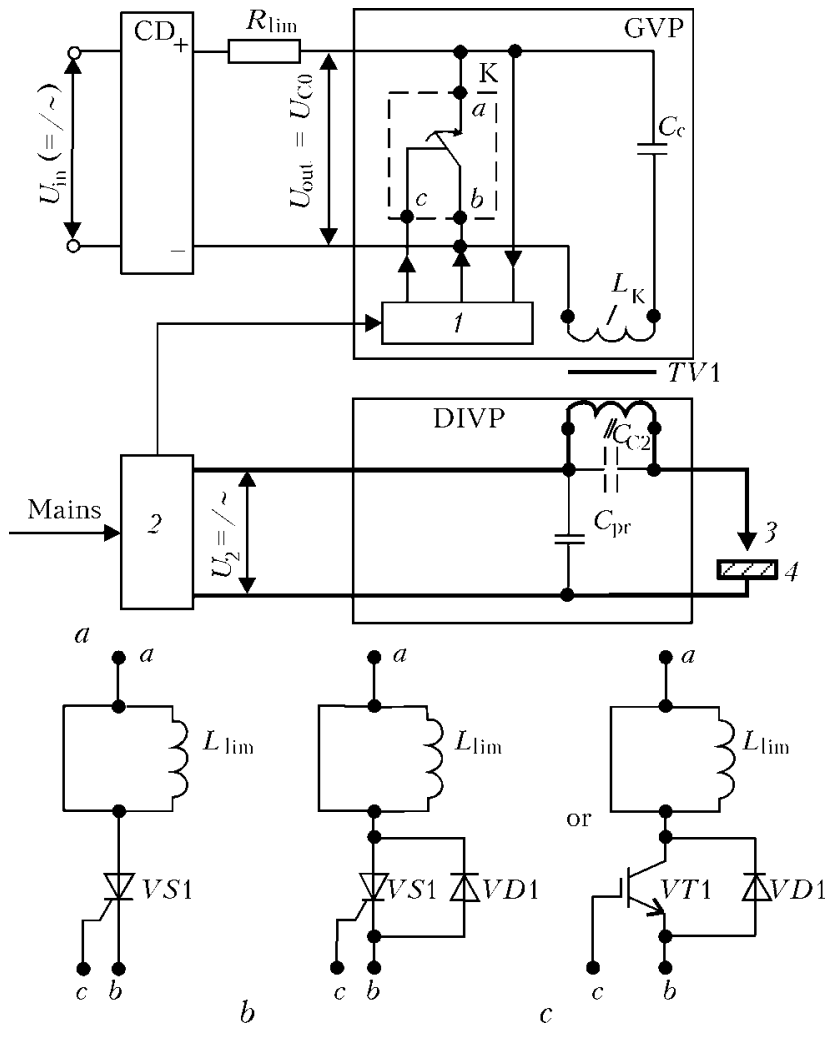

Figure 1. Structural scheme of AESA with series connection to welding circuit $(a)$; electric schematic diagram of semiconductor GVP switching key with unidirectional conduction (b); variants of electrical schematic diagram of semiconductor GVP switching key with two-directional conductivity $(c)$ : 1 - AESA control scheme; 2 - arc power supply; 3 - welding electrode; 4 - part being welded; CD - step-up charging device; $R_{\lim }-$ current-limiting resistor; GVP - generator of increased voltage pulses; $\mathrm{K}-$ semi-conductor switching key of GVP; $C_{c}-$ capacitor of GVP forming circuit; $T V 1$ - step-up pulse transformer with primary $I$ and secondary $I I$ windings; $L_{\mathrm{c}}$ - inductance of GVP forming circuit (inductance of winding $I$ of $T V 1$ transformer); $L_{\lim }$ - additional inductance limiting speed of current buildup through GVP switching key; DIVP device for input of high-voltage pulses to arc circuit; $C_{\mathrm{C} 2}-$ capacitor of additional forming circuit of DIVP; $C_{\mathrm{pr}}-$ protective (block) DIVP capacitor; VS1 - thyristor of semi-conductor GVP switching key; VT1 - transistor of semi-conductor GVP switching key; VD1 - back diode of semi-conductor GVP switching key

where $\operatorname{tg} \gamma=\delta / \beta_{0}$, and «minus» sign for $i_{C}$ indicate direction of discharge current of capacitive storage $C_{c}$ opposite to direction of current of its charge.

Based on relationship $u_{L}=L \frac{d t}{d t}$ and expression (2) inductance transition voltage $L_{\mathrm{c}}$ can be determined by formula

$$
u_{L}=-\frac{U_{C 0}}{\beta}(\beta \cos \beta t-\delta \sin \beta t) e^{-\delta t} .
$$

It can be supposed under made assumptions that $\beta_{0} / \beta \approx 1$ for GVP circuit, and, therefore, formula (3) with accuracy, sufficient for practice, can be represented as

$$
u_{L}=-U_{C 0} \cos (\beta t-\gamma) e^{-\delta t} .
$$



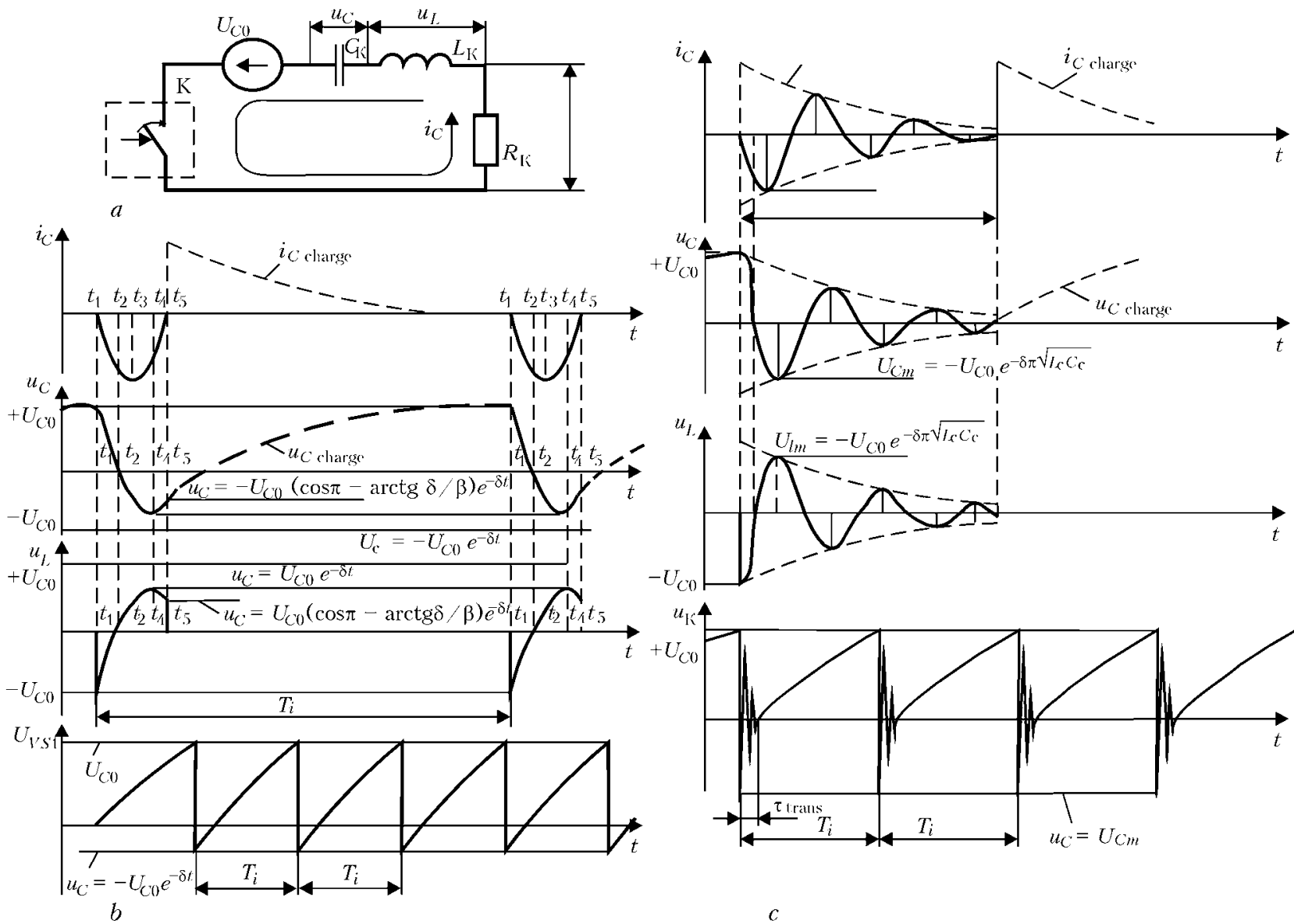

Figure 2. GVP equivalent circuit ( $a$ ), and diagrams of currents and voltages in GVP circuits at unidirectional (b) and two-directional $(c)$ conductance of semi-conductor switching key $\mathrm{K}$

In (2)-(4) $\beta$ represents itself angular frequency of own oscillations at transition process in $R_{\mathrm{c}} C_{\mathrm{c}} L_{\mathrm{c}}$-circuit; $\delta$ is the coefficient of attenuation of these oscillations.

Diagrams of current $i_{C}$, voltages $u_{C}$ and $u_{L}$, reflecting the nature of transition process in $R_{\mathrm{c}} C_{\mathrm{c}} L_{\mathrm{c}}$-circuit of GVP depending on type of conductance (unidirectional or two-directional - see Figure 1, $b$ and $c$, respectively) of key $\mathrm{K}$ are given in Figures 2, $b$ and $c$, respectively.

Process of recharging of capacitive storage $C_{\mathrm{c}}$ via inductance $L_{\mathrm{c}}$ of GVP circuit takes place from the moment of its turn-on $t_{1}$ (Figure $2, b$ ) at unidirectional conductance of key K (thyristor $V S 1$ is usually used as the latter - see Figure 1, b). At that, GVP circuit starts to pass current $i_{C}$, which will be changes by sine law from zero in moment $t_{1}$ to amplitude value $I_{C m}=U_{C 0} / \beta L$ iv $\mu$ o $\mu \varepsilon v \tau t_{3}$, and from amplitude value to zero in moment $t_{5}$. As a consequence, key $\mathrm{K}$ in moment $t_{5}$ will naturally transfer into non-conducting state and this is the moment of beginning of process of GVP capacitive storage charging. Voltage $u_{C}$ of capacitive storage $C_{\mathrm{c}}$ from moment $t_{1}$ starts changing by cosine law from value $+U_{C 0}$ to zero in moment $t_{2}$, and then from amplitude value $U_{C m} \approx-U_{C 0} e^{-\delta t}$ in moment $t_{4}$, and from amplitude value to value $u_{C}=-U_{C 0} \cos (\pi-\operatorname{arctg} \delta / \beta) e^{-\delta t}$ in moment $t_{5}$, from which growing by exponential law takes place providing charging of GVP storage up to $U_{C 0}$ value. In turn, $u_{L}=-U_{C 0}$ voltage appear in moment $t_{1}$ on $L_{\mathrm{c}}$ inductance of GVP circuit, which starts changing by cosine law from $-U_{C 0}$ value to zero in moment $t_{2}$, then from zero to amplitude value $U_{L m} \approx U_{C 0} e^{-\delta t}$ in moment $t_{4}$, and from amplitude value to $u_{L}=U_{C 0} \cos (\pi-$ $-\operatorname{arctg} \delta / \beta) e^{-\delta t}$ value in moment $t_{5}$, after what it immediately drops to zero. Time shifts $\Delta t=t_{3}-$ $-t_{2}=t_{5}-t_{4}$ depend on $Q$-factor of GVP $R_{\mathrm{c}} C_{\mathrm{c}} L_{\mathrm{c}}-$ circuit, which is determined by expression

$$
Q=\frac{\sqrt{L_{\mathrm{c}} C_{\mathrm{c}}}}{R_{\mathrm{c}}} .
$$

Duration of transition process at unidirectional conduction of key $\mathrm{K}$ can be determined by formula

$$
\tau_{\text {trans }}=\pi \sqrt{L_{\mathrm{c}} C_{\mathrm{c}}} .
$$

Two-directional conductance of semi-conductor key K (see Figure 1,c) from moment of its connection to GVP circuit will provoke classical transition process with attenuating oscillations, described by known equation (1), solution of which are expressions (2)-(4). Figure 2, $c$ shows curves of change of current $i_{C}$ and voltages $u_{C}$ and $u_{L}$ during transition process with attenuating 
oscillations. It is known from $[8,9]$ that phase shifts between $i_{C}$ current and $u_{C}$ and $u_{L}$ voltages and duration of transition process at two-directional conductance of key $\mathrm{K}$ depend on GVP $R_{\mathrm{c}} C_{\mathrm{c}} L_{\mathrm{c}}$-circuit $Q$-factor, at that duration of transition process with attenuating oscillations is determined by relationship

$$
\tau_{\text {trans }}=\frac{6 L_{\mathrm{c}}}{R_{\mathrm{c}}} .
$$

Process of charging of capacitive storage $C_{\mathrm{c}}$ to $U_{C 0}$ value starts repeating from moment of ending of transition process attenuating oscillations in GVP circuit. One of the peculiarities of transition process with attenuating oscillations is virtual symmetry of curves of current $i_{C}$ and voltages $u_{C}$ and $u_{L}$ relatively to zero, that provides for the possibility of efficient use of pulse step-up transformer $T V 1$ (see Figure 1, a). At that, such a transformer can operate at maximum allowable span of induction in its core, i.e. from $+B_{\text {sat }}$ to $-B_{\text {sat }}$.

Another peculiarity of GVP circuit, key K of which has two-directional conductance, lies in the fact that duration of transition process with attenuating oscillation exceeds duration of transition process at unidirectional conductance of key $\mathrm{K}$. This promotes for more continuous retention of plasma in impact ionization state in interelectrode gap. This is particularly important in the cases, when AESA is used for excitation of low-amperage arcs, as well as stabilizing of burning process of low-stable alternating current arcs (for example TIG welding of aluminum and its alloys or MMA welding by electrodes with lime fluorspar coating). The latter are characterized by quick deionization of inter electrode gap at change of arc current polarity [4, 10].

However, it should be noted that in comparison with GVP, which consists of key with unidirectional conductance, realizing of two-directional conductance of key $\mathrm{K}$ requires some complication and application of semiconductor devices with higher allowable back voltages as well as key control scheme capable to provide duration of control signals being neither less, not more than duration of transition process with attenuating oscillations.

Nonfailure operation of semiconductor key K requires inductance value $L_{\mathrm{c}}$ of GVP circuit which provides for fulfillment of the requirements $I_{\mathrm{Cm}}<I_{\mathrm{OS} \text {.OVL max }}$ and $(d i / d t)_{\mathrm{c}}<$ $<(d i / d t)_{\mathrm{cr}}$, where $I_{\mathrm{OS} . \mathrm{OVL} \max }$ is the maximum allowable repeatable overload current of on-state semiconductor key (maximum allowable current of operating overload $) ;(d i / d t)_{\mathrm{c}}$ is the maximum value of speed of current buildup $i_{C}$ in GVP circuit; $(d i / d t)_{\text {cr }}$ is the value of critical speed of current buildup at on-state key K. Maximum amplitude value of $I_{\mathrm{C} m}$ current in GVP circuit according to (2) can be determined by expression

$$
I_{\mathrm{C} m}=U_{C 0} \sqrt{\frac{C_{\mathrm{c}}}{L_{\mathrm{c}}}},
$$

and in real models of AESA makes form 80 to 445 A. Taking into account that duration of such current does not exceed few microseconds and maximum speed of current buildup $i_{C}=50-$ $80 \mathrm{~A} / \mathrm{s}$, fulfillment of the requirement on nonfailure operation of on-state key $\mathrm{K}$ based on allowable current of operating overload $I_{\text {OS.OVL max }}$ and critical speed of current buildup in AESA is totally reachable [11].

Moreover, calculation and designing of pulse step-up transformer (PT) of AESA promote some difficulties due to high values of magnetic field intensity $H$ in the core, caused by amplitude values of current $I_{\mathrm{C} m}$ in GVP circuit. It is known fact that inductance in PT core at its change from $-B_{\text {sat }}$ to $+B_{\text {sat }}$ is related with intensity $H$ by $B=$ $=\mu H$ relationship, where $\mu=\mu_{0} \mu_{\mathrm{e}}$ is the magnetic permeability of PT core material; $\mu_{0}$ is the magnetic constant equal $4 \pi \cdot 10^{-7} ; \mu_{\mathrm{e}}$ is the effective magnetic permeability of the core (for cores without gap $\mu_{\mathrm{e}}$ value can be taken equal initial magnetic permeability $\left.\mu_{\text {init }}\right)$. Intensity $H$ in PT core is determined as [12]

$$
H=\frac{I_{\mathrm{C} m} W_{1}}{l_{\mathrm{c}}},
$$

where $W_{1}$ is the number of turns of PT primary winding; $l_{\mathrm{c}}$ is the length of average line of magnetic inductance in the core. Table 1 gives the largest calculation values of $H_{\max }$ and $B_{\max }$ depending on calculated according to (8) $I_{\mathrm{Cm}}$ current values at $U_{C 0}=700 \mathrm{~V}, l_{\mathrm{c}}=0.44 \mathrm{~m}, W_{1}=1, \mu_{\mathrm{e}}=1.58 \cdot 10^{3}$ and typical for GVP values of $C_{\mathrm{c}}$ and $L_{\mathrm{c}}$.

It follows form data of Table 1 that application of single ferrite cores without gap with acceptable geometry parameters, in which value of saturation induction $B_{\text {sat }}$ can make $0.48-0.50$ T [13], at typical for GVP values of $I_{\mathrm{C} m}, C_{\mathrm{c}}, L_{\mathrm{c}}$ and $\mu_{\mathrm{init}}$ is virtually impossible in PT of AESA.

Application of such widespread method of increase of $H_{\max }$ allowable value as introduction of gap with length not higher than $1 \%$ of $l_{\mathrm{c}}$ in the core [12], at which induction in PT ferrite core does not exceed $B_{\text {sat }}$ value, is more effective. In this case $\mu_{\mathrm{e}}$ value can make $(0.12-0.14) \mu_{\text {init }}$ (due to which $H_{\max }$ value can reach $2700-$ $3000 \mathrm{~A} / \mathrm{m}$ depending on $B_{\text {sat }}$ ). However, reduction of $\mu_{\text {init }}$ value provokes for proportional decrease of value of induction coefficient $A_{L}=$ $=L_{\mathrm{c}} / W_{1}^{2}=\mu_{0} \mu_{\mathrm{e}} A_{\mathrm{e}} / l_{\mathrm{c}}$, where $A_{\mathrm{e}}$ is the effective area of section of single core. This provides for the necessity of application of PT core consisting 
SCIENTIFIC AND TECHNICAL

Table 1. Dependence of $B_{\max }$ on $H_{\max }$ at different values of $C_{\mathrm{c}} / L_{\mathrm{c}}$ relationship

\begin{tabular}{|c|c|c|c|c|c|c|}
\hline \multirow{2}{*}{$C_{\mathrm{c}}, \mu \mathrm{F}$} & \multicolumn{2}{|c|}{$L_{\mathrm{c}}=20 \mu \mathrm{H}$} & \multicolumn{2}{|c|}{$L_{\mathrm{c}}=14 \mu \mathrm{H}$} & \multicolumn{2}{|c|}{$L_{\mathrm{c}}=1 \mu \mathrm{H}$} \\
\hline & $H_{\max }, \mathrm{A} / \mathrm{m}$ & $B_{\max }, \mathrm{T}$ & $H_{\max }, \mathrm{A} / \mathrm{m}$ & $B_{\max }, \mathrm{T}$ & $H_{\max }, \mathrm{A} / \mathrm{m}$ & $B_{\text {max }}, \mathrm{T}$ \\
\hline 0.25 & 178 & 0.353 & 213 & 0.423 & 252 & 0.499 \\
\hline 0.50 & 252 & 0.499 & 301 & 0.597 & 356 & 0.706 \\
\hline 1 & 356 & 0.706 & 424 & 0.841 & 503 & 0.999 \\
\hline 2 & 503 & 0.999 & 602 & 1.194 & 712 & 1.412 \\
\hline 3 & 616 & 1.223 & 736 & 1.461 & 871 & 1.729 \\
\hline 4 & 712 & 1.412 & 851 & 1.689 & 1006 & 1.997 \\
\hline
\end{tabular}

from several single cores, in order to receive acceptable value of $L_{c}$. Besides, introduction of gap does not eliminate the necessity of application of ferrite cores with significant length of median line of magnetic induction $l_{\mathrm{c}}(>0.2 \mathrm{~m})$, that inevitably provokes for increase of weight, dimension size and price of PT.

Significantly better results can be received at PT designing in form of transformer with completely open rod-type ferrite core (Figure 3), for which expressions [12] are true:

$$
\mu_{\mathrm{e}}=\frac{\mu_{\text {init }}}{1+g\left(\mu_{\text {init }}-1\right)}, \quad g=0.84\left(D / l_{\mathrm{f}}\right)^{1.7},
$$

where $\mu_{\text {init }}$ is the initial magnetic permeability of core; $g$ is the demagnetizing factor of rod-type ferrite core; $D$ is the diameter; and $l_{\mathrm{f}}$ is the length of ferrite rod. Such PT structure provides for significant reduction of its weight-dimension indices and virtually eliminated possibility of its core saturation, that is achieved due to low $\mu_{e}$ typical for this structure. Moreover, this predetermines low value of inductance $L_{W 1}$ of PT primary winding (not more than $7 \mu \mathrm{H}$ ), which can be provided only at increased number of turns of primary winding (usually up to 11-12) and, respectively, secondary winding of PT. In addition to this, low value of inductance $L_{W 1}$ provokes necessity of introduction of additional inductance $L_{\text {add }}$ (see Figure $1, b, c$ ), having series connection to switching key $\mathrm{K}$, in GVP scheme for providing conditions of nonfailure operation of key K. Fulfillment of $L_{\mathrm{c}}=L_{W 1}+L_{\text {add }}>$ $>U_{C 0} /(d i / d t)_{\text {cr }}$ requirement is one of them.

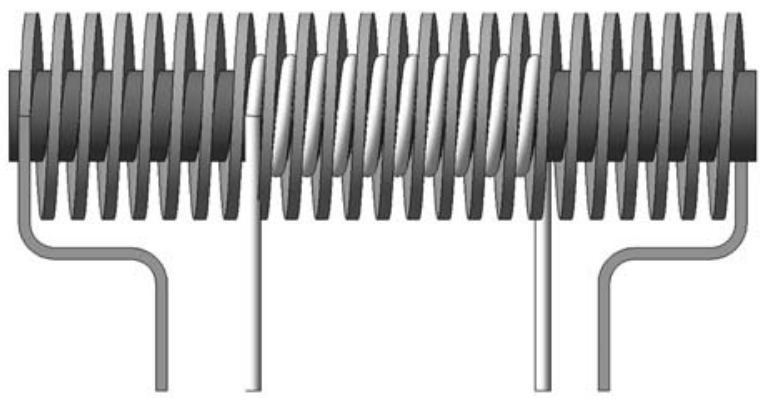

Figure 3. Structure of AESA step-up pulse transformer with completely open rod-type ferrite core
Production of secondary winding in form of single-layer winding, having edgewise winding due to necessity of distribution of this winding along the whole length of the core and providing minimum possible gap between winding and core, is also typical for PT with rod-type ferrite core. It should be noted that up to now literature does not include information on dependence and procedure of calculation of demagnetizing factor for open ferromagnetic cores allowing analytically strict determination of their effective magnetic permeability. This is why experimental data are used as a rule. Besides, number of turns of secondary winding in such PT is limited by length of industrially produced ferrite rods and usually does not exceed 28-30. Nevertheless, PT with rod-type ferrite core finds more and more application in AESA. It is indicated by practice of design and manufacture of welding inverters (mainly for TIG welding) by leading companies from Sweden, Italy, Finland, Ukraine, China, Russia and other countries.

Analysis of possible values of amplitude and frequency GVP parameters allows making a conclusion that core of pulse step-up GVP transformer shall be made from material giving low effective magnetic permeability $\mu_{\mathrm{e}}$ and, simultaneously, sufficiently high saturation induction $B_{\text {sat }}$ for receiving optimized electromagnetic and weight-dimension characteristics. Such properties are characteristic for cores from iron powder (IPC), being widely used in the recent years in inductance elements of switching power supplies and representing itself ferromagnetic structures with distributed air gap [14].

High saturation inductance typical for iron $\left(B_{\text {sat }} \leq 1.5 \mathrm{~T}\right)$ in combination with distributed gap provides for the possibility of producing a core with low effective magnetic permeability $\left(\mu_{\mathrm{e}} \leq 120\right)$ and allowable values $H_{\max }=8000-$ $20000 \mathrm{~A} / \mathrm{m}$, capable to function in wide range of frequencies (more $100 \mathrm{kHz}$ ) [15-17]. Significant advantage of IPC is the fact that iron powder has the lowest price among the most widespread materials with high saturation inductance. Such 
IPC characteristics provides for the possibility to create compact PT with rational number of winding turns and optimized weight-dimension indices. IPC application allows reaching inductance values of primary winding around $8 \mu \mathrm{H}$ and more in GVP pulse step-up transformer. At that, calculation of PT with IPC can be made using known and, to significant extent, processed procedures $[12,17]$ as well as results of additional experimental investigations. It can be expected that PT with IPC as well as chokes with such cores receive wide distribution in the future years not only in AESA, but welding inverters and converters.

It is noted in [6] that resistance of inter electrode gap is sufficiently high (from several tens to hundred of $\mathrm{kOhms}$ ) in breakdown and spark discharge being referred to independent unstable discharges in gases. Therefore, effect of welding circuit, including DIVP circuits, on GVP parameters is negligibly small and expressions (2)(8) are true for open-circuit AESA mode as well as spark discharge mode (up to the moment of transition of spark discharge of interelectrode gap to stationary arc).

Expressions (2)-(10) and results of experimental investigations as well as experience of designing and operation of AESA can be used for calculation of parameters and selection of components of basic GVP variant (see Figure 1, $a$ ) in the following way:

1. Calculation and nominal value of capacity $C_{\mathrm{c}}$ of GVP storage and type of applied capacitors are determined based on necessary value of energy of pulses being injected in the circuit of main and pilot arc in accordance with recommendations given in [6, 7] and according to relationship $C_{\mathrm{c}} \geq 2 W_{C} / U_{C 0 \text { min }}^{2}$, where $W_{C}$ is the energy accumulated in GVP capacitive storage at its charge; $U_{C 0 \text { min }}$ is the minimum possible value of steady-state charge voltage of capacitive storage in specific CD scheme. At that, the largest allowable voltage of direct current $U_{V D C}$ for capacitor (capacitors) of GVP capacitive storage shall fulfill the condition

$$
U_{V D C} \geq 1.6 U_{C 0 \max },
$$

where $U_{C 0 \text { max }}$ is the maximum possible value of steady-state charge voltage of capacitive storage in specific CD scheme.

2. Reference data, indicated, for example in $[11,18-21]$ as well as recommendations of work [6], are used for determination of values of constituents of GVP circuit active resistance, in accordance with which $R_{\mathrm{c}}$ resistance value does not exceed $30 \mathrm{mOhm}$ in most cases.
3. Calculation of inductance of GVP circuit is carried out depending on chosen PT structure, material and geometry of its core.

3.1. If PT design with $\Pi$ - or E-shaped ferrite cores are selected by design or economy issues, than it is reasonable to set values of inductance $L_{\mathrm{c}}$ of primary winding and number of its turns $W_{1}$ for PT calculation as well as determine number of turns $W_{2}$ of secondary winding and crosssection area of its conductor applying the recommendations of work [6]. Recommended $L_{\mathrm{c}}$ values make $16-22 \mu \mathrm{H}$ and $W_{1}$ is 1-2 turns. Then current amplitude value $I_{C m}$ in GVP circuit is determined by expression (8) and necessary calculation value of $A_{L}$ inductance coefficient is received by set values of $L_{\mathrm{c}}$ and $W_{1}$. Reference data given, for example in $[12,13,17,18,22]$, are used for preliminary selection of standard dimension-type of single ferrite $\Pi$ - or E-shaped core with $0.20<$ $<l_{\mathrm{c}}<0.37 \mathrm{~m}$ and $\mu_{\mathrm{e}}<1600$ and determination of effective area $A_{E C}$ of its section, as well as (using standard procedure) necessary area $A_{W}$ of core port taken by conductors of PT winding. Coefficient of turns laying, thickness of interturn and interwinding insulation and increased PT temperature at its cooling by means of natural convection are taken into account. After that, maximum possible value $H_{1}$ of magnetic field intensity in single core is calculated by formula (9) considering corresponding to them received and set values of $I_{C m}, W_{1}$ and $l_{c}$. After that, required $\mu_{\mathrm{e}}$ value for fulfillment of $B_{\text {sat }}>\mu_{0} \mu_{\mathrm{e}} H_{1}$ condition is determined by expression

$$
\mu_{\mathrm{e}} \leq \frac{B_{\mathrm{sat}}}{\mu_{0} H_{1}},
$$

where $B_{\text {sat }}$ is the allowable value of saturation induction of single ferrite core, which is recommended to be taken equal $0.35-0.40 \mathrm{~T}$. Based on this, required value of $\mu_{\mathrm{e}}$ can be provided only under condition of introduction of gap into the core. Necessary length of such gap $l_{\text {gap }}$ is determined from relationship [12]

$$
\mu_{\mathrm{e}}=\frac{\mu_{\text {init }}}{1+\mu_{\mathrm{e}} \frac{l_{\text {gap }}}{l_{\mathrm{c}}}} .
$$

Recommended values of $l_{\text {gap }}$ are from 0.5 to $1.0 \mathrm{~mm}$. If calculation results exceed recommended $l_{\text {gap }}$ values and do not provide necessary $\mu_{\mathrm{e}}$ values, than dimension-type of core with larger $l_{\text {gap }}$ should be taken, whereupon verification calculations are carried out again and final selection of dimension-type of the core is performed on their basis. In order to provide set value of $L_{\mathrm{c}}$ and required value of $A_{L}$ at taken number of turns $W_{1}$ the minimum necessary value of effective section area $A_{E}$ of the core is calculated based on received data using expression 


$$
A_{E}=\frac{l_{\mathrm{c}} A_{L}}{\mu_{0} \mu_{\mathrm{e}}}
$$

from which number $n_{\mathrm{c}}$ of single cores, making PT core, is determined as $n_{\mathrm{c}}=A_{E} / A_{E C}$ (where $A_{E C}$ is the effective section area of selected single core). At that $n$ value is rounded upwards natural number. As for the rest the calculation of PT with ferrite core is carried out using known procedures as well as recommendations given in [6].

3.2. In the case of PT with completely open rod-type ferrite core the calculation of inductance of its primary winding is started from selection of rod-type ferrite core with low initial magnetic permeability $\mu_{\text {init }}(\leq 200)$ and relationship of length of ferrite core to its diameter $l_{\mathrm{f}} / d_{\mathrm{f}}$ equal 10-14. Ferrite cores of Patron Passive Elektronic Company of $\mathrm{YC} 10 \times 100-\mathrm{YC} 10 \times 140$ or $\mathrm{YC} 13 \times 100-\mathrm{YC} 13 \times 140$ types from R2KW material [23] can be used, for example, as such a core. Then, values of effective $\mu_{\mathrm{e}}$ or relative $\mu_{\text {rel }}$ magnetic permeability of the core are determined theoretically, according to (10), or experimentally, using given in literature, in particular in [12], data and results of investigation performed earlier. After that inductance $L_{W 1}$ of PT primary winding is calculated by relationship $L_{W 1}=$ $=L_{C 1} / \mu_{\mathrm{e}}$ or $L_{W 1}=L_{C 1} / \mu_{\mathrm{rel}}$, where $L_{C 1}$ is the inductance of PT primary winding without core, determined using known procedures [12, 17, 24] for single layer coil with internal diameter equal ferrite rod diameter. Recommended values of $W 1$ turns of PT primary winding make $10-12$ and inductance $L_{W 1}$ of this winding is $6-8 \mu \mathrm{H}$ based on experience of designing, development and application of AESA. This predetermines the necessity of introduction of additional inductance $L_{\text {add }}=2-3 \mu \mathrm{H}$ in GVP circuit. PT secondary winding also should be single layer and have edgewise winding. At that internal diameter of winding is taken equal $d_{\mathrm{f}}$ and winding step $\tau_{\text {wind }}$ is such as to provide dense laying of turns of primary winding between neighboring turns of secondary winding on ferrite core. Length of winding $l_{\text {wind }}$ depending on number of turns $W 2$ of secondary winding is calculated by expression $1_{\text {wind }}=\tau_{\text {wind }}(W 2-1)$. In part number of turns $W 2$ of PT secondary winding is determined taking into account recommendations of work [6] and following from relationship

$$
W 2=W 1 \frac{U_{\text {out }}}{U_{C 0}\left(1-L_{\text {add }} / L_{W 1}\right.},
$$

where $U_{\text {out }}$ is the amplitude value of open-circuit voltage of PT secondary winding. At that considerations should be given to limitations of achievable values of $W 2$ and $U_{\text {out }}$, promoted by finite values of maximum possible length $l_{\mathrm{f}}$ of available industrially manufactured ferrite cores, that in turn, limits area of application of AESA with such PT.

Additional inductance $L_{\text {add }}$ is recommend to be performed by connecting stranded cable in form of cylindrical single-layer coil without core, outer diameter of which makes $12-20 \mathrm{~mm}$. Calculation of number of turns of such a coil by set $L_{\text {add }}$ value is carried out using known procedures, given, for example, in [12, 17].

3.3. Calculation of PT with IPC is started from selection of core material. Materials of -26 , -40 or -53 [13-17] grades are recommended by combination of electromagnetic parameters and cost indices. The main parameters of magnetization curves for these materials are given in $\mathrm{Ta}-$ ble 2 and dependencies $\mu_{\mathrm{e}}$ on $H, \mu_{\mathrm{e}} / \mu_{\text {init }}$ on $H$, and $\mu_{\mathrm{e}} / \mu_{\text {init }}$ on $B-$ in Figure 4 .

Further number of turns $W 1$ of PT primary winding, recommended values of which makes $2-4$, are set and, using recommendations of work [6] the number of turns $W 2$ of secondary winding is determined as well as type and insulation of copper strip used as conductor of this winding. Recommended width of copper strip makes 40$45 \mathrm{~mm}$, thickness is $0.2-1 \mathrm{~mm}$ and arc current density is not more than $5 \mathrm{~A} / \mathrm{mm}^{2}$. Than value of necessary area $A_{W}$ of core port is found using well-known procedures. For this total port area, taken by PT winding conductors at its cooling due to natural convection, is calculated and port height is taken equal $50-55 \mathrm{~mm}$. After that, $\mu_{\mathrm{e}}$ value is determined considering allowable values $H_{\text {max }}=4500-6000 \mathrm{~A} / \mathrm{m}$ and $B_{\max }=0.5-0.9 \mathrm{~T}$ and using diagram given in Figure 4. It usually makes 85-120 under taken assumptions depending on selected material. $I_{C m}$ value is calculated using expression (8) by setting $U_{C 0}$ from 600 to $700 \mathrm{~V}, C_{\mathrm{c}}$ from 0.5 to $4.0 \mu \mathrm{F}$ and $L_{\mathrm{c}} \geq 10 \mu \mathrm{H}$. $H_{\max }$ values is checked by expression (9) and $B_{\max }$ value by relationship $B=\mu_{0} \mu_{\mathrm{e}} H$ taking into account received values of $I_{C m}$ and $\mu_{\mathrm{e}}$, selected number of turns $W 1$ and recommended values of length of medial line of magnetic induction in core $l_{\mathrm{c}}=$ $=0.18-0.22 \mathrm{~m}$. Further, minimum necessary value of effective section area $A_{E}$ of PT core is calculated using expression (14) in form of

$$
A_{E}=\frac{L_{\mathrm{c}} l_{\mathrm{c}}}{W_{1}^{2} \mu_{0} \mu_{\mathrm{e}}} .
$$

$A_{E}$ value is used for determination of $n_{\mathrm{c}}$ constituents number of PT core of single cores applying relationship $n_{\mathrm{c}}=A_{E} / A_{E C}$ and at that rounding $n_{\mathrm{c}}$ value upwards natural number. Recommended values of effective section area $A_{E C}$ of single core are (9.4-9.8) $10^{-4} \mathrm{~m}^{2}$ and core rod size make $25 \times 38,28 \times 35,30 \times 32 \mathrm{~mm}$. PT core 
Table 2. Main parameters of IPC magnetization curves

\begin{tabular}{|c|c|c|c|}
\hline \multirow{3}{*}{ Parameter } & \multicolumn{3}{|c|}{ Value } \\
\hline & \multicolumn{3}{|c|}{ Material } \\
\hline & -26 & -40 & -52 \\
\hline $\begin{array}{l}\text { Largest allowable value of induc- } \\
\text { tance } B_{\max }, \mathrm{T}\end{array}$ & \multicolumn{2}{|c|}{1.38} & 1.40 \\
\hline Initial magnetic permeability $\mu_{\text {init }}$ & 75 & 60 & 75 \\
\hline Residual induction $B_{\mathrm{r}}, \mathrm{T}$ & 0.175 & 0.1 & 0.145 \\
\hline Coercitive force $H_{\mathrm{c}}, \mathrm{A} / \mathrm{m}$ & 40 & 37 & 510 \\
\hline \multicolumn{4}{|c|}{$\begin{array}{l}\text { Note. Saturation induction for given materials } B_{\text {sat }}=1.5 \mathrm{~T} \text { and the } \\
\text { largest allowable value of magnetic field intensity } H_{\max }= \\
=20,000 \mathrm{~A} / \mathrm{m} \text {. }\end{array}$} \\
\hline
\end{tabular}

structure and its main dimensions are determined following from $A_{W}, A_{E}$ and $A_{E C}$ values found in course of calculation taking into account its Eor $\Pi$-shaped form, after what $l_{\mathrm{c}}, H_{\max }, B_{\max }, L_{\mathrm{c}}$ and $I_{C m}$ are specified. As for the rest, similar to PT with ferrite core, known procedures as well as recommendations given in [6] are used for calculation of PT with IPC.

4. $\tau_{\text {trans }}$ duration of transition process in GVP (i.e. duration of pulses on PT windings) are determined using selected and received values $C_{\mathrm{c}}$ and $L_{\mathrm{c}}$ and expression (6) or (7), and $\tau_{\text {trans }}$ value is applied for finding necessary value of $\tau_{\text {contr }}$ duration of control pulses being fed in the control circuit of GVP switching key, which should fulfill the condition

$$
\tau_{\text {contr }} \geq 1.15 \tau_{\text {trans. }}
$$

5. Considering low frequency of passing of AESA output pulses (not more than $200 \mathrm{~Hz}$ ), their high relative pulse duration and significant levels of amplitudes of transition current and voltage in GVP circuit, domestic low-frequency thyristors of unified series T122-25 or T131-40 at $U_{C 0 \max } \leq 700 \mathrm{~V}$, and $\mathrm{T} 132-35$ or $\mathrm{T} 141-40$ at $U_{C 0 \text { max }}>700 \mathrm{~V}$, or their foreign analogs are more favorable in selection of element base of GVP switching key. Class of thyristors on repeating pulse back voltage $U_{\text {back.p }}$ are selected from the condition $U_{\text {back.p }} \geq 1.6 U_{C 0 \max }$, and maximum average $I_{\mathrm{OS} \text {.av }}$ and acting $I_{\mathrm{OS} \text {. a }}$ values of current, passing through thyristor in its open state, are determined using procedure of work [6], by expressions

$$
I_{\text {OS.av }}=0.5 I_{C m} \frac{\tau_{\text {trans }}}{T_{\mathrm{p}}}, \quad I_{\text {OS.a }}=\frac{I_{C m}}{\sqrt{\tau_{\text {trans }} / T_{\mathrm{p}}}},
$$

where $T_{\mathrm{p}}$ is the period of frequency of passing of AESA output pulses (turn-on frequency of GVP switching key).

6. Back diode of key (see Figure 1,c) in designing GVP switching key with two-way conductance is selected from the condition
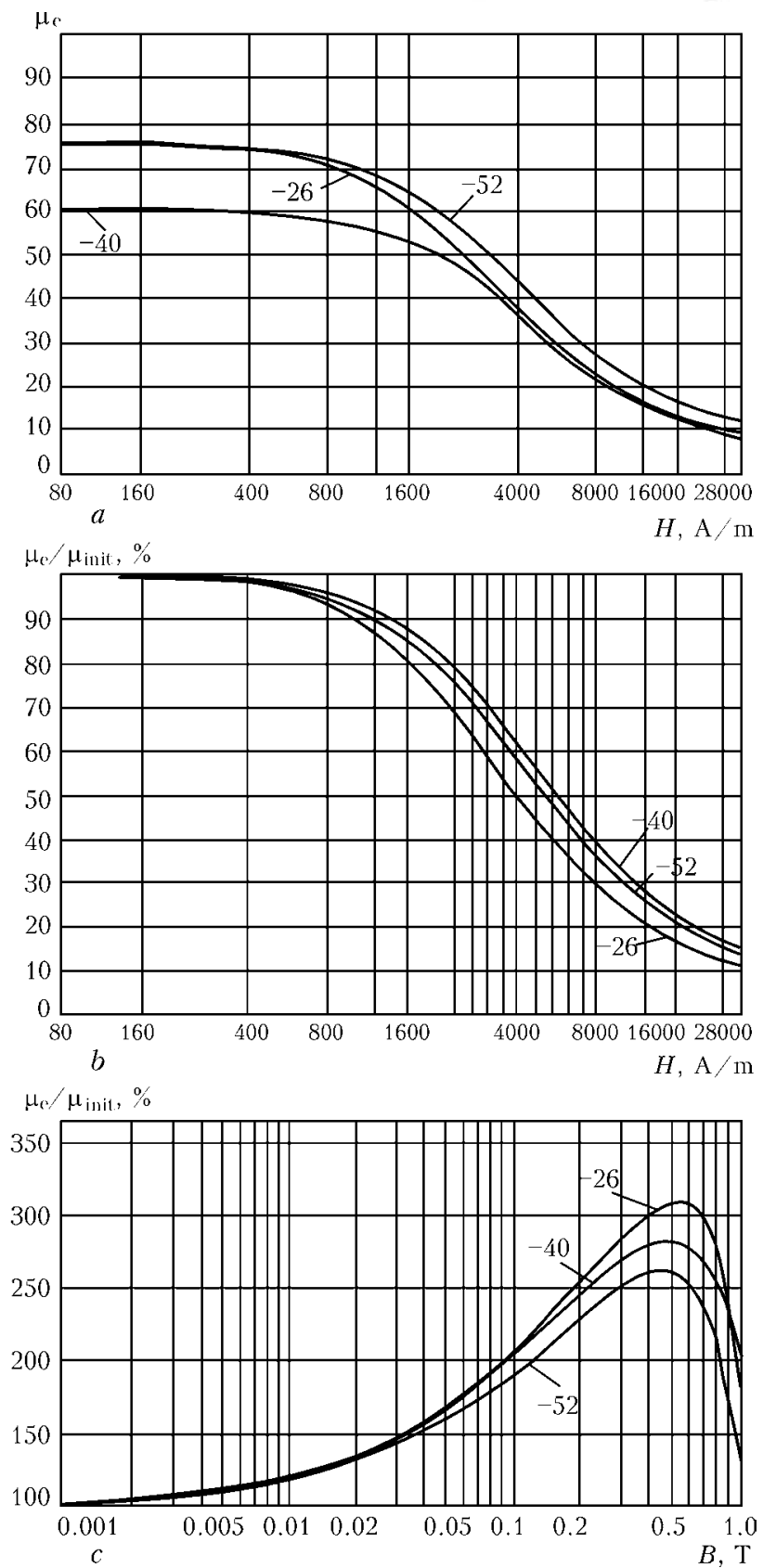

Figure 4. Diagrams of $\mu_{\mathrm{e}}(a)$ and $\mu_{\text {init }}(b)$ dependence on $H$, and $\mu_{\mathrm{e}} / \mu_{\text {init }}$ dependence on $B(c)$ in PT with IPC

$U_{R} \geq 1.6 U_{C 0 \max }, \quad I_{F(A V)} \geq 0.8 I_{\text {OS.av }}, \quad I_{F S M} \geq I_{C m}$,

where $U_{R}$ is the maximum allowable back voltage of diode; $I_{F(A V)}$ is the maximum allowable value of direct current passing through diode; $I_{F S M}$ is the maximum allowable value of repeating direct pulse current passing through diode. High-voltage fast diodes with small values of the largest forward drop $\left(U_{F} \leq 1.5 \mathrm{~V}\right)$ and reverse recovery time $\left(t_{r r} \leq 150 \mathrm{~ns}\right)$ are the most favorable. For example, fast rectifying diode VS-40EPF1 of Vishay Semiconductor company [25] meets these requirements.

Peculiarities of analysis and calculation of AESA with CD built based on application of 
resonant pumping method. CD built on application of method of resonant pumping are widely used in medical equipment, measuring and radar engineering, in laser devices, in electrotechnological units, devices of automobile electronics and many other technical fields. Such CDs have found application in boosters of units for arc and plasma welding $[1,26]$. Principle of operation of such CD is based on the fact that GVP capacitive storage is the element of resonant $L C$-circuit, including series current-limiting charge choke, pickoff diode and capacitor of GVP forming circuit being recharged at each turn-on of switching key of this circuit. At that, charge voltage $U_{C 0}$ of GVP capacitive storage in steady-state mode can significantly exceed CD input voltage. In theory, process of increase of $U_{C 0}$ value can go into infinity, however, practically achievable value of voltage of $U_{C 0}$ charge exceeds value of $C D$ input voltage not more than in 3-5 times [26] due to finite values of Qfactor in real resonant circuits of charge and discharge of GVP capacitive storage and inevitable ohmic losses in their elements.

Basic variant of AESA with CD scheme, built based on application of method of resonant pumping, are given in Figure 5, $a$. Such AESA (as AESA with CD based on key scheme with dosing reactor) is characterized by wide range of possible levels of input voltage $U_{\text {in }}$ (in most cases making from 100 to $350 \mathrm{~V}$ ) as well as invariance of such CD by nature of AESA supply voltage. At that, normal functioning of CD in AESA supply with alternating current voltage does not depend on its frequency. If only direct current voltage is supposed for AESA supply, than presence in scheme, given in Figure 5, $a$, of rectifier $U Z 1$ and buffer capacitor $C 1$ is not strictly necessary.

Charging of capacitive storage (capacitor $C 2$ ) of GVP forming circuit in AESA with CD (see Figure $5, a$ ) is carried out by special mode called resonant. Feeding of supply voltage $U_{\text {sup }}$ to AESA promotes gradual buildup by sine law of charge current $i_{C}$ of capacitive storage (capacitor $C 2$ ), and $u_{C}$ charge voltage of this capacitor by exponential law. At the time, when $u_{C}=U_{\text {in }}$ is provided, charge current $i_{C}$ will achieve its amplitude value $I_{m}$, after what $i_{C}$ current starts drop also by sine law, that promotes emf of self-induction on $L 1$ choke, acting in accordance with $U_{\text {in. }}$. As a result of this, charging of capacitor $C 2$ will continue up to the moment when voltage $u_{C}$ on it reaches virtually double value $U_{\text {in }}$, and, because of presence of $V D 1$ diode, such a level of $u_{C}$ voltage of $C 2$ capacitor charge will remain up to the moment of turn-on of GVP switching key (thyristor VS1). Turn-on of thyristor $V S 1$ provides for beginning of process of capacitor $C 2$ re-charging in GVP forming circuit via PT primary winding (transformer $T V 1$ ). Duration of process of $C 2$ capacitor re-charging is determined by semi-period of own oscillations of GVP forming circuit and does not depend on frequency of turn-on of its switching key (thyristor VS1). Recharging current (current in GVP circuit) will reach its maximum value $I_{C m}$ in the moment when key voltage on it reduces to zero in process of capacitor $C 2$ re-charging. After that, re-charging current drop by sine law will start, that promotes appearance of emf of self-induction on inductance of PT primary winding (transformer $T V 1$ ), providing passing of current in GVP circuit in the interval from $\pi / 2$ to $\pi$ of semi-period of own oscillations. Voltage of capacitor $C 2$ at the end of re-charging process will be close in modulus to value of voltage before re-charging beginning and negative to the latter by polarity. At that re-charging current drops virtually to zero, due to what thyritor VS1 will turn-off. From this moment second cycle of charge of capacitive storage (capacitor C2) of GVP forming circuit is started, however, in this case voltage and charge current will be determined by sum of voltage $U_{\text {in }}$ and acting in accordance with it steady-state recharging voltage of capacitor $C 2$. This will promote increase of voltage on $C 2$ capacitor up to the value close, at least, to four-fold value of $U_{\text {in }}$ to the moment of ending of charging cycle.

Further all processes in CD, scheme of which is given in Figure 5, $a$, are repeated similar to described above. Voltage in the third cycle of charge can only insignificantly exceed charge voltage in the second cycle due to finite values of Q-factor of charge and discharge circuits of GVP capacitive storage. It was experimentally stated that charge voltage of GVP capacitive storage (capacitor C2) can be considered as steady-state one starting from the moment of ending of third charge cycle.

Equivalent circuit of CD, built based on application of resonant pumping mode, is given in Figure 5, b. In this circuit $R=R_{L 1}+R_{\mathrm{CLR}}+$ $+E S R_{C 1}+E S R_{C 2}+r_{\mathrm{dyn}}+R_{I}$ is the active resistance of charge circuit. Here, $R_{L 1}$ is the $L 1$ choke active resistance; $R_{\mathrm{CLR}}$ is the active resistance of current-limiting resistor $R 1 ; E S R_{C 1}$ and $E S R_{C 2}$ are the equivalent active series resistances of $C 1$ and $C 2$ capacitors, respectively; $r_{\text {dyn }}$ is the dynamic resistance of $V D 1$ diode; $R_{I}$ is the active resistance of $T V 1$ transformer primary winding); $L=L_{\text {choke }}+L_{I}\left(L_{\text {choke }}-\right.$ inductance of choke $L 1 ; L_{I}$ is the inductance of $T V 1$ transformer primary winding); $C$ is the capacity of GVP capacitive storage (capacitor $C 2$ ). Since $R_{C L R}>R_{L 1}+$ 
$+E S R_{C 1}+E S R_{C 2}+r_{\text {dyn }}+R_{I}$, and $L_{\text {choke }}>L_{I}$, than $R=R_{\mathrm{CLR}}$ and $L=L_{\text {choke }}$ can be assumed with sufficient level of accuracy.

It can be seen from CD equivalent circuit (see Figure $5, b$ ) that charge circuit of GVP capacitive storage (capacitor $C 2$ ) represents itself series $L C R$-circuit. Process of charging of capacitive storage of such circuit for $i_{C}$ current and $u_{C}$ voltage is described by known differential equations $[8,9]$. At that, variant with zero initial condition (i.e. in the moment of cycle beginning $i_{C}=0$, $\left.u_{C}=0\right)$ is considered for the first charge cycle, and that for the second and further cycles is the variant with non-zero initial conditions, at which at the moment of beginning of each cycle $i_{C}=0$ and $u_{C}=-U_{C 0}$, where $U_{C 0}$ is the steady-state charge voltage of GVP capacitive storage. According to $[8,9]$ and considering peculiarities of circuits, given in Figure 5, solutions of these equations for the first cycle of charge of GVP capacitive storage can be represented in form of

$$
\begin{gathered}
i_{C}=\frac{U_{\text {in }}}{\omega^{\prime} L} e^{-\delta T} \sin \omega^{\prime} t ; \\
u_{C}=U_{\text {in }}+U_{\text {in }} \frac{\omega_{0}}{\omega^{\prime}} e^{-\delta t} \cos \left(\omega^{\prime} t-\gamma\right),
\end{gathered}
$$

where $\delta=R / 2 L ; \omega_{0}=1 \sqrt{L C} ; \omega^{\prime}=\sqrt{\omega_{0}^{2}-\delta^{2}}$; $\operatorname{tg} \gamma=\delta / \omega^{\prime}$, and for the second and further charge cycles in form of

$$
\begin{gathered}
i_{C}=-\frac{U_{\text {in }}+(N-1) U_{C 0}}{\omega^{\prime} L} e^{-\delta t} \sin \omega t ; \\
u_{C}=\left(U_{\text {in }}+U_{C 0}\right) e^{-\delta t} \cos \left(\omega^{\prime} t-\gamma\right),
\end{gathered}
$$

where $N=-U_{C 0} / U_{\text {in }}$ is the coefficient of voltage increment on GVP capacitive storage to the level preceding beginning of charge cycle. As shown in [27], charge voltage $U_{C 0}$ of GVP capacitive storage (capacitor $C 2$ ) in steady-state mode can be determined by formula

$$
U_{C 0}=U_{\text {in }} \text { cth }\left(\frac{\pi}{2 \sqrt{\frac{4 L}{R^{2} C}-1}}\right),
$$

and amplitude value $I_{m}$ of charge current $i_{C}$ by expression

$$
I_{m}=U_{\text {in }}\left(1+\operatorname{cth} \frac{\pi}{2 \gamma}\right) \sqrt{\frac{C}{L}} e^{\frac{-1}{\gamma} \operatorname{arctg} \gamma},
$$

where $\gamma=\sqrt{\frac{4 L}{R^{2} C}-1}$.

Relationships (19) and (20) are true under condition $C 1>C 2$, that is virtually always fulfilled in AESA with CD built based on resonant pumping method. It also follows from expressions (19) and (20) that resistor $R 1$ is not only cur-

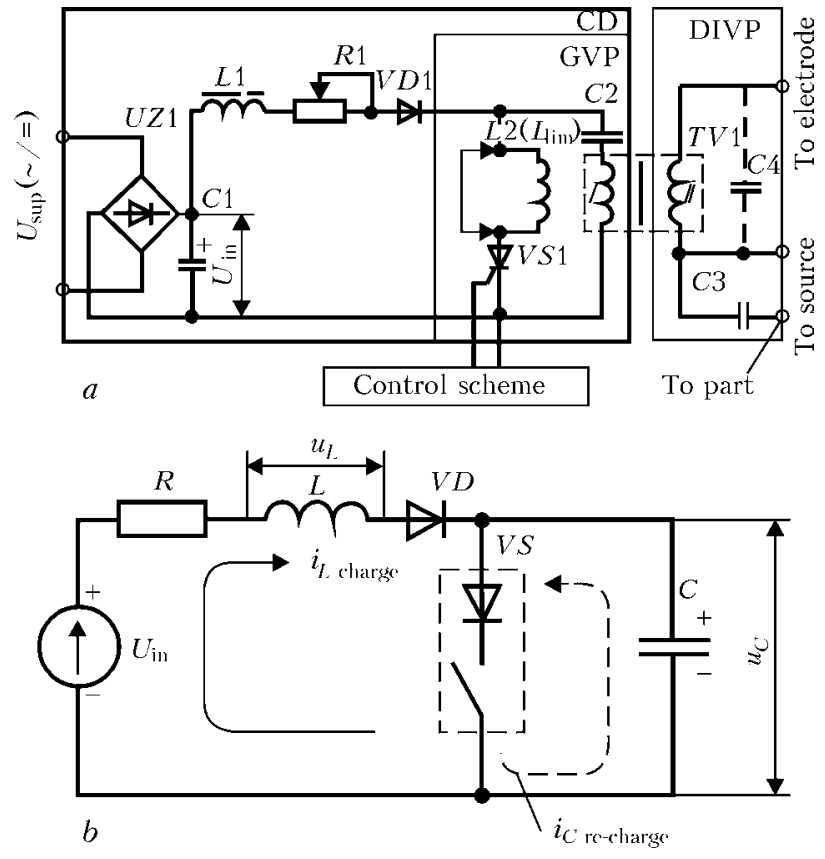

Figure 5. Electric schematic diagram of basic variant of AESA with CD based on application of method of resonant pumping $(a)$, and scheme of equivalent circuits of charge and re-charge of GVP capacitive storage of basic variant of AESA with CD based on application of method of resonant pumping (b)

rent-limiting element, but element allowing limiting steady-state charge voltage of GVP capacitive storage at set level. Duration $\tau_{\text {charge }}$ of pulses of charge current $i_{C}$ is determined by semi-period of frequency $\omega^{\prime}$ by formula

$$
\tau_{\text {charge }}=\frac{\pi}{\sqrt{\frac{1}{L C}-\frac{R^{2}}{4 L^{2}}} .}
$$

Diagrams of $i_{C}$ current, $u_{C}$ and $u_{L}$ voltages, representing nature of transition processes in CD and GVP in AESA, built using resistant pumping method, are given in Figure 6.

Calculation of parameters and selection of components of charge circuit of CD built based on application of resonant pumping method can be performed in the following way.

1. Calculation and nominal values of GVP capacitive storage and type of applied capacitors are determined based on recommendations given in $[6,7]$ and in present work. At that, it is proceeded from the fact that steady-state charge voltage $U_{C 0}$ of GVP capacitive storage makes $550 \pm 50 \mathrm{~V}$ in the majority of cases.

2. Expression (22) is used for determination of amplitude value $I_{m}$ of charge current $i_{C}$. Recommended $I_{m}$ values make 0.9 to $1.5 \mathrm{~A}$ according to results of carried investigations and experimental data, depending on set values of $C, U_{\text {in }}$ or $U_{C 0}$, at that lower $C, U_{\text {in }}$ or $U_{C 0}$ values correspond to lower $I_{m}$ values. 


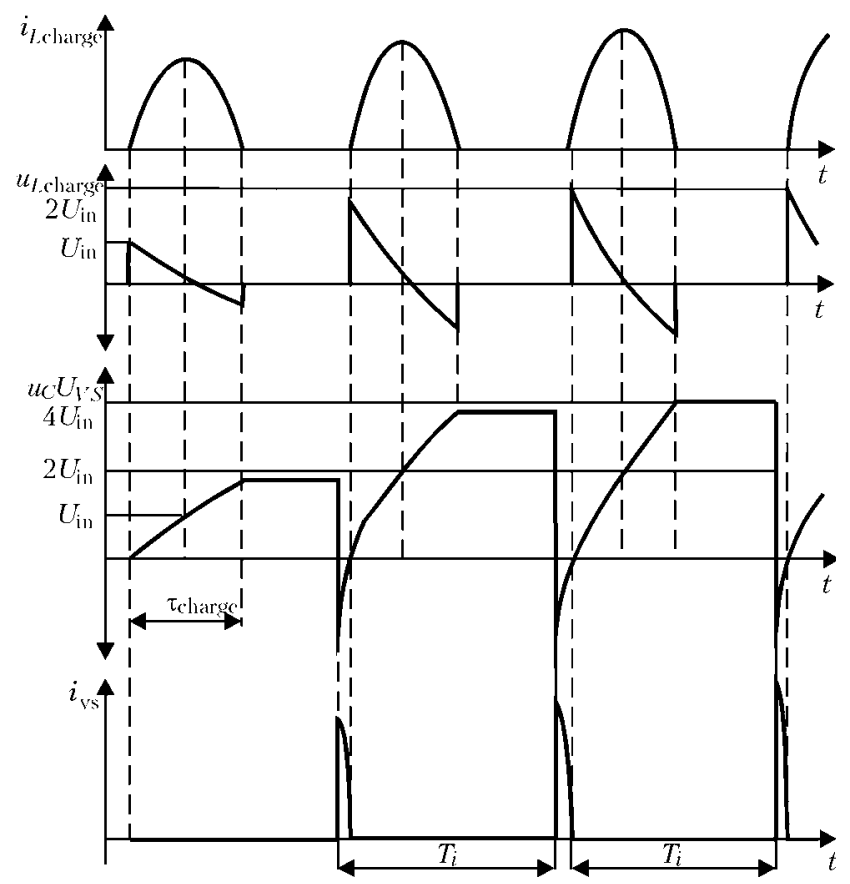

Figure 6. Diagrams of currents and voltages in CD circuits and GVP of AESA with CD based on application of method of resonant pumping

3. Assuming that inductance of charging choke $L 1$ (see Figure 5, $a$ ) is linear and does not depend on current $i_{C}$ passing though choke, and using calculated or selected values of $I_{m}$ and $C$ as well as set values of $U_{\text {in }}$ and energy $W_{C}$ accumulated in GVP capacitive storage, $L$ value is determined by expression

$$
L \geq \frac{C U_{C 0}^{2}}{I_{m}} .
$$

Recommended values of inductance of charging choke $L 1$ make 65 to $200 \mathrm{mH}$, coming from range of $I_{m}$ recommended values, expression (24) and experience of designing of AESA with CD based on resonant pumping method. The most reasonable choke design is a shell-type structure. It can be realized based on cores from standard E-shaped plates or strip magnetic conductors from thin coldrolled anisotropic electrical steel of 3411-3414 grades. At that, length of total diamagnetic gap in the core of charging choke should make 0.9$1.5 \mathrm{~mm}$. Electromagnetic and design calculations of this choke can be carried out by known procedures, given, for example, in [12,17].

4. The following things should be considered in determination of resistance $R$. Namely, first of all, $R \approx R 1$ (see Figure $5, a$ ), and secondly that application of initial (virtually linear) section of exponent is desirable to be used in charging of GVP capacitive storage, and $L / R \leq \tau_{\text {charge }}$ condition should be fulfilled for this. Taking into account results of calculations and experimental data, the recommended values of resistor resis- tance $R 1$ make from 47 to $120 \mathrm{Ohm}$, moreover the more $U_{\text {in }}$ value is, the more these values are. The largest dissipation value $P_{R 1 \text { max }}$, emitted in resistor $R 1$, can be determined by known expression $P_{R 1 \max }=I_{\mathrm{act}} R 1$, where $I_{\mathrm{act}}=$ $0.707 I_{m} / \sqrt{T / \tau_{\text {charge }}}$ is the maximum acting current value $i_{C}$ passing via resistor $R 1 ; T$ is the period of frequency of pulses of charge current (frequencies $f_{\mathrm{p}}$ of turn-on of GVP switching key). $P_{R 1 \max }=26.66 \mathrm{~W}$ at $I_{m}=1.5 \mathrm{~A}, R 1=$ $=120 \mathrm{Ohm}, \tau_{\text {charge }}=1 \mathrm{~ms}$ and $f_{\mathrm{p}}=200 \mathrm{~Hz}$. At the same values of $I_{m}, R 1, \tau_{\text {charge }}$ and $f_{\mathrm{p}}=$ $=100 \mathrm{~Hz}, P_{R 1 \max }=13.44 \mathrm{~W}$, and $P_{R 1 \max }=$ $=6.92 \mathrm{~W}$ at $f_{\mathrm{i}}=50 \mathrm{~Hz}$. It follows from this that recommended area of frequencies $f_{\mathrm{p}}$ is limited by values from 80 to $120 \mathrm{~Hz}$, and in the case of AESA application only for initial excitation of direct current arc the nominal power of resistor $R 1$ can be significantly reduced in comparison with calculation one and make 4-6 W. Power resistors of $\mathrm{C} 5-\mathrm{C} 35$ or SPS, SQZ, SQHG series [28] are reasonable to be used as $R 1$ resistor.

5. The main parameters for selection of $V D 1$ diode (see Figure 5, a) are maximum allowable value of average direct current $I_{F}$ and back voltage $U_{R}$ as well as maximum values of direct drop of voltage $U_{F}$ and reverse recovery time $t_{r r}$. At that diode parameters should fulfill the conditions

$$
U_{R \max } \geq 1.2 N U_{\mathrm{in}}, \quad I_{F \max } \geq 1.2 I_{\mathrm{av} . \max }
$$

where $I_{\mathrm{av} \text { max }}$ is the maximum average value of charge current of GVP capacitive storage, which can be determined using expression

$$
I_{\text {av. max }}=0.637 I_{m} \tau_{\text {charge }} / T .
$$

Calculation of parameters and selection of GVP components of AESA, built based on application of resonant pumping method, do not differ from given in present work for basic variant of GVP with switching key of unidirectional conduction.

If AESA (including one containing CD, built based on resonant pumping) is designed not only for initial excitation, but for stabilizing of process of burning of arc with low stability, than efficiency of AESA work at unidirectional conduction of GVP switching key can be reached with the help of additional high-frequency circuit of impact excitation, formed by inductance of PT secondary winding and parallel to this winding capacity of high voltage capacitor (for example, KVI-3 series), designated as $C_{\mathrm{C} 2}$ in Figure 1, $a$, or $C 4$ in Figure 5, $a$. Recommended values of nominal capacity of such capacitor is from 1000 to $3300 \mathrm{pF}$.

It should be noted that currently AESA with $\mathrm{CD}$ based on application of resonant pumping method find more and more distribution and is 
used as independent lowering units (for example, exciter-stabilizers VSD-01 U3) [1] for equipping arc welding stations as well as for functional blocks, imbedded in welding equipment, mainly in welding power supply sources (for example, power supply ITs 616 U13.1 and ITs 617 U3.1 for TIG welding) [29].

\section{Conclusions}

1. GVP design with step-up PT with completely open rod-type ferrite core is the most reasonable for AESA, pulse energy of which is not more than $0.1 \mathrm{~J}$ and which are designed only for excitation of arc in TIG welding. AESA, energy of generated pulses of which makes from 0.10 to $0.25 \mathrm{~J}$, can apply PT with ferrite core of $\Pi$ - or E-shaped form with total gap to $1 \mathrm{~mm}$. Using of iron powder cores in PT is reasonable virtually in all possible range of energies of AESA generated pulses, including at $1 \mathrm{~J}$ level and more.

2. AESA with CD, based on application of method of resonant pumping, the same as $\mathrm{CD}$, based on key scheme with dosing reactor, do not depend on nature of AESA supply voltage and capable to function in supply with direct as well as alternating current of harmonic or rectangular or close to them forms of frequency from tens of hertz (including $50 \mathrm{~Hz}$ ) to tens of kilohertz. The first and the second AESA virtually have no limitations on technologically grounded levels of energy of generated pulses, which can make from 0.01 to $1 \mathrm{~J}$ and more. Both AESA have wide area of application in arc and plasma welding and can be used in traditional power supplies as well as in invertor-type power supplies. Such AESA can be efficiently applied in manual methods of arc and plasma welding and in automatic welding machines, in particular, in single- and multi-station systems for automatic orbital TIG welding of pipeline joints. The advantage of AESA with CD, based on application of resonant pumping method, is the fact that only one controlled semi-conductor key and significantly simpler control scheme are necessary for its construction. The advantage of AESA, based on key scheme with dosing reactor, is wider range of possible values of supply voltage.

3 . Engineering procedure for calculation of basic variant of GVP as well as CD, based on application of resonant pumping method, is developed as a result of analysis considering experience of development, designing, manufacture and operation of AESA. Recommendations on selection of their element base are worked out that can be useful not only for AESA development, but for other similar devices designed for application in different branches of science and technology.
1. (1986) Equipment for arc welding: Refer. Book. Ed. by V.V. Smirnov. Leningrad: Energoatomizdat.

2. Temkin, B.Ya. (1981) Theory and calculation of welding arc exciters: Syn. of Thesis for Cand. of Techn. Sci. Degree. Leningrad.

3. Dudko, D.A., Fedotenkov, V.G., Makhlin, N.M. (1980) Thyristor pulse generators of UPD-1 type. Avtomatich. Svarka, 6, 61-63.

4. Paton, B.E., Zaruba, I.I., Dymenko, V.V. et al. (2007) Welding power sources with pulse stabilizing of arcing. Kyiv: Ekotekhnologiva.

5. Fedotenkov, V.G., Makhlin, N.M., Temkin, B.Ya. (1981) Pulse generator for excitation and stabilizing of alternatiing current arc. Svarochn. Proizvodstvo, 8, 33-34.

6. Makhlin, N.M., Korotynsky, A.E. (2014) Analysis and procedure of calculation of series connection electronic devices for contactless arc excitation. The $\mathrm{Pa}$ ton Welding J., 1, 30-40.

7. Makhlin, N.M., Korotynsky, A.E. (2015) Asynchronous exciters and stabilizers of welding arc. Analysis and design procedure. Pt 1. Ibid., 3/4, 24-35.

8. Atabekov, G.I. (2009) Theoretical principles of electrical engineering. Linear electric circuits: Manual. 7 th ed. St.-Petersburg: Lan.

9. (2008) Theoretical principles of electrical engineering: Handbook on theory of electrical circuits. Ed. by Yu.A. Bychkov et al. St.-Petersburg: Piter.

10. Leskov, G.I. (1970) Electric welding arc. Moscow: Mashinostroenie.

11. Zamyatin, V.Ya., Kondratiev, B.V., Petukhov, V.M. (1988) Power semi-conductor devices. Thyristors: Handbook. Moscow: Radio i Svyaz.

12. Baev, E.F., Fomenko, L.A., Tsymbalyuk, V.S. (1976) Inductive elements with ferromagnetic cores. Moscow: Sov. Radio.

13. http://www.coretech.com.uahttp://www.microme tals.com

14. Cox, J. (2006) Iron power cores in pulse power sources. Pt 1. Sovrem. Elektronika, 1, 58-65.

15. Cox, J. (2006) Iron power cores in pulse power sources. Pt 2. Ibid., 2, 66-69.

16. Cox, J. (2006) Iron power cores in pulse power sources. Pt 3. Ibid., 3, 70-75.

17. Kalantarov, P.L., Tsejtlin, L.A. (1986) Calculation of inductances: Refer. Book. Leningrad: Energoatomizdat.

18. http: / / www.epcos.com

19. http://www.icel.it

20. Handbook on electrotechnical materials. Ed. by Yu.V. Koritsky et al. 3rd ed. Leningrad: Energoatomizdat.

21. Belorussov, N.I., Saakyan, A.E., Yakovleva, A.I. (1987) Electric cables, wires, cords: Handbook. Ed. by N.I. Belorussov. 5th ed. Moscow: Energoatomizdat.

22. Sidorov, I.N., Khristinin, A.A., Skornyakov, S.V. (1989) Small-sized magnetic conductors and cores: Handbook. Moscow: Radio i Svyaz.

23. http: / / www.patron-components.com

24. Volgov, V.A. (1977) Parts and units of electronic devices. Moscow: Energiya.

25. http://www.vishay.com

26. Belinsky, S.M., Kagansky, B.A., Temkin, B.Ya. (1975) Equipment for nonconsumable-electrode inertgas welding. Leningrad: Energiya.

27. Pentegov, I.V. (1982) Bases of theory of charging circuits of capacitor storage. Kiev: Naukova Dumka.

28. http://www.dart.ru/cataloguenewresistors / ty / h tml/cement.shtml

29. Makhlin, N.M., Korotynsky, A.E., Bogdanovsky, V.A. et al. (2011) Single- and multioperator systems for automatic welding of position butt joints of nuclear power plant piping. The Paton Welding J., 11, 28-36. 


\title{
CONVERTER OF FREQUENCY AND NUMBER OF PHASES FOR FLASH-BUTT WELDING OF RAILS
}

\author{
S.I. KUCHUK-YATSENKO, P.M. RUDENKO, V.S. GAVRISH, A.V. DIDKOVSKY and E.V. ANTIPIN \\ E.O. Paton Electric Welding Institute, NASU \\ 11 Bozhenko Str., 03680, Kiev, Ukraine. E-mail: office@paton.kiev.ua
}

\begin{abstract}
The aim of the work is experimental verification of possibility of using the thyristor frequency converter with direct connection for $37.5 \mathrm{~Hz}$ for power supply of two-phase flash-butt welding machine from threephase mains for its uniform loading. For experimental verification and tests the converter was designed according to the circuit with two three-phase full-wave controlled rectifiers connected in an antiparallel mode. The industrial tests were conducted in welding of steel R65 rails using continuous and pulsating flashing during two years at the rail welding enterprise. It was found that the quality of welded joints met the technical specifications. The analysis of plots of changes of effective values of phase currents showed that difference of these values did not exceed $\pm 2 \%$. At the same time the phase currents were $20 \%$ lower than the current at the load. Thus, the pilot tests of the frequency converter for $37.5 \mathrm{~Hz}$ showed its possibility and rationality for application for flash-butt welding, in particular, of railroad rails due to uniform loading of three-phase mains. At that the efficiency of using converter can be significantly increased by applying it in the flash-butt welding machine power transformer, designed for $37.5 \mathrm{~Hz} .7$ Ref., 3 Figures.
\end{abstract}

Keywords: flash-butt welding of rails, thyristor frequency converter, uniform loading of three-phase mains

For flash-butt welding of the railroad rails the stationary and suspended welding machines are used, which basically have two different circuits of electric power [1, 2]: from single-phase (twophase) alternating current mains of $50 \mathrm{~Hz}$ $(60 \mathrm{~Hz})$ frequency, and from three-phase mains and source of rectified voltage.

The single-phase (two-phase) machines have the most simple and the cheapest circuit of power supply. The machines with a rectifier in the secondary circuit are much more complicated and expensive both in their manufacture as well as in operation [3]. They have a lower efficiency factor due to significant losses at the rectifier in the secondary circuit, but due to power consumption from three phases they surpass the machines of alternating current in terms of providing quality of the mains being used (GOST 13109-97). To provide this value, which is important for nowadays, in the machines of alternating current the converter of frequency and a number of phases with direct connection (hereinafter - converter) may be used.

In works $[1,2]$ it was shown that such converters of low frequency (about several hertz) found application in resistance welding and were at the first time designed by «Sciaky». However, this converter should operate with welding transformer, which has many times increased weight and dimensions as compared to the machines of industrial frequency, and cannot be used for power supply of the existing single-phase resistance machines for $50 \mathrm{~Hz}$.

In work [1] it is shown that the converter with a direct connection can be applied for power supply of the single-phase resistance welding machines, if the frequency of voltage at its output will be increased to $30 \mathrm{~Hz}$ and the value of voltage decreased [2]. It is known that the converter of frequency and a number of phases with direct connection can generate voltage only of certain frequencies. It is shown in work [4] that except of $30 \mathrm{~Hz}$ frequency for power supply of the resistance welding machines the converter with output voltage of $37.5 \mathrm{~Hz}$ may be used. The increase of frequency of output voltage improves the conditions of its use for welding transformers of industrial frequency, in particular, the requirement of reducing the value of generated voltage and, which is most important, achieving the uniform loading of phases.

The aim of the work is the experimental verification of possibility of using a thyristor frequency converter with direct connection at $37.5 \mathrm{~Hz}$ for power supply of two-phase flash-butt welding machine from three-phase mains for its uniform loading.

In flash-butt welding of rails the technology with programmed change of basic parameters is used, including voltage between the edges of welded parts, which is equal to voltage at the 
output of welding transformer [5]. Since minimum voltage, at which the stable flashing is possible, depends on heating of welded parts, at the beginning of welding a high voltage is required and almost the same voltage must be at the final stage of welding. Thus, the time intervals of the transformer operation with higher voltage amount to $10-30 \%$ of the total duration of welding and the heat losses in the transformer increase negligibly.

There is also a high probability of sharp increase in the load to electrical power mains. This is connected with the fact that decrease in frequency results in increase of working induction, which can reach saturation induction, and magnetizing current can reach very high values in accordance with nonlinearity of magnetization curve for transformer steels. In this case, even a short-term increase in supply current of welding machine may result in its emergency stop by circuit breaker. Therefore, the use of $37.5 \mathrm{~Hz}$ in the frequency converter is more preferable unlike $30 \mathrm{~Hz}$.

For experimental verification and testing the converter with output voltage with frequency of $37.5 \mathrm{~Hz}$ was designed and assembled according to the circuit with two three-phase full-wave controlled rectifiers connected in an anti-parallel mode $[4,6,7]$. It is designed for rated output voltage of $400 \mathrm{~V}$, rated current of $1000 \mathrm{~A}$ at the duty cycle of $100 \%$.

The frequency converter consists of the unit of thyristor rectifiers, switching unit of thyristors, unit of thyristors protection, computer control system and sensors of phase currents $I_{\mathrm{A}}, I_{\mathrm{B}}$, $I_{\mathrm{C}}$, welding current $I_{\mathrm{w}}$, output voltage of converter $U_{\mathrm{w}}$, and temperature of casings of thyristors $T,{ }^{\circ} \mathrm{C}$ (Figure 1). The protection unit of the thyristors realizes the control of values of phase currents and at the values of more than $1500 \mathrm{~A}$ disconnects the control circuits from the input of the switching unit of thyristors. The response time of protection is $2 \mathrm{~ms}$. However, the switched on thyristor cannot be instantly disconnected from the control circuit. Therefore, to protect the thyristors the quick-break fuses $\mathrm{Fu} \mathrm{1,2}$ and 3 are also used.

The converter control system of $75 \mathrm{~Hz}$ frequency measures the welding current, i.e. the value of current in each separate pulse. This value is used to calculate the signal of control movement speed of mobile column of welding machine. In addition, the converter control system measures also the output voltage of frequency converter and stabilizes the preset value of voltage, controls the temperature of thyristors of power

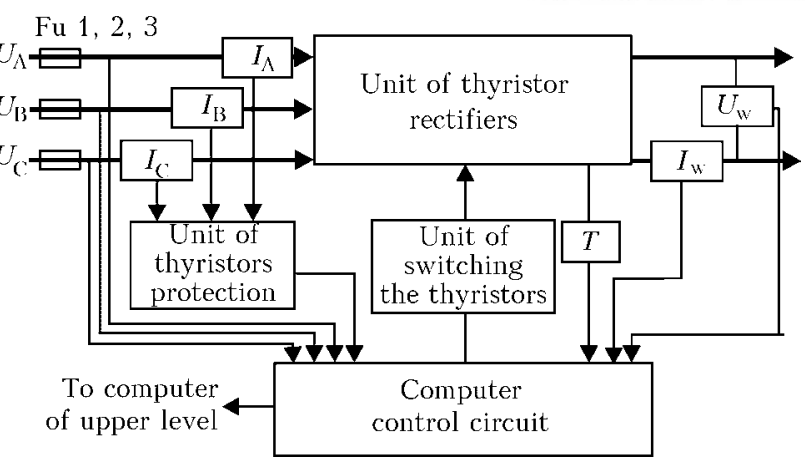

Figure 1. Schematic diagram of converter

rectifiers and stops welding at exceeding the allowable value.

The ranges of measurement of welding current are 10-1000 and 200-2000 A, the range of preset voltage at the output of converter is $200-400 \mathrm{~V}$, the given error of measurement of welding current and voltage stabilization is less than $3 \%$, the rate of data transfer to serial channel is 19600 baud. The serial communication channel is used to link the control converter system with control system of the upper level of welding machine reception of the value of preset voltage and transmission of the measured current and diagnostic messages.

The control system of upper level is assembled on the basis of industrial controller Siemens SIMAT1C S7-300 with processor CPU314C-2 PtP. The main function of this system is the control of welding process in real time and control according to the preset cyclogram.

To evaluate the required decrease of value of output voltage of the converter the characteristics of open-circuit current of the welding transformer of flash-butt welding machine K1000 was studied. Due to the effect of saturation of the welding transformer at low voltage frequency the open-circuit current grows significantly (Figure 2), which leads to a great overheating of the primary circuit of welding transformer and power cables of welding machine,

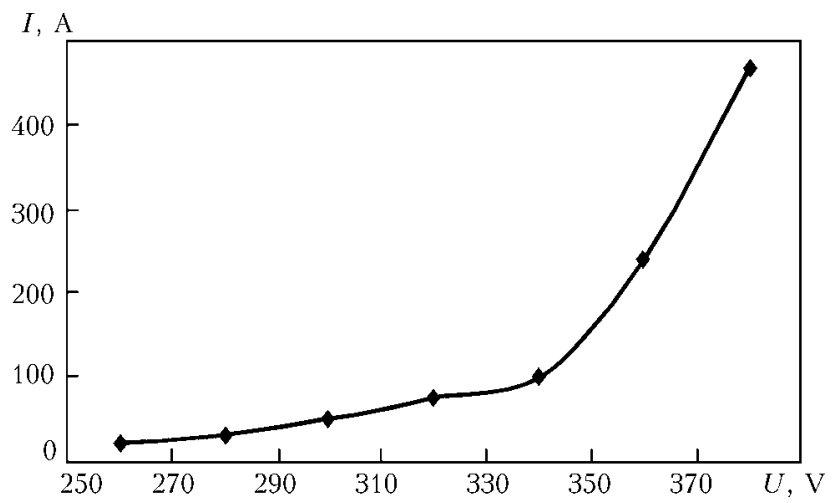

Figure 2. Dependence of open-circuit current on input voltage for welding transformers of machines K-1000 at power supply from converter of $f=37.5 \mathrm{~Hz}$ 


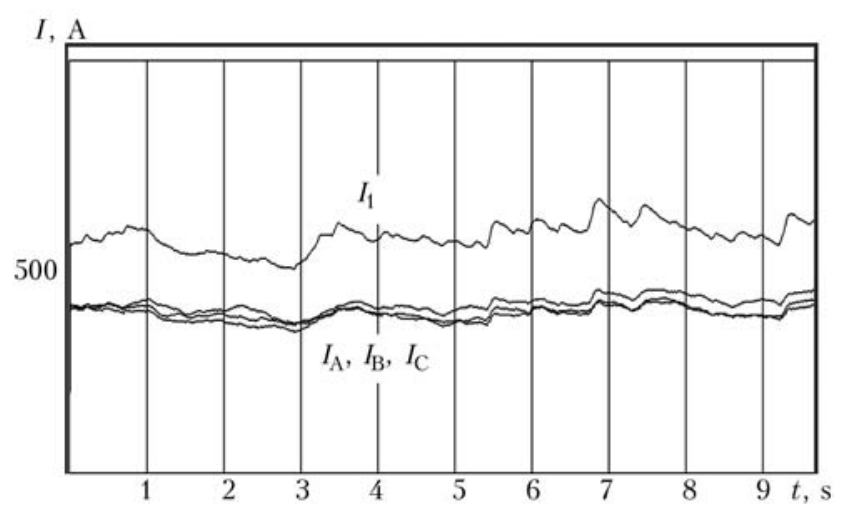

Figure 3. Oscillograms of currents $I_{\mathrm{A}}, I_{\mathrm{B}}, I_{\mathrm{C}}$ in phases $\mathrm{A}$, $\mathrm{B}, \mathrm{C}$ and current $I_{1}$ in the primary circuit of welding transformer during welding of rails in K-1000 machine using the converter of frequency and number of phases

and may result in their premature wear and accident. In further tests during welding of specimens and full-scale products the voltage was preset up to $340 \mathrm{~V}$. As far as the maximum effective voltage at the output of the converter during its power supply from mains of $380 \mathrm{~V}$ is $416 \mathrm{~V}$, for its reducing the autotransformer of machine $\mathrm{K}$ 1000 was used.

The converter passed industrial tests in welding of rails within almost two years at the rail welding enterprise. The technology of welding of rails R65 was practiced using continuous and pulsating flash. At the same time, the selection of modes and welding of specimens of new and used repaired rails of steel M76 (production of «Azovstal») and used repaired rails E76F «Evraz» production (Nizhny Tagil Metallurgical Works, Russia) was carried out. The quality of welding was controlled by mechanical tests for a static three-point bending of specimens of welded butts by values of strength and ductility, as well as by ultrasonic flaw detection method, according to the approved standard documents of Ukraine. It was found that the quality of welded joints met the technical conditions of TU U 27.1-000334045-1353:2007. At the same time, the reliability of converter meets the industrial conditions. At the final stage of testing, welding of rail sections was carried out, which were mounted to the main track of railway. Both in the first and second cases, the quality of welded products met their technical requirements.

To evaluate the uniformity of loading the phases of three-phase mains, a continuous registration of phase currents was carried out with sampling rate of 128 measurements over the period of mains using measuring complex SATEK EDL 175XR N822584. Also current sensors
FLUKE i3000s flex were used, which were connected to the phases of cable input of $0.4 \mathrm{kV}$ of the welding machine cabinet. The analysis of plots of effective values of phase currents showed that the difference between these two values of phase currents did not exceed $\pm 2 \%$. At the same time, phase currents were $20 \%$ lower than current at the load (at the output of source) (Figure 3), which, in its turn, allows reducing the load to power substation of the transformer for each phase, and therefore, increasing its lifetime before repair; connecting additional consumers of electric power energy without increasing the power of power transformer of the substation; eliminating imbalance of phase voltages and improving the working conditions of three-phase electrical devices and, in the first turn, asynchronous motors, which increases their service life and improving the quality of the consumed electric power.

\section{Conclusions}

1. The pilot industrial tests of the frequency converter for $37.5 \mathrm{~Hz}$ showed the possibility and rationality of its application for flash-butt welding, in particular, of rails due to uniform loading of three-phase mains.

2. The efficiency of use of the converter can be significantly increased by using the power transformer, designed for $37.5 \mathrm{~Hz}$, in flash-butt welding machines.

1. Lebedev, V.K., Pismenny, A.A. (2001) Power systems of resistance welding machines. The Paton Welding J., 11, 28-32.

2. Lebedev, V.K., Pismenny, A.A. (1998) Improvement of power systems of resistance welding machines. In: Welding and related technologies into the 21st century, 130-136.

3. Kuchuk-Yatsenko, S.I., Rudenko, P.M., Gavrish, V.S. et al. (2015) Comparative evaluation of power and technological characteristics in continuous flashbutt welding of thick-walled parts at direct and alternating current. The Paton Welding J., 1, 11-17.

4. Rudenko, P.M., Gavrish, V.S. (2013) Thyristor direct converters for supply of resistance welding machines. Ibid., 8, 54-56.

5. Kuchuk-Yatsenko, S.I., Lebedev, V.K. (1976) Flashbutt welding. Kiev: Naukova Dumka.

6. Kuchuk-Yatsenko, S.I., Gavrish, V.S., Rudenko, P.M. et al. Method of electric supply of single-phase resistance machines of alternating current. Pat. 86279 Ukraine. Int. Cl. B23K 11/24. Publ. 10.04.2009.

7. Kuchuk-Yatsenko, S.I., Gavrish, V.S., Rudenko, P.M. et al. Method of electric supply of welding transformer of single-phase resistance machines of alternating current. Pat. 100064 Ukraine. Int. Cl. B23K 11/24. Publ. 12.11.2012.

Received 04.03.2015 


\title{
INDUSTRIAL APPLICATION OF HYBRID LASER-ARC WELDING (Review)
}

\author{
I.V. KRIVTSUN ${ }^{1,2}$, V.Yu. KHASKIN ${ }^{2}$, V.N. KORZHIK ${ }^{1,2}$ and LUO ZIYI ${ }^{1}$ \\ ${ }^{1}$ Guangdong General Research Institute for Industrial Technologies \\ (Guanzhou Research Institute of Non-Ferrous Metals) \\ Guangzhou, PRC \\ ${ }^{2}$ E.O. Paton Electric Welding Institute, NASU \\ 11 Bozhenko Str., 03680, Kiev, Ukraine. E-mail: office@paton.kiev.ua
}

\begin{abstract}
Welding technology improvement is the prerequisite for progress of industrial production. Development of new structures often requires application of high-efficient welding processes, which ensure minimizing the residual deformations. Unfortunately, capabilities of the traditional arc technologies do not always meet such requirements. Laser welding technologies are not always acceptable, either, in view of the high equipment cost and requirements to preparation of items to be welded. Over the recent years hybrid laser-arc welding technologies, combining the advantages of arc and laser processes, have become ever wider accepted. Therefore, this work is a review of modern tendencies in development of hybrid laser-MIG welding of metals and alloys. It is shown that alongside continuation of research, such tendencies include industrial application (for instance, in different sectors of transportation, chemical, power and food industry) oriented towards partial replacement of laser and arc welding technologies. Examples of such applications are given. Development of new technologies of hybrid welding, focused on joining structures differing by their composition and geometry, as well as designing new production equipment for realization of these technologies is noted. Under the conditions of a new stage in laser equipment development, which began in the last decade, and which is associated with a broad industrial introduction of fibre and disc lasers, the issue of selection of laser or hybrid welding has become the subject of scientific-technical and economic analysis. 37 Ref., 5 Figures.
\end{abstract}

Keywords: hybrid laser-MIG welding, welding heads, process parameters, mode selection, development history, industrial application

Welding technology improvement is a prerequisite for progress of industrial production. Creation of new structures often requires application of high-efficient welding processes, which ensure minimizing the residual deformations. Unfortunately, the possibilities of traditional arc technologies do not always meet such requirements. Laser welding technologies are not always acceptable, either, in view of the high cost of equipment and requirements to preparation of items to be welded. Over the recent years, hybrid laser-arc welding technologies, combining the advantages of arc and laser processes, have been ever wider accepted. This study is devoted to tendencies in their development.

As was shown by Steen et al. in their works $[1,2]$, combining laser radiation with electric arc allows development of new welding technologies, offering considerable technological advantages, compared to laser welding (Figure 1) [3]. These advantages include, primarily, deep penetration, low level of residual stresses and lower requirements to fit-up of the edges to be welded.

(c) I.V. KRIVTSUN, V.Yu. KHASKIN, V.N. KORZHIK and LUO ZIYI, 2015
Heating of metal being welded by the electric arc increases the coefficient of laser radiation absorption, that leads to lowering of laser energy losses and allows welding speed to be increased. The same effect is manifested in increase of cross-

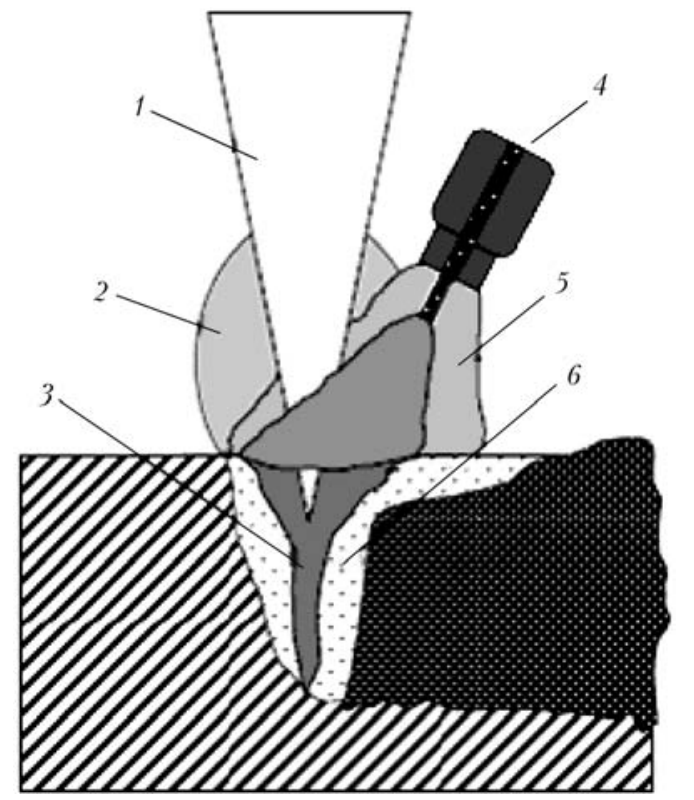

Figure 1. Schematic of hybrid laser-MIG welding [3]: 1 laser radiation; 2 - laser plasma; 3 - vapour-gas channel; 4 - consumable electrode arc; 5 - shielding gas; $6-$ weld pool 

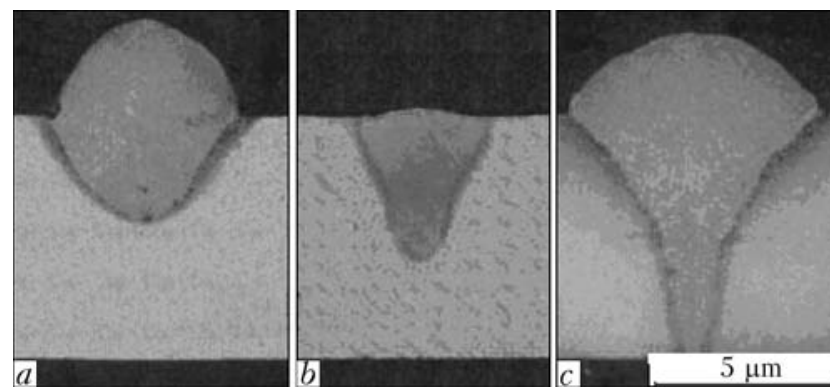

Figure 2. Cross-sections of penetrations made in mediumcarbon steel plate by arc $(a)$, laser $(b)$ and hybrid $(c)$ processes (in hybrid welding distance between wire and focused beam $D_{\mathrm{LA}}=2 \mathrm{~mm}$, wire extension of $11 \mathrm{~mm}$, arc torch inclination of $60^{\circ}$ ) [4]: $a-$ cross-sectional area of $20.31 ; b-7.30 ; c-30.08 \mathrm{~mm}^{2}$

sectional area of metal remelted in hybrid welding, compared to the sum of cross-sectional areas of beads produced by arc and laser welding separately (Figure 2) [4]. In its turn, electric arc is constricted to the dimensions of welded metal vapour plume, formed under the impact of laser radiation, and complements the effect from laser radiation impact. Therefore, hybrid laser-MIG welding requires smaller power lasers, compared to laser welding, that makes the process less costly. Modification of thermal cycle of laser welding, occurring under the arc impact, improves weld structure $[2,5]$.

The torch for modern hybrid welding can be both a simple combination of laser welding head with arc torch (Figure 3), and a complex integrated device (Figure 4). Such torches are oriented to application in the arm of an anthropomorphous robot. PWI developed a number of torches, oriented to application in single- and multiaxes manipulator of plotter type ( $\mathrm{Fi}^{-}$ gure 5). The advantage of these torches is their integration with filler wire feed mechanism and reduction of wire feeding Bowden to $0.1-0.5 \mathrm{~m}$, that markedly lowers the risk of electrode wire jamming. Moreover, such torches have maximum
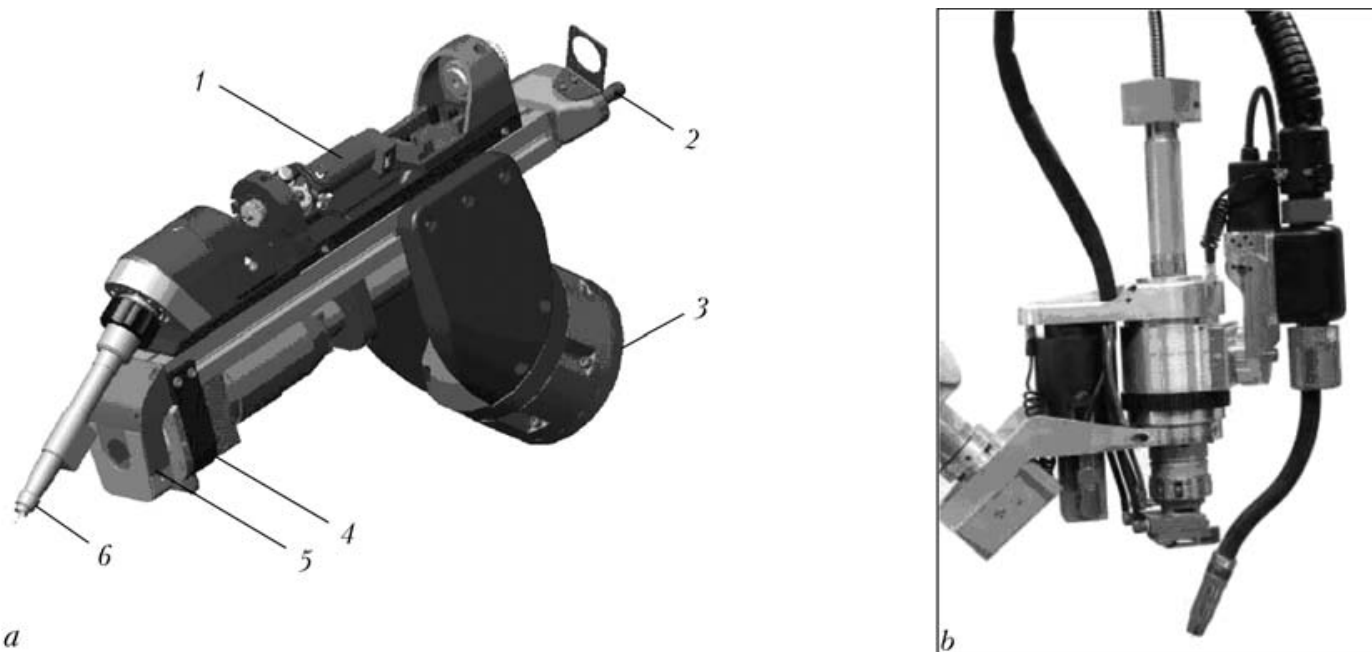

Figure 3. Heads for hybrid laser-arc robotic welding of Fronius $(a)$ and Cloos $(b)$ company [4]: 1 - wire feeder; $2-$ air in-take; 3 - fastening on robot arm; 4 - protective glass; 5 - cross-jet; 6 - water-cooled nozzle

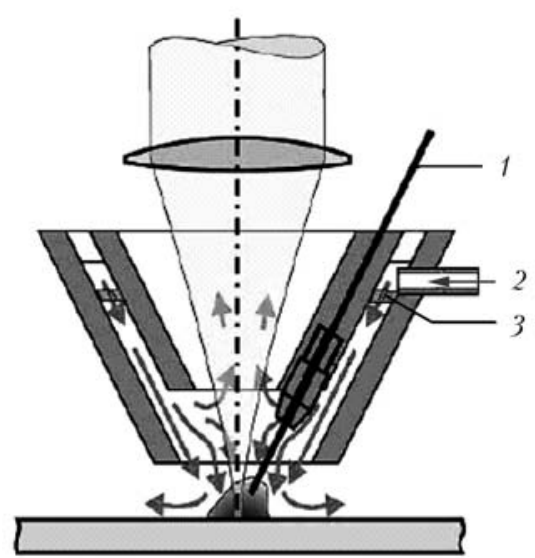

$a$

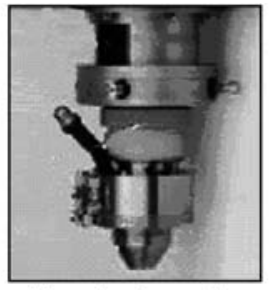

Standard nozzle

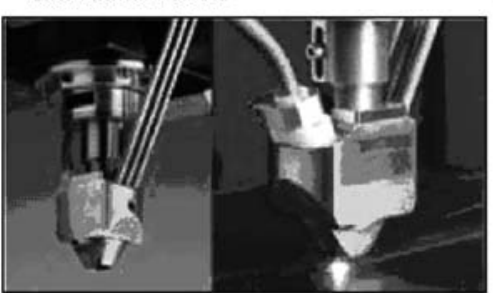

Thin nozzle б

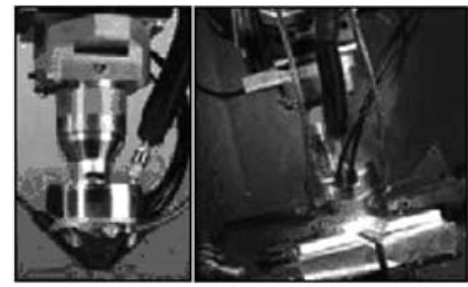

Heavy-duty mode

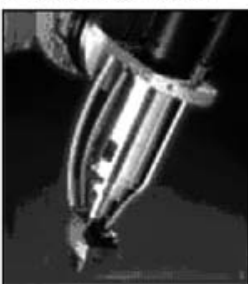

Super thin nozzle

Figure 4. Block-diagram $(a)$ and appearance $(b)$ of heads for hybrid laser-arc welding with integrated nozzle [4]: 1 electrode wire; 2 - auxiliary gas; 3 - diffusion aperture 

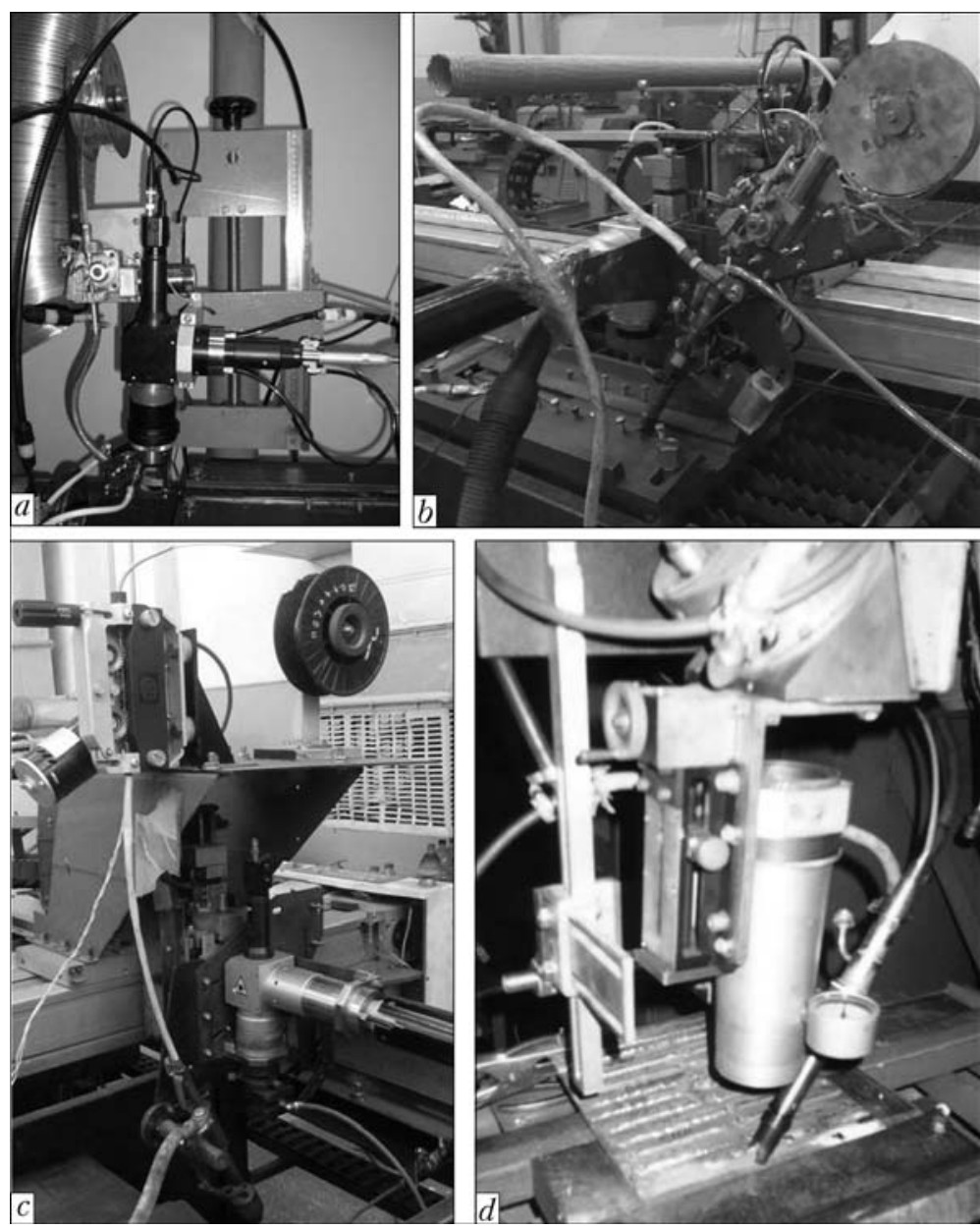

Figure 5. Appearance of heads for hybrid laser-arc welding performed with single- and three-axes manipulator developed at PWI: $a-c-$ for lasers with up to $1.06 \mu \mathrm{m}$ wave length; $d-10.6 \mu \mathrm{m}$

simplified and reliable design, using the simplest standard laser focusing system. Here, it is possible to apply for correction of head displacement path both a TV camera and red laser radiation in the case of diode or Nd:YAG lasers (Figure 5, $a-c)$, and just red radiation in the case of $\mathrm{CO}_{2-}$ laser (Figure 5, $d$ ).

Hybrid welding minimizes the disadvantages of both the laser and MIG welding. According to [3, 4], the main advantages of hybrid laser-arc welding, compared to laser welding, are as follows:

- reduction of capital costs for equipment by 30-40\% compared to laser welding (because of reduction of consumed laser power);

- high welding speeds;

- lowering of edge preparation accuracy;

- controlling weld composition through welding wire selection;

- lowering the risk of quenching structure formation in weld and HAZ metal;

- improvement of process reliability;

- improvement of overall process efficiency, lowering power intensity to $50 \%$.

Achievement of the above advantages, however, requires correct selection of a number of parameters. Let us consider them in keeping with recommendations of $[3,4,6,7]$.

Laser power. Increase of this parameter usually increases the penetration depth. In hybrid laser-arc welding this phenomenon is enhanced due to lowering of reflectivity of metal heated by the arc.

Welding speed. With lowering of welding speed, penetration depth is increased, due to increase of energy applied per a unit of weld length. Moreover, stability of welding wire feeding and melting is improved at lower welding speeds.

Relative position of focused laser radiation and consumable electrode arc. Distance between laser radiation axis and wire tip is one of the most important parameters of optimization of hybrid laser-arc welding. It is usually selected small (up to $2 \mathrm{~mm}$ ). In addition to that, important factors of weld formation are arc torch position in front or at the back in the direction of welding, as well as angle of its inclination.

Focal position. Maximum penetration depth in laser-arc welding is usually achieved at laser beam focusing below the surface of sheets being welded to the depth of $2-4 \mathrm{~mm}$. 
Angle of electrode inclination. Penetration depth rises with increase of the angle of electrode inclination to item surface up to $50^{\circ}$. Gas flow coming out of arc torch deflects the vapour-gas plume formed by laser radiation, and reduces laser energy losses (particularly, at application of $\mathrm{CO}_{2}$-lasers). Therefore, the angle of electrode inclination to item surface usually is equal to about 40 to $50^{\circ}$.

Shielding gas composition. Inert gas (helium, argon, or heir mixtures) is usually applied. At application of $\mathrm{CO}_{2}$-lasers, shielding gas with a higher ionization potential is required to prevent formation of plasma, capable of deflecting or absorbing laser radiation. Therefore, helium is preferable to argon for laser welding. However, helium lightness is a disadvantage, so that it is often used in mixtures with heavier argon. More over, reactive gases such as oxygen and carbon dioxide are added to increase penetration depth.

Modulation of arc component power. Direct current is usually used for powering the welding arc. Pulsed mode is also often used to reduce spatter at preservation of deep penetration. Increase of arc voltage promotes weld widening that reduces the weld form factor (ratio of penetration depth to its width) for the same laser power. Therefore, arc voltage (and wire feed rate) are increased in case of welding loosely fitting edges. Welding current is, usually, directly proportional to welding wire diameter. Welding current increase promotes increase of penetration depth and of weld form factor.

Alignment of edges to be welded. A gap of up to $0.2 \mathrm{~mm}$ is allowable for laser welding. Large gaps lead to such defects as weld sagging or lack-of-fusion. Hybrid laser-arc welding allows joining parts with gaps of up to $1 \mathrm{~mm}$ and more (at high wire feed rates).

Edge preparation. Regular laser welding requires parallel straight edges and narrow gap. For arc welding edge preparation is used (most often, V-shaped). In the case of hybrid laser-arc welding, requirements to edge preparation are lower than for laser welding. Edge preparation is, usually, applied for material thickness greater than 8 to $10 \mathrm{~mm}$.

For better understanding of modern tendencies in development of hybrid laser-MIG welding, let us consider the main stages in evolution of this process according to study [8] performed at PWI.

$1970 \mathrm{~s}$. At the end of $1970 \mathrm{~s}$, a team led by W. Steen at the Imperial College in London made the first attempts at combining laser radiation and electric arc (TIG) for welding metals. This new hybrid laser-arc welding process had a num- ber of advantages, compared to laser and arc processes. It ensured increased process stability, much higher welding speed, deeper penetration and a narrow weld. Nonetheless, this innovation was not immediately accepted by industry [5, 6]. Approximately in 1979-1980 PWI performed the first experiments on laser-arc welding.

1980s. Appearance of reliable and comparatively inexpensive high power lasers allowed introducing laser welding into industry [9]. It was established that its disadvantages can be minimized by combining laser welding with regular arc welding. This allowed increasing process effectiveness, lowering requirements to preparation of edges to be welded, eliminating a number of metallurgical problems and lowering the reflectivity of the metal being welded. Thus, most of the obstacles for laser introduction into welding production were eliminated $[5,6]$.

1990s. Tendencies of industrial realization of laser and hybrid welding, laid down as far back as in 1980s, are manifested. Laser equipment power becomes higher. Development of hybrid laser-arc welding revealed such disadvantages of laser welding, as high cost, complexity of edge preparation and fastening the parts to be welded, as well as a number of metallurgical problems. Investigations of advantages and disadvantages of hybrid laser-arc welding are pursued in all the industrialized countries of the world (USA, Europe and Japan) [10, 11]. Development of these technologies was promoted by industrial need for high-quality welds, produced at a high speed. Such industrial sectors as automotive, shipbuilding and pipeline transportation, became interested in hybrid laser-arc welding.

2000s. Hybrid laser-arc welding equipment has now proved its suitability for many industrial sectors. Integrated hybrid welding heads are being actively developed (for instance, Exial, Fronius, Prima Industry, Permanova Lasersystem) $[6,12]$, various specific production scenarios are simulated and verified. For instance, the issue of joining materials of various type, configuration and thickness by hybrid laser-arc welding is studied. Investigations of the features of this welding process are also carried on, for instance, resonance phenomena occurring at summation of frequency of electrode metal drop transfer with weld pool natural oscillations [13] or influence of pulsed modulation of laser and arc components on the nature of weld formation and their mechanical properties, are studied [14].

Hybrid laser-MIG welding combines the advantages of arc and laser processes, that leads to improvement of welding stability and weld quality and lowering of residual deformations. Industrial advantages include increase of productivity, 
simplification of adjustment procedure and lowering of the cost of one running meter of weld. Nonetheless, this technology still is only at the initial stage of introduction in modern industry sectors. The causes for slow pace of industrial introduction are the high level of investment and process complexity, associated with a large number of its parameters. Despite that, hybrid welding has already been accepted to a certain extent in such industries as automotive and shipbuilding, pipeline transportation, aerospace and aircraft industry, power generation, off-highway and heavy vehicle sectors.

Automotive. Such well-known automotive companies as Volkswagen and Audi are convinced in the superiority of hybrid laser-MIG welding $[12,15]$. Another example of this welding application is Volvo company [16]. Any type of car has a large number of welds, differing by their configuration and applied materials. In many cases, such welding processes as MIG, laser and hybrid laser-MIG welding are combined - depending on weld configuration and requirements to it. MIG welding is applied in the presence of considerable gaps between the edges being welded and with their minimum preparation. $\mathrm{La}^{-}$ ser welding ensures low residual deformations, deep penetration and high speed in the case of accurate fit-up of the parts being welded. And, finally, hybrid welding ensures high welding speeds in combination with relatively broad tolerances. Used for this purpose are 2 to $4 \mathrm{~kW}$ lasers at welding speeds of approximately $4 \mathrm{~m} / \mathrm{min}$ [17]. PWI performed work on development of technologies of laser-arc welding of zincplated steel for automotive applications and thin aluminium alloys for AvtoVAZ company (Toliatti, $\mathrm{RF})$. Technology of reconstructive surfacing of internal combustion engine pistons was also developed [18]. This technology was aimed at both filling the worn grooves of motor transport pistons (from cars up to heavy tractors), and at restoration of railway diesel engine pistons.

Shipbuilding. Hybrid welding process is of great interest for shipbuilding industry all over the world [19, 20]. This process is being actively applied by European and Asian shipyards, whereas in the US shipyards it is introduced rather slowly. Hybrid welding yields a significant saving of time and costs, replacing multipass welding due to realization of deep penetration mode. Here powerful Nd:YAG lasers of up to $6 \mathrm{~kW}$ and $\mathrm{CO}_{2}$-lasers of up to $25 \mathrm{~kW}$ are applied. Examples of shipyards using this technology are Meyer in Germany, Kvaerner in Finland, and Fincantieri in Italy. PWI performed work on development of laser-arc welding technology for ship honeycomb panels from carbon steels 3-
$7 \mathrm{~mm}$ thick for CR\&DI of CM «Prometej» (St.Petersburg, RF).

Pipeline transportation. Investigations of hybrid laser-MAG welding are being performed, aimed at improvement of welding quality and reduction of production costs in manufacturing of large-diameter pipes and mounting of the main pipelines. A process of laser welding of the root weld with subsequent welding up of a narrow gap in one, two or three passes by laser-MAG process was developed for realization under industrial conditions [21]. Stainless steel pipelines are welded without pores, with preservation of austenitic structure and without any significant increase in hardness. Welding speed for these pipelines with 5 to $8 \mathrm{~mm}$ wall thickness is up to $1.2 \mathrm{~m} / \mathrm{min}$ [22]. PWI developed several techniques of welding large-diameter pipes and their position butts [23, 24].

Aerospace and aviation industry. Leading position in aircraft industry is taken by Airbus company, in particular, owing to innovative developments. For several years now this company has applied laser welding process for manufacturing aircraft hull sections, in particular, for Airbus 318 and Airbus 380 models [25, 26]. Recently Airbus has shown interest in hybrid welding technology. This technology also is of great interest for solving aerospace and military tasks when working with titanium alloys [27]. PWI performed a number of studies on welding titanium alloys, aluminium alloys and stainless steels to meet the objectives of Ukrainian aerospace industry [28]. In this work the applicability of both laser and hybrid welding was studied.

Power generation. In equipment applied for power generation it is often necessary to weld plates of more than $15 \mathrm{~mm}$ thickness. In particular, technology of laser welding of such materials has been studied and applied in industry [29], but hybrid welding is gradually attracting ever greater attention for solving this problem, as it is capable of overcoming the disadvantages of laser welding [30]. Here, both laser and hybrid welding are usually applied in multipass mode [31]. In addition to thick plates thin stainless steels are also used in power machine-building, for instance, for manufacturing expansion bellows assemblies. PWI developed technologies and equipment for welding such assemblies for Research-Information Center «Armatom» (Kiev, Ukraine) [32]. Here, preference was given to laser, and not hybrid welding.

Off-highway and heavy vehicles. Laser welding is an already well-established technology in heavy vehicle industry for joining parts from structural steels, and its effectiveness has been proved more than once [33]. Nonetheless, hybrid welding has demonstrated its superiority, com- 
pared to laser welding (for instance, shortening of the time of preparation for welding and finish treatment), and, for this reason, it is gradually becoming ever wider accepted in this industry [34]. Some technological solutions for this industry sector were also developed at PWI [35].

Just several examples of industrial application of hybrid welding have been considered, which is being continuously expanded now. Other possible applications include household appliances, railway transportation, chemical industry (in particular, welding stainless steel tanks and pipes), etc. [36]. Application of laser-arc welding to address the tasks of aluminium structure manufacturing has a special place [37].

\section{Conclusions}

1. Introduction into industry (for instance, in various sectors of transportation, chemical, power and food industry), oriented to partial replacement of laser and arc welding technologies, can be regarded as the main modern tendency of development of hybrid laser$\mathrm{MIG}$ / MAG welding.

2. General tendencies of hybrid welding progress include development of new technologies, focused on welding structures of different chemical composition and geometry, as well as designing new equipment for industrial introduction of the developed technologies.

3 . In connection with a new stage in laser equipment development, which began in the last decade and which is associated with wide industrial introduction of fibre and disc lasers, the issue of giving preference to laser or hybrid welding has become the subject of thorough scientific-technical and economic studies.

1. Steen, W.M., Eboo, M. (1979) Arc augmented laser welding. Metal Constr., 11(7), 332-335.

2. Steen, W.M., William, M. (2003) Laser material processing. 3rd ed. London: Springer-Verlag Ltd.

3. Wouters, M. (2005) Hybrid laser-MIG welding: An investigation of geometrical considerations. Lulea: University of Technology.

4. Kah, P. (2011) Usability of laser-arc hybrid welding processes in industrial applications. Lappeenranta: University of Technology

5. Seyffarth, P., Krivtsun, I.V. (2002) Laser-arc processes and their applications in welding and material treatment. In: Welding and Allied Processes, Vol. 1 London: Taylor and Francis Books.

6. Bagger, C., Olsen, F.O. (2005) Review of laser hybrid welding. J. Laser Appl., 17(1), 2-14.

7. Jokinen, T., Jernstrom, P., Karhu, M. et al. (2003) Optimisation of parameters in hybrid welding of aluminium alloy. Proc. of SPIE, Vol. 4831, 307-312.

8. Shelyagin, V.D., Khaskin, V.Yu. (2002) Tendencies in development of laser-arc welding (Review). The Paton Welding J., 6, 25-28.

9. Ready, J.F. (1997) Industrial applications of lasers London: Acad. Press.

10. Dilthey, U., Wieschemann, A. (2000) Prospects by combining and coupling laser beams and arc welding processes. Welding in the World, 44(3), 37-46.

11. Ishide, T., Tsubota, S., Watanabe, M. et al. (2003) Latest MIG, TIG, arc-YAG laser hybrid welding systems. J. JWS., 72(1), 22-26.
12. Staufer, H. (2005) Laser hybrid welding and laser brazing: State of the art in technology and practice by the examples of the Audi A8 and VW-Phaeton. In: Proc. of 3rd Int. WLT Conf. on Lasers in Manufacturing (Munchen, 2005), 203-208.

13. Shelyagin, V.D., Khaskin, V.Yu., Garashchuk, V.P. et al. (2002) Hybrid $\mathrm{CO}_{2}$-laser and $\mathrm{CO}_{2}$ consumablearc welding. The Paton Welding J., 10, 35-37.

14. Zhernosekov, A.M., Khaskin, V.Yu., Nabok, T.N (2014) Pulsed laser-arc welding of carbon steels. Vost. Evrop. Zhurnal Pered. Tekhnologij, 71(5/1), 12-15.

15. Graf, T., Staufer, H. (2003) Laser-hybrid-welding drives VW improvements. Welding J., 1, 42-48.

16. Lakhti, K.E. (2003) One + one is more than two!!! Svetsaren, 2, 22-24.

17. Staufer, H. (2007) Laser hybrid welding in the automotive industry. Welding J., 10, 36-40.

18. Khaskin, V.Yu. (2009) Application of laser-arc cladding for filling up narrow cavities in aluminium alloy items. The Paton Welding J., 2, 31-34.

19. Merchant, V. (2003) Shipshape laser applications. Industrial Laser Solutions, August. wrew.industriallasers.com

20. Denney, P. (2002) Hybrid laser welding for fabrication of ship structural components. Welding J., 81(Sept.), 58.

21. Staufer, H., Ruehrnoessl, M. (2006) Blechdicken und hohe Schweissgeschwindigkeiten: Laserhybrid- + Tandemschweissen. Der Praktiker, 10, 300-302.

22. Thomy, C., Schilf, M., Seefeld, T. et al. (2003) CO2-Laser-MSG-Hybridschweissen in der Rohrfertigung. Werkstattstechnik on-line, 93(6), 462-466.

23. Shelyagin, V.D., Khaskin, V.Yu., Shitova, L.G. et al. (2005) Multi-pass welding of heavy steel sections using laser radiation. The Paton Welding J., 10, 46-49.

24. Shelyagin, V.D., Khaskin, V.Yu. (2009) Multi-pass welding of pipe steels using laser radiation. Svarshchik, 69(5), 36-38.

25. (2004) Laserstrahlschweissen macht Flugzeuge leichter. Fraunhofer Magazin, 4, 36-37.

26. Mendez, P.F., Eagar, T.W. (2002) New trends in welding in the aeronautic industry. In: Proc. of 2nd Conf. on New Manufacturing Trends (Bilboa, Spain, Nov. 19-20, 2002), 1-10.

27. Shinn, B.W., Farson, D.F., Denney, P.E. (2005) Laser stabilization of arc cathode spots in titanium welding. Sci. and Techn. of Welding \& Joining, 10(4), 475-481.

28. Shelyagin, V.D., Lutsenko, V.I., Khaskin, V.Yu et al. (2012) Development of equipment and technology of automated laser welding of pipe compensating elements for aerospace industry. Nauka $i$ Innovatsii, $8(6), 53-59$.

29. Jokinen, T., Kujanpaa, V. (2003) High power $\mathrm{Nd}$ YAG laser welding in manufacturing of vacuum vessel of fusion reactor. Fusion Eng. and Design, 69(1-4), 349-353.

30. Jokinen, T., Karhu, M., Kujanpaa, V. (2003) Welding of thick austenitic stainless steel using Nd:yttrium-aluminum-garnet laser with filler wire and hybrid process. J. Laser Appl., 15, 220-224.

31. Jokinen, T., Karhu, M., Kujanpaa, V. (2003) Narrow gap hybrid welding of thick stainless steel. In: Proc. of 22nd ICALEO (Jacksonville, FL, USA, 1316 Oct. 2003), 66-75.

32. Lukashenko, A.G., Melnichenko, T.V., Lukashenko, D.A. (2012) Laser welding of sheet stainless steel by modulated radiation. The Paton Welding J., 4, 15-19.

33. Nilsson, K., Engstrom, H., Flingfeldt, J. et al. (2000) High power laser welding of construction steels. Svetsen, 59(1)

34. Hyatt, C.V., Magee, K.H., Porter, J.F. et al. (2001) Laser-assisted gas metal arc welding of 25 -mm-thick HY-plate. Welding J., 80(7), 163-172.

35. Shelvagin, V.D., Krivtsun, I.V., Borisov, Yu.S. et al. (2005) Laser-arc and laser-plasma welding and coating technologies. The Paton Welding J., 8, 44-49.

36. Kah, P Salminen, A Martikainen, J (2010) Laserarc hybrid welding processes (Review). Ibid., 6, 32-40.

37. Khaskin, V.Yu. (2013) Development of laser welding of aluminium alloys at the E.O. Paton Electric Welding Institute (Review). Ibid., 5, 51-55. 


\title{
EVALUATION OF STRENGTH OF JOINTS PRODUCED USING WELDING WITH CONCURRENT BRAZING
}

\author{
V.I. SAVULYAK, S.A. ZABOLOTNY and D.V. BAKALETS \\ Vinnytsa National Technical University \\ 95 Khmelnitskoe Shosse, 231021, Vinnytsa, Ukraine. E-mail: vsavulyak@mail.ru
}

\begin{abstract}
Grounded was the rationality and the technology of producing permanent joints by combining the processes of welding and brazing using heat generated in the process of arc burning was described. The aim of the work is to establish the influence of formed brazed component on strength of the joint and structure as a whole. Developed were the methods for manufacture of pilot specimens, allowing establishing the necessary dependencies of strength of joints on type of braze material and its quantity. Namely the strength tests and processing of experimental data were performed in accordance with recommendations of GOST 28830-90. The use of programs of finite element analysis allowed determining the optimal welding conditions with concurrent brazing and the amount of braze material that can be melted. This technology can be used for repair of frames of transport machinery, damaged by cracking, by welding-on of strengthening cover plates. Also, it is rational to use the developed technology in production of frame structures. It was proved that the use of technology for producing permanent joints by combining the processes of welding and brazing using braze alloys based on copper can increase the strength of joint by one third as compared to conventional joint. 12 Ref., 3 Tables, 4 Figures.
\end{abstract}

$\boldsymbol{K} \boldsymbol{e} \boldsymbol{y} \boldsymbol{w} \boldsymbol{o r d} \boldsymbol{s}:$ frame structure, transport, crack, technology, repair, strengthening, welding, brazing, strength

The perspective direction of increasing and improving the service properties of welded structures during repair and manufacture is the use of combination of several related processes [1-4]. The use of such technologies is rational to provide the increased requirements to reliability and long life. As an example, the repair of frames of transport means, in particular longerons, the areas of which are damaged with cracks, is given [2, 5]. For their repair and strengthening it was suggested to mount the additional elements by their welding-on using the concurrent brazing. The technology envisages the use of high-temperature braze alloys, allowing improving strength of the joints and corrosion resistance of the near-weld zone $[6,7]$. The peculiarity of the technology is that braze alloy is mounted between the main elements, which are welded together and melted due to heat in the near-weld zone, released in the process of arcing [2].

The previous investigations established that the use of welding with concurrent brazing allows increasing the life of structure as compared to other known methods of repair [5]. However, to establish the influence of formed brazed component on strength of joint and structure as a whole the additional studies are necessary.

The generally-accepted technology of hightemperature brazing includes such additional operations [8] as cleaning and tinning of base ma-

(c) V.I. SAVULYAK, S.A. ZABOLOTNY and D.V. BAKALETS, 2015 terial, preceding the assembly of structure into the required position with a necessary gap. Afterwards, the base is heated to the temperature higher than the melting point of braze alloy, the flux is applied and only then the braze alloy is introduced, previously coated with flux. Introduction of braze alloy is carried out by its touching the heated place in the area of joint, as a result of which it is melted and flows into the gap between the parts [9].

In the technology providing the combination of welding with concurrent brazing the performance of all the operations recommended above is almost impossible or complicated. The realization of welding with concurrent brazing is performed using another technology and, therefore, it becomes necessary to study the strength characteristics of brazed area of produced joint, which will allow predicting its general strength.

The brazed areas were investigated, produced using copper, copper-silver, copper-zinc and selffluxing copper-phosphorus braze alloys. The previous micro- and macroanalysis of brazed area showed the possibility of producing the highquality joints [2].

The test on strength and processing of experimental data were performed by recommendations of GOST 28830-90. Before carrying out welding with concurrent brazing of that parts 1 and 2 (Figure 1,a), at the places of location of braze alloy 3 additional elements 6 were welded-on, which is necessary for fixing in the machines for rupture test. For shear tests a specimen ( $\mathrm{Fi}^{-}$ gure $1, b$ ) was cut out from the welded-brazed 

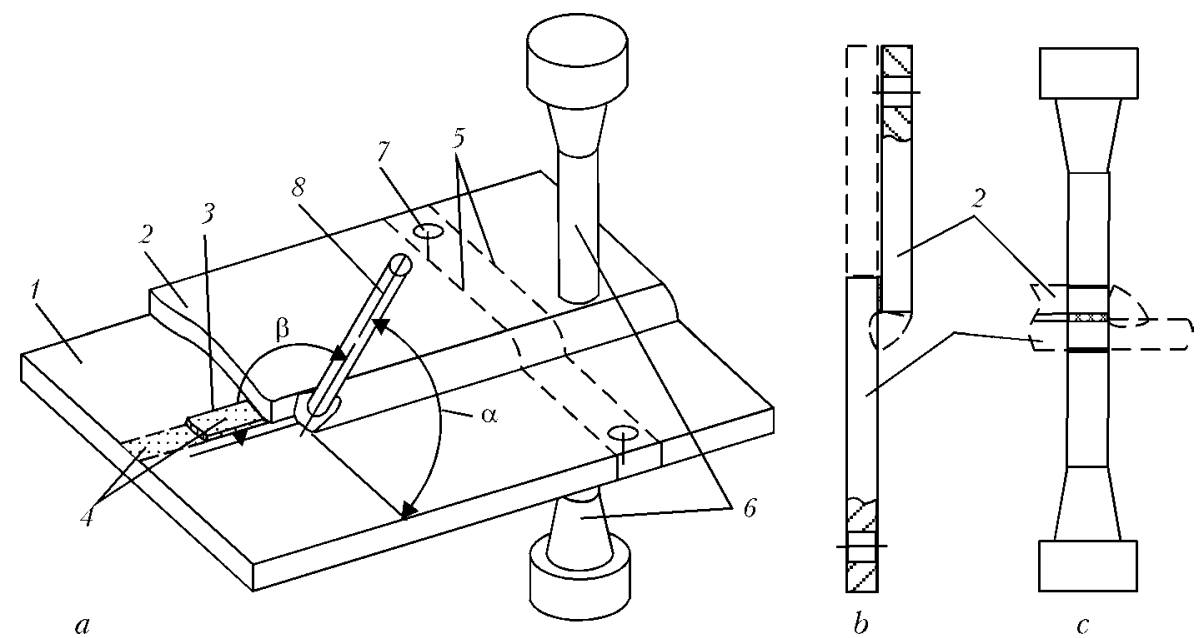

Figure 1. Scheme of preparation of specimens for rupture and shear testing of the brazed area: $a-$ welding with concurrent brazing; $b$ - specimen of V-type; $c$ - specimen of II-type (for designations see the text)

structure (Figure, 1, a) along the dotted line 5, and two holes 7 were drilled.

After welding with concurrent brazing the specimens for rupture test (type II) and shear test (type $\mathrm{V}$ ) were machined till the sizes in accordance with GOST 28830-90. At the same time the weld was completely removed and only the brazed joint remained (Figure 1, $b, c$ ).

While producing the brazed joints on test specimens the researchers tried as much as possible to approach the real technological process of welding-on of cover plates for strengthening, i.e. the surface of base and braze material was cleaned mechanically and then assembled (see Figure 1, $a$ ) and welding process was carried out. In a number of experiments a thin layer of flux 4 , based on boric acid and borax, was placed between the braze material and semi-product [10]. It was established that the increase of its amount results in excessive pore formation, and its absence significantly reduces the ability of braze alloy to wet the steel surfaces.

In the course of experimental studies it was not always managed to reach the complete melting of braze material by the heat, which was spread from the weld pool. It was established that the maximum width of strip, which can be melted in the process of welding, depends essentially on power of the arc, temperature of melting of braze material, geometry of the parts (walls thickness of frame structure, strengthening elements, etc.), as well as spatial position of electrode relatively to the parts during welding process (see Figure 1, $a$, angles $\alpha$ and $\beta$ ).

Investigation of influence of the abovementioned parameters was performed using the package of applied programs of finite element analysis. One of the most informative methods of output of simulation results is temperature fields, the value and nature of distribution of which allows judging about the maximum amount of braze material which can be melted under the preset conditions.

For example, let us consider the model of welding-on of cover plate of $5 \mathrm{~mm}$ thickness to $7 \mathrm{~mm}$ thick base. The thickness of strip of braze alloy (in the specified model) here is $1 \mathrm{~mm}$, welding power is $37 \mathrm{~W} / \mathrm{mm}^{2}$. The welding was carried out using electrode of $4 \mathrm{~mm}$ diameter at direct current of straight polarity at angle $\alpha=$ $=45^{\circ}$. The section across the weld pool indicates the character of propagation of temperature field from welding zone (Figure 2, $a$ ) perpendicular to the weld. This section of temperature field does not completely determine the allowable width of the strip of braze alloy as its propagation speed is not equal to welding speed. The correct one is the use of additionally plotted isotherms of quasi-stationary temperature field on the horizontal section $A-A$ passing along the axis of plate of braze material (Figure 2,b).

The rational width of the strip of braze alloy can be determined using its main heat and physical characteristics (melting point, thermal conductivity, specific heat) [6]. In this study braze material is used with melting points of 800 and $600{ }^{\circ} \mathrm{C}$. The tangents plotted towards the isotherms of melting points (see Figure $2, b$ ) should be parallel to the axis of the plate of braze material. The width of braze strip should be placed within the limits from the border of weld till the corresponding tangent. Considering the scale of plates let us determine the width of braze alloy plates. For braze alloy with melting point of $800{ }^{\circ} \mathrm{C}$ the width should be $4.2 \mathrm{~mm}$, and for $600{ }^{\circ} \mathrm{C}$ it should be $7.6 \mathrm{~mm}$ under the conditions of abovementioned parameters. To melt the braze material, except of the required temperature, it requires time, at which the necessary amount of heat will be supplied to it. For its determination the thermograms of heating of braze plate in the process of welding with respect to the most dis- 

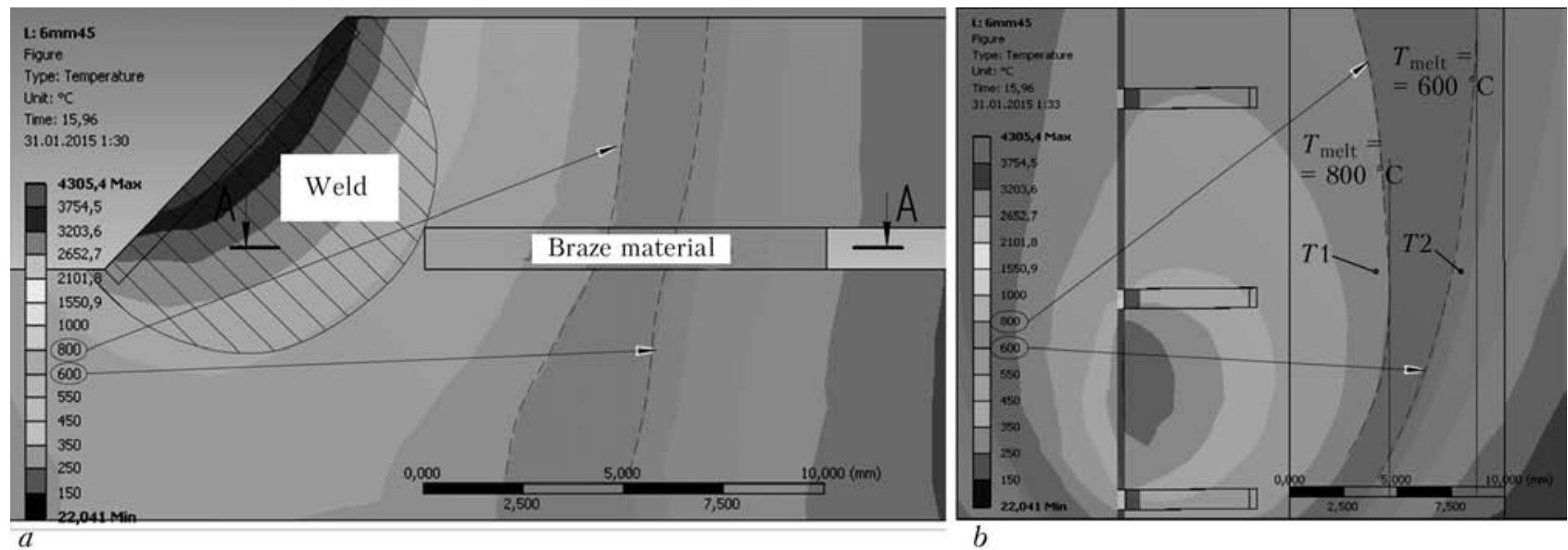

Figure 2. Temperature field of welding process with plotted isotherms: $a$ - cross-section; $b-$ horizontal section $A-A$

tant weld points $T 1, T 2$ are plotted (Figure 3 ). According to the plotted thermograms, except of maximum temperature, the time of staying the braze material in a certain temperature range can be determined. For braze alloy with melting point of $800{ }^{\circ} \mathrm{C}$ it is determined from the gap between lines $I$ and $I I$, and lasts $10 \mathrm{~s}$.

Investigation of the influence of spatial position of electrode regarding the parts on configuration of the temperature fields and position of isotherms in the process of welding was performed using computer simulation and checked up experimentally. For the scheme of overlap welding the position of electrode regarding the parts is determined by the angle $\beta$ to weld axis and angle $\alpha$ in the plane perpendicular to axis of the weld (see Figure 1, $a$ ). The change in the latter in overlap welding is controlled by GOST 5264-80 and may range within $30-60^{\circ}$. It partially determines the cross-section shape of weld, amount of weld metal, and accordingly affects the speed of welding. Therefore, the inclination angle of electrode changes the amount and distribution of heat energy over the volume of parts and partially determines the amount of braze material, which can be melted by welding heat.

In Tables 1 and 2 the data are given on choice of strip width of braze alloy of $1 \mathrm{~mm}$ thickness depending on inclination angle of electrode $\alpha$ in

Table 1. Width of strip of braze alloy with $T_{\text {melt }}=800^{\circ} \mathrm{C}$

\begin{tabular}{||c|c|c|c|c|c|c|c||}
\hline \multirow{2}{*}{$\begin{array}{c}\text { Angle } \\
\alpha, \text { deg }\end{array}$} & \multicolumn{7}{|c||}{ Wall thickness of longeron frame, mm } \\
\cline { 2 - 8 } & 5 & 6 & 7 & 8 & 9 & 10 & 12 \\
\hline 30 & 5.2 & 4.5 & 3.8 & 3.5 & 3.2 & 3 & 3 \\
\hline 35 & 5.3 & 4.6 & 3.9 & 3.5 & 3.2 & 3 & 3 \\
\hline 40 & 5.4 & 4.7 & 4.1 & 3.6 & 3.2 & 3 & 3 \\
\hline 45 & 5.6 & 4.8 & 4.2 & 3.6 & 3.2 & 3 & 3 \\
\hline 50 & 6 & 4.9 & 4.5 & 3.7 & 3.2 & 3 & 3 \\
\hline 55 & 6.6 & 5.1 & 4.8 & 3.8 & 3.3 & 3.1 & 3 \\
\hline 60 & 8.2 & 6.5 & 5.3 & 4 & 3.4 & 3.1 & 3 \\
\hline
\end{tabular}

the process of welding for different wall thicknesses of the longeron of frame structure. The thickness of cover plate in this case was $5 \mathrm{~mm}$, and welding power $-37 \mathrm{~W} / \mathrm{mm}^{2}$.

For the large thicknesses of the frame longeron the calculations were not performed, since the width of braze alloy strip, which can be melted, almost does not change with further increase in thickness of its wall.

Using the developed recommendations the quality welded and brazed joints were produced, and their mechanical tensile and shear tests were carried out, and tensile and shear strength values of the brazed seam area were calculated (Table 3 ).

The tests established that the use of $\mathrm{Cu}-\mathrm{P}$ braze alloys for strengthening the welded joints is inappropriate, since the increase in strength due to brazed area is insignificant.

For calculations of strength of welded-brazed joint and prediction of strength of structure as a whole, the direction and value of loads affecting it must be taken into account (Figure 4).

The widespread variant of fracturing the overlap joints, loaded with forces $F$, occurs along the line of the smallest section of weld and brazed area $I-I I$, and the strength depends on grade of materials, and working areas of section of weld and braze material [11, 12]. Furthermore, in the project calculations it is proposed to consider the service factor of theld (0.85-1) and the strength factor of

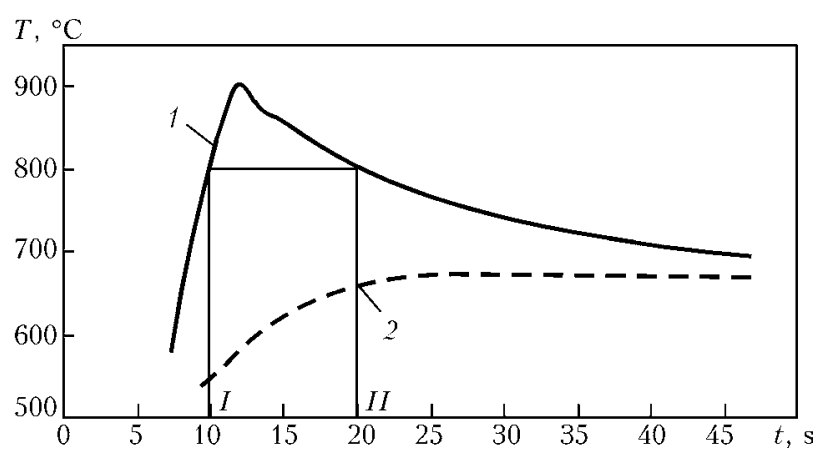

Figure 3. Thermograms: $1-$ point $T 1\left(800{ }^{\circ} \mathrm{C}\right) ; 2-T 2$ $\left(600{ }^{\circ} \mathrm{C}\right) ; I-I I$ - brazed area 


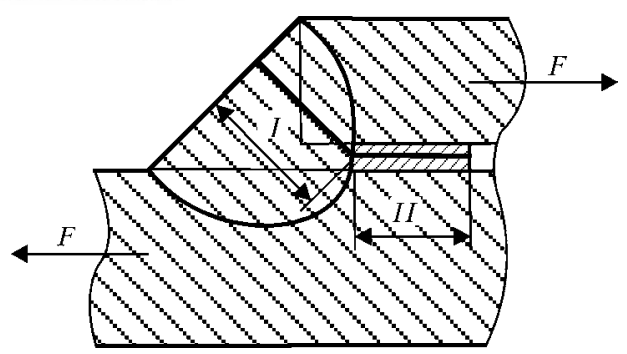

Figure 4. Scheme of design section of welded-brazed overlap joint

braze alloys $(0.50-0.65)$. Thus, the maximum allowable forces on welded-brazed joints $F_{\mathrm{WBJ}}$ will be calculated according to formula:

$$
F_{\mathrm{WBJ}}=S_{\mathrm{w}} R_{\mathrm{w} . \mathrm{y}} \gamma_{\mathrm{s}}+S_{\mathrm{b} . \mathrm{a}} \tau k_{\mathrm{b} . \mathrm{s}},
$$

where $S_{\mathrm{w}}$ is the smallest sectional area of weld; $R_{\text {wy }}$ is the calculated resistance of weld (we shall take it according to tensile strength of base metal); $\gamma_{\mathrm{s}}$ is the service factor (we shall take the maximum possible 0.85$) ; S_{\text {b.a }}$ is the brazed area working for shear; $\tau$ is the shear strength of brazed area; $k_{\mathrm{b} s \mathrm{~s}}$ is the strength factor of braze alloys (we shall accept 0.5 ).

The brazed area is defined as the product of length by width of braze material. The area of smallest section of weld is located at angle of $45^{\circ}$ to the legs, and calculated according to formula

$$
S_{\mathrm{W}}=\cos 45 k l \approx 0.7 k l,
$$

where $k$ is the leg of weld (we shall take it in accordance with thickness of cover plate); $l$ is the estimated length of weld equal to the actual one minus $10 \mathrm{~mm}$.

The efficiency of using welding technology with concurrent brazing was considered for the case of welding-on of cover plate $5 \mathrm{~mm}$ thick to wall of longeron of frame of steel 09G2S $\left(R_{\mathrm{w} . \mathrm{y}}=\right.$ $=500 \mathrm{MPa}$ ) with $7 \mathrm{~mm}$ thickness and braze material with $T_{\text {melt }}=800{ }^{\circ} \mathrm{C}$. In the case of welding-on of cover plate using electrode with inclination angle $\alpha=30^{\circ}$ (width of plate of $\mathrm{Cu}-\mathrm{Zn}$ braze alloy was $3.8 \mathrm{~mm}$ ) the strength of joint is increased by $22 \%$, while at the same conditions with inclination angle $\alpha=60^{\circ}$ (width of braze plate was $5.3 \mathrm{~mm}$ ) it is increased by $30 \%$. In the case of using the copper braze alloy for welding with concurrent brazing the strength of overlap joint can be increased by $36 \%$ as compared to welding without brazing.

\section{Conclusions}

A number of practical recommendations was developed regarding the use of welding with concurrent brazing for repair of frames of transport machinery by welding-on the strengthening overlays.

The methods given in the article, based on use of the programs of finite element analysis, allows determining the optimal parameters of

\begin{tabular}{|c|c|c|c|c|c|c|c|}
\hline \multirow{3}{*}{$\begin{array}{l}\text { Angle } \\
\alpha, \text { deg }\end{array}$} & \multicolumn{7}{|c|}{ Wall thickness of longeron frame, mm } \\
\hline & 5 & 6 & 7 & 8 & 9 & 10 & 12 \\
\hline & \multicolumn{7}{|c|}{ Width of braze alloy strip } \\
\hline 30 & 9.2 & 7.1 & 6.7 & 6.2 & 5.7 & 5.2 & 5.1 \\
\hline 35 & 9.5 & 7.6 & 6.9 & 6.3 & 5.8 & 5.2 & 5.1 \\
\hline 40 & 10 & 8.4 & 7.2 & 6.4 & 6 & 5.3 & 5.1 \\
\hline 45 & 10.5 & 9 & 7.6 & 6.8 & 6.3 & 5.4 & 5.1 \\
\hline 50 & 11 & 9.7 & 8 & 7.3 & 6.6 & 5.5 & 5.2 \\
\hline 55 & 12 & 10.3 & 8.9 & 7.9 & 6 & 5.7 & 5.2 \\
\hline 60 & 13 & 12 & 10 & 8.5 & 7.6 & 6 & 5.2 \\
\hline
\end{tabular}

Table 2. Width of strip of braze alloy with $T_{\text {melt }}=600{ }^{\circ} \mathrm{C}$

Table 3. Mechanical properties of brazed joint

\begin{tabular}{||c|c|c|c|c||}
\hline \multicolumn{5}{|c||}{ Type of braze alloy } \\
\hline $\begin{array}{c}\text { Mechanical } \\
\text { properties }\end{array}$ & $\mathrm{Cu}$ & $\mathrm{Cu}-\mathrm{Ag}$ & $\mathrm{Cu}-\mathrm{Zn}$ & $\mathrm{Cu}-\mathrm{P}$ \\
\hline$\sigma_{\mathrm{t}}, \mathrm{MPa}$ & 293 & 89 & 230 & - \\
\hline$\tau, \mathrm{MPa}$ & 205 & 73 & 172 & - \\
\hline
\end{tabular}

welding mode with accompanying brazing and the amount of braze material, which can be melted.

For welding with concurrent brazing it is rational to use the high-temperature braze alloys based on copper, which allow increasing the strength of overlap joint by up to $36 \%$ as compared to welding without brazing.

1. Savulyak, V.I., Zabolotny, S.A., Bakalets, D.V. (2014) Combination of joining and brazing for repair of frames of transport facilities. Problemy Trybologii, 73(3), 17-21.

2. Savulyak, V.I., Zabolotniy, S.A., Bakalets, D.V. (2013) Improvement of strengthening and repair of frame structures welding methods. $J$. New Technol. and Products in Machine Manufact. Technologies, 20, 189-192.

3. Khorunov, V.F., (2008) Principles of brazing of thin structures from high-strength steels. Kiev: Naukova Dumka.

4. Marynenko, S.Yu., Kramar, G.M. (2014) Specifics of brazing of low-tungsten hard alloys. Progres. Tekhnologii i Systemy Mashynobud., 47(1), 196-200.

5. Bakalets, D.V., Savulyak, V.I. (2012) Increase in reliability and repair of metal structures of transport and agricultural machines. In: Transact. of VNAU. Series Tekhnichni Nauky, Issue 11(66), Vol. 2, 302-306.

6. Petrunin, I.E., Lotsmanov, S.N., Nikolaev, G.A. (1973) Brazing of metals. Moscow: Metallurgiya.

7. Lyapina, O.V. (2006) Physico-chemical processes on surface of copper alloy films: Syn. of Thesis for Cand. of Techn. Sci. Degree. Ivano-Frankivsk: V. Stefanyk PkNU.

8. Kortes, A.P. (2007) Welding, cutting, brazing of metals. Moscow: Adelant.

9. (1976) Technology of welding, brazing and inspection of cutter billets: Recommend of VNII. Ed. by K.P. Imshennik. Moscow: NIIMashprom.

10. Ekatova, A.S. (1975) Fluxes and gas atmospheres: Refer. Book. Moscow: Mashinostroenie.

11. (1989) Manual for design of steel structures to SNIP P-23-81 «Steel structures» of Kucherenko TSNIISK Gosstroya USSR. Moscow: TsITP Gosstroya SSSR.

12. (1990) Strength of welded joints under alternating loads. Ed. by V.I. Trufyakov. Kiev: Naukova Dumka. 


\title{
NEW POSSIBILITIES OF RADIATION CONTROL OF QUALITY OF WELDED JOINTS
}

\author{
V.A. TROITSKY \\ E.O. Paton Electric Welding Institute, NASU \\ 11 Bozhenko Str., 03680, Kiev, Ukraine. E-mail: office@paton.kiev.ua
}

\begin{abstract}
The digital technologies get ever wider application in various fields of engineering, including also in radiation control of quality of welded joints. In the work a high flaw detection efficiency of flash radiography and radiography without intermediate information carriers (films, memory plates) is shown, providing a low cost and ability to multi-angle real-time monitoring of inner defects of welded joints. At the same time the speed of control is significantly reduced. The portable equipment for implementation of this technology is described allowing achieving the sensitivity of up to $0.1 \%$ of thickness of the inspected metal and resolution exceeding 10 pairs of lines per millimeter. 11 Ref., 4 Figures.
\end{abstract}

Key words: non-destructive testing, flash radiography, digital image, X-ray TV system, scintillator, CCD array, flat panel detector, inner defects of welded joints

The most widespread type of non-destructive testing (NDT) of quality of welded joints, materials and products is radiation control. It can be applied to the products of any material, geometry and thickness. Due to visibility of results the radiation methods are preferred both in the quality control of welded and brazed joints, as well as in control of casting quality. This method is used to evaluate the validity of other NDT methods.

In the recent years, the qualitative changes in the system of radiation NDT occurred, first of all due to appearance of new multi-element semiconductor detectors of radiation images, as well as intensive introduction of digital technologies for acquisition, processing and analysis of images. Using such detectors, the ionizing radiation, passing through the examined object and carrying information on its inner defects, is converted using the electronic means into array of electric signals, which are then digitized, processed and used to generate a digital image (DI) of the examined object. DI of the object contains information on its inner structure and is formed immediately during radiation, i.e. in real time. Such method of radiation control is called a digital radiography or a flash radiography [1]. This is actually a portable $\mathrm{X}$-ray television with electronic record of information, which may be posted in the Internet without its additional processing.
A distinctive feature of the flash radiography is absence of intermediate information carriers (radiographic films, semiconductor selenium plates, memory plates with photo-stimulated memory), which are now widely applied in welding industry. They require long operations of exposure, processing and special devices for reading of information. Respectively, the absence of such intermediate carriers allows significantly increasing the productivity and reducing the cost of quality control.

NDT based on portable X-ray TV technology, DI processing fundamentally changes the technology, increases spreading of the most valid radiation NDT. In the recent years the concepts «digital radiography» and DI found wide application. The hardware and software complexes of $\mathrm{X}$-ray films and their DI processing find ever wider spreading [2-6]. Now DI are obtained using three different technologies (Figures 1-3), the procedures of their processing are general, and this is an important trend in the modern radiation flaw detection. The most often DI are obtained by digitization of radiographs. Rarely they are obtained in processing of latent image, read from the memory plates of multiple use, or from digital detectors of the flash radiography.

DI, obtained by any of the three indicated methods, should be equally interpreted. The results of DI radiography processing as to their sensitivity and resolution should be no worse than the result obtained by negatoscope from radiographic film, i.e. the images on DI of the standard reference specimens should be identical to the images on X-ray films. 


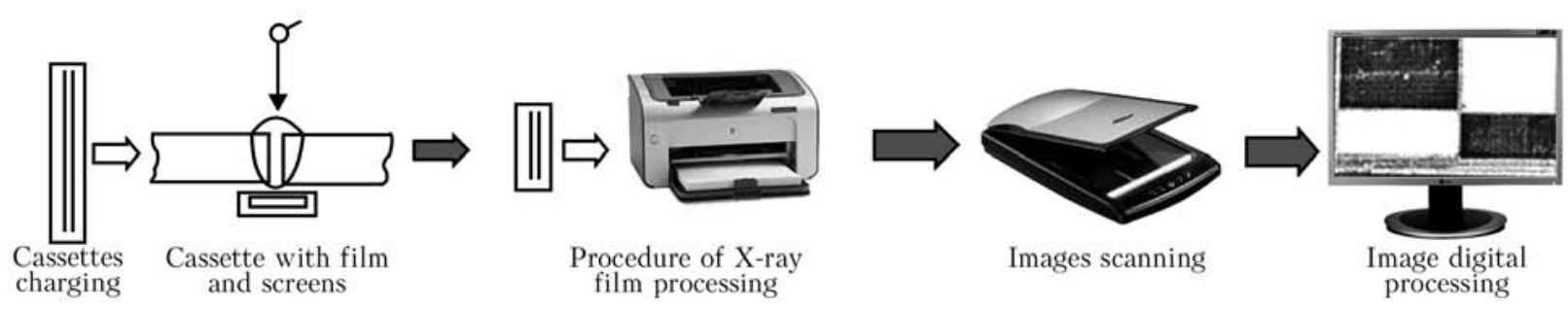

Figure 1. Traditional scheme of radiographic testing using film and digitizing of roentgenograms

The methods for obtaining DI of radiation control results in electronic form are different, but the principles of processing and subsequent decoding of these images are the same [1-7].

Figure 1 shows a classical technological scheme of obtaining DI due to digitizing of film radiographs. This technology is widespread throughout the world, requires preparation of cassete with film and screens. The radiation is followed by the procedures of chemical treatment, drying of the film, reading of information on negatoscope and digitization of results using the appropriate computer complex. This lengthy and expensive technology is used in all industrial sectors, mainly because of the possibility of a compact archiving of NDT in electronic form and for obtaining the additional information, which cannot be obtained without digitizing.

Figure 2 shows the scheme of a more advanced technology of obtaining DI based on memory plates. As compared to the previous scheme of obtaining DI, this technology provides possibility of multiple use of intermediate information carrier. In this case there is no wet process of developing. It provides quicker control, but does not make it cheaper and requires a higher qualification of personnel, much time on auxiliary operations and expensive reading equipment. Often memory plates have their own defects.

Highly evaluating the possibilities of obtaining the additional information during DI processing and an archaic nature of digitization of film images, the world film manufacturers, such as Agfa, Fudjie, Kodak and other took the way of replacement of film by semiconductor memory plates of multiple use.
Figure 3 shows the scheme of technology of instant (flash) digital radiography based on fluoroscopic and solid-state detectors [1-3]. This is the quickest and the cheapest way of obtaining DI of inner defects of welded joints, which does not require processing and reading equipment and the corresponding auxiliary time.

Both new types of filmless radiation control (see Figures 2 and 3) may provide better results than the results of the image digitization obtained using X-ray film.

The quality of X-ray image is determined by sensitivity standards (GOST 7512-82). The classification of welded joints according to the results of radiographic testing is carried out in accordance with GOST 23055-78. It is known that the higher density of blackening and the higher exposure, the more information an exposed film contains. Therefore, to digitize the films, to obtain their informative DI a good scanner is required. The widespread reading devices, inexpensive scanners cannot provide an acceptable quality of digitization of X-ray images if their relative density of blackening is higher than 3 . All the attempts to obtain a satisfactory DI from denser films were not successful. Therefore, in a variant with the film (see Figure 1) obtaining a satisfactory DI is possible if the optical density of the films is only in the range of 1.5-2.5. At such values the noises of digitizer do not introduce irreversible distortions into DI. The experience of digitization of film images with a density of 3.0-3.2 already shows unsatisfactory results, precise information is hardly reproduced. For example, the images of small pores of diameter less than $0.2 \mathrm{~mm}$ and cracks with small opening get

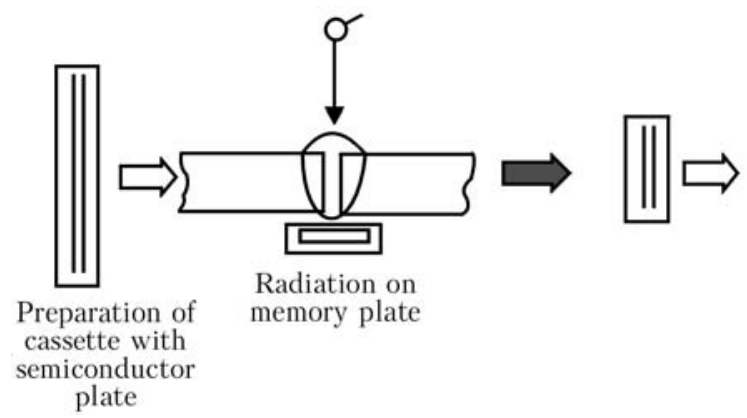

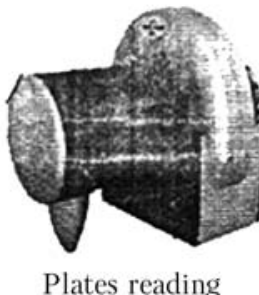

Plates reading

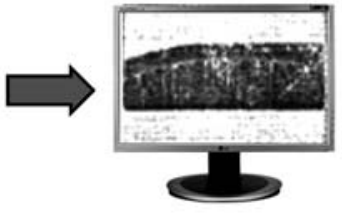

Processing and issue of conclusions

Figure 2. Scheme of radiation technology with the use of memory plate 
lost. Thus, digitization of films has significant limitations. A part of the defects detected using negatoscope is not found on DI. This is a significant drawback of traditional film radiography.

The filmless technologies according to the schemes of Figures 2 and 3 do not have this drawback, they differ in a large dynamic range, which extends the capabilities of NDT. The experience of DI analysis according to the technological schemes of Figures 2 and 3 confirmed that detection of small pores, cracks and inclusions in different welded joints exceeds the information on them on the film. The technology of flash radiography according to Figure 3 based on solidstate or optoelectronic transducers, where after the computer processing of DI it is possible to obtain the sensitivity of up to $0.1 \%$ and also to perform control in motion, has especially great prospects. Moreover, the detectability of defects increases due to the fact that the human eye distinguishes better the tiny moving images than those being in statics. In the absence of intermediate information carriers during radiation according to the scheme in Figure 3 there is a possibility to change its direction, i.e. the tomographic effect is present. For the three technologies (Figures 1-3) the obtained DI is easily archived and transferred via the Internet. The speed, cost of obtaining of one DI according to the technological schemes of Figures $1-3$ is approximately correlated as 10:5:1, and the cost of equipment for these purposes is respectively $5: 20: 1$.

Figure 4 shows the schematic diagrams of obtaining the DI of radiation control in electronic form according to three described technologies.

A common disadvantage of the first two techniques (Figures 1,2) with an intermediate information carrier is non-obviousness in correct designation of the primary radiation mode, the need in repeated, sometimes multiple radiation for finding the optimal values of anode voltage, exposure time, focal distance, as well as supporting procedures with the information carrier. Typically, for the operator to obtain a new object previously not subjected to testing, it is necessary to preset correctly the specified parameters most often by the repeated selection, i.e. with repetition of all the preparatory procedures before radiation. In case of the technology according to Figure 3 the parameters of radiation can be specified in the process of radiation during observation of changes in the image on monitor screen. Thus the optimal modes are found, the image of inner defect is studied from many angles of camera.

During the flash radiography [1] all three parameters or part of them $\left(U_{\mathrm{a}}, I, t\right)$ may vary,
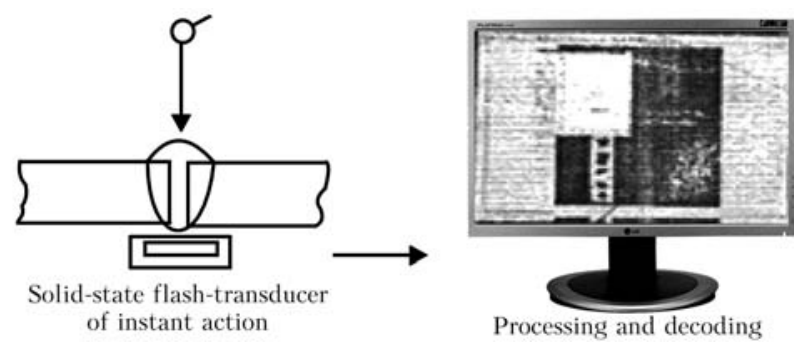

Figure 3. Scheme of radiation without intermediate information carriers

observing the changes of the image on the monitor screen in real time. This circumstance significantly reduces the time and consumables. In addition, the own artifacts of films, screens, memory plates, cassettes in the technologies with intermediate information carriers can be hardly deleted and is poorly defined. In case of studying the image in real time, i.e. according to the technology of Figure 3, with the possibility of varying the parameters of testing mode the artifacts of detector are easily detected and further corrected. The algorithms for work with electronic images are available, providing accumulation and subtraction of individual fragments in DI.

Study [2] of Prof. Majorov is devoted to the comparison of the image quality obtained from different detection systems. He notes that for the technologies without intermediate information carriers, the methods of calibration, subtraction of intrinsic noises of transducers were developed. Thus, they improve the contact sensitivity to such a level that it is possible to mark the changes of thickness radiation as $1 / 1000$, whereas using the best films of class $\mathrm{C} 1$ according to European Standard EN 584-1 and American ASTM E 1815 the best contrast of $1 / 100$ can be achieved.

The image quality [2] is characterized by many specific indicators:

- basic spatial resolution, measured using the reference with double wires (EN 462-5) equal to half of the registered smear or the effective size of pixel (in case of the technology according to Figure 3). The resolution power is determined by the distance of adjacent elements to the image. The value inverse to this distance is the spatial frequency measured in line pairs per one millimeter;

- smear of the image, which has a multifactorial origin due to geometry, projection circumstances, non-sharpness of the detector;

- signal/noise ratio (SNR), which depends on exposure and quality of radiation tract. This ratio increases as the square root of area of working pixels;

- contrast/noise ratio, which depends on SNR of the detector and absorption coefficient of the object material; 


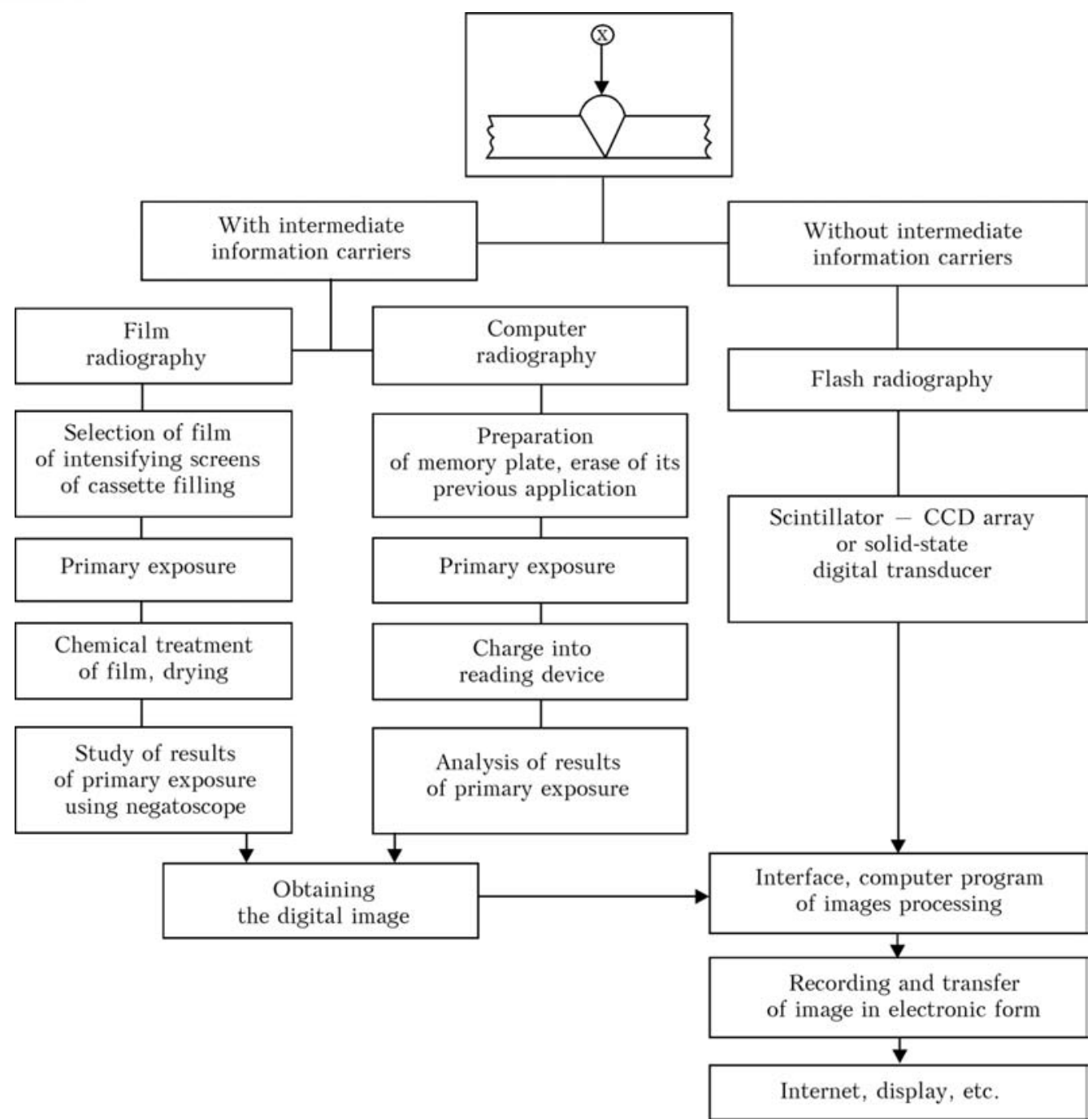

Figure 4. Schematic diagram of technological procedures of obtaining the results of radiation control in electronic form at film, computer and flash radiography

- dynamic range. This is the object thicknesses, available for a satisfactory analysis on one image. The large dynamic range provides significant advantages over the technologies according to schemes in Figures 2 and 3. Usually a large dynamic range is achieved due to the exposure dose, which in the film systems is limited by relative density of blackening 3-4. After that the films become unreadable. In case of digital detector systems (without intermediate carriers) due to the computer technologies «exposure», i.e. accumulation of information, has no limitations. SNR increases as the square root of the dose. This is equivalent to the exposure time or the number of averaged images. Thus SNR is achieved equal to several thousands and of high quality of DI. In practice, this process is limited to the contrast sensitivity of $0.1 \%$, which corresponds to SNR of about 1000.

Therefore, no doubt that the future belongs to the portable X-ray television without intermediate information carriers (memory plates, films, etc.) with the elements of scanning, changes in direction radiation passing through the object [8-11].

The schemes of digital processing of DI (see Figure 4), independently of their method of preparation are almost the same. They include operations of evaluating the fitness of DI, measurements of the intensity of grey, optical density and sensitivity. The digital scale of grey is 16-bit [6], has 65 thousand shades, and the histogram of DI must lie approximately at the center of the scale, to avoid underexposure or overexposure. The central location of the histogram provides digital processing of higher quality, i.e. allows scaling the intensity of grey. The calibration operation is applied according to the size, which allows measuring the defects, performing other procedures unusual for traditional film radiography.

\section{Conclusions}

1. The most informative one, with easy understandable results, is the radiographic method of 
testing welded joints. Using this method it is possible to achieve resolution of about 10 pairs of lines per millimeter, which is very important to detect different cracks in welded structures.

2. One of the serious disadvantages of film radiography is need in powerful light emitters (negatoscopes) in order to see the defects of object captured by X-ray film. Moreover, the darker the picture, the more information it contains on thin defects. At a relative density of blackening of more than 4 the pictures become almost unreadable. This drawback is absent in the modern filmless technologies, which provide, moreover, the result of radiation control in electronic form without special digitizing complexes.

3. The electronic digital information contains illustrative radiation images of inner defects, extends the possibilities of flaw detection, reduces the speed and the cost of control. This provides increase in both accuracy of control and its productivity. Especially the flash radiography is effective based on portable X-ray television. Moreover, intermediate information carriers (films, semiconductor plates) are not required, as far as the same sources of radiation are used, which are used in film radiography. It becomes possible to consider the inner defects from different camera angles, which is not available for other NDT methods.

4. The most challenging one is the flash radiography based on portable X-ray television technology with digital solid-state transducers. At the same time the sensitivity of up to $0.1 \%$ of the thickness of radiated metal and the resolution exceeding 10 pairs of lines per millimeter may be achieved. The use of small-sized movable solidstate transducers opens up new technological possibilities in NDT of quality of welded joints.

1. Troitsky, V.A. (2013) Flash radiography. Territoriya ND, Oct.-Dec., 44-49.

2. Majorov, A.A. (2009) Digital technologies in radiation control. V Mire Nerazrush. Kontrolya, 3, 21-24.

3. Troitsky, V.A., Mikhajlov, S.P., Pastovensky, R.A. et al. (2015) Modern systems of radiation nondestructive testing. Tekhn. Diagnostika $i$ Nerazrush. Kontrol, 1, 23-25.

4. Stepanov, A.V., Lozhkova, D.S., Kosarina, E.S. (2010) Computer radiography of results of practical investigations of possibility to replace the film technologies, 11-14. Moscow: VIAM.

5. Grudsky, A.Ya., Velichko, V.Ya. (2011) Digitizing of radiograms is not very simple. V Mire Nerazrush. Kontrolya, 4, 32-34.

6. Tsvetkova, N.K., Novitskaya, K.A., Kologov, A.V. et al. (2014) Peculiarities of application of digital radiography complexes in nondestructive testing of casing production. Tekhnologiya Mashinostroeniya, 7, 47-50.

7. Varlamov, A.N. (2014) Experience of operation of digital radiography complex in field conditions. $V$ Mire Nerazrush. Kontrolya, 63, 25-28.

8. Majorov, A.A. (2007) X-ray television in industrial NDT. Ibid., 35(1), 4-9.

9. Zscherpel, U., Ewert, U., Bavendiek, K. (2007) Possibilities and limits of digital industrial radiology: The new high contrast sensitivity technique - Examples and system theoretical analysis. Lyon.

10. GOST 27947-88: Nondestructive testing. X-ray TV method. General requirements. Moscow.

11. GOST 29025-91: X-ray TV detectors. General technical requirements. Moscow.

Received 09.04.2015 


\section{INTERNATIONAL CONFERENCE «SURFACING - SCIENCE, PRODUCTION, PROSPECTS»}

During the period from 16 till 17 June, 2015 the International Conference «Surfacing - Science, Production, Prospects» was held at the E.O. Paton Electric Welding Institute of the NAS of Ukraine.

The organizers of the Conference were the E.O. Paton Electric Welding Institute, International Association «Welding», Association «Elektrod», Society of Welders of Ukraine, Russian Scientific-Technical Welding Society.

About 100 specialists took part in the Conference from Ukraine, Austria, Germany, Lithuania, Poland, Russia and France. 40 plenary papers were presented on the following directions: theoretical problems of surfacing; new surfacing materials; new technological processes of surfacing; experience of application of surfacing technologies in different branches of industry (metallurgy, mining industry, petrochemistry, transport, machine building); equipment for mechanized and automatic processes of surfacing; systems of monitoring and control of technological processes of surfacing; serviceability; service life of surfaced components; standard documents, including those of an international level for fulfillment of surfacing works.

It is possible to find papers of the Conference in a special issue of journal «The Paton Welding Journal» Nos. 5 / 6, published for the Conference.

The Conference was opened by Prof. K.A. Yushchenko (PWI), presenting the review paper «Some basic directions in the development of principles and processes of surfacing», in which the attention of the participants was concen-

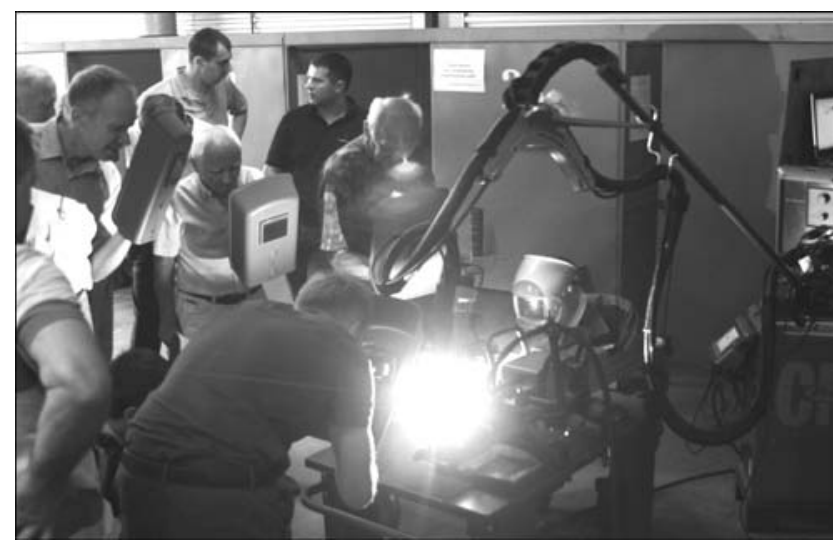

CMT surfacing trated on the new approaches to solution of nowadays problems using surfacing.

The papers-presentations are to be noted, which presented the great interest to the Conference participants, but were not included into the Proceedings, namely: «Advanced methods of surfacing in industry» by V.L. Bondarenko, K.Yu. Korzin («Fronius Ukraine», Kiev region, vil. Knyazhichi); «Assessment of defects in surfacing» by R. Rosert (Dr. Rosert RCT GmbH, Dresden, Germany); «3D laser additive treatment. New stage of the further development of machine building» by V.S. Kovalenko (NTUU «Kiev Polytechnic Institute»); «Modernization of plasma-powder surfacing process in Kennametal Stellite equipment» by A. Pavlenko, E. Dubinina (Kennametal Stellite GmbH \&Co. KG, Koblenz, Germany); «Flux-cored wire for surfacing and repair of parts of carbon-manganese steels» by N.A. Solovej (NPF «Elna», Kiev).

Innovation approaches were presented in two papers of specialists from NTUU «KPI»: «Wearresistant surfacing with adding of nanooxides into weld pool» by V.D. Kuznetsov and «Capabilities of laser radiation for improvement of electrode wire quality» by S.B. Shevchenko, I.V. Krivtsun, L.F. Golovko, A.N. Lutaj, and V.P. Slobodyanyuk from company «PlasmaTech», Vinnitsa, Ukraine).

From the PWI the larger number of papers was presented by the Department «Physical-metallurgical processes of surfacing of wear- and heat-resistant steels», headed by I.A. Ryabtsev (10 papers) and the Department «Hardfacing

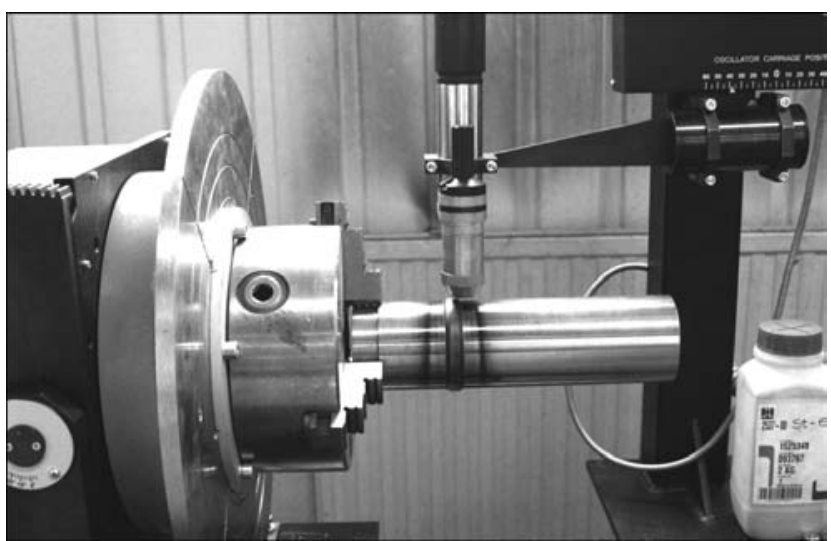

Plasma-powder surfacing 


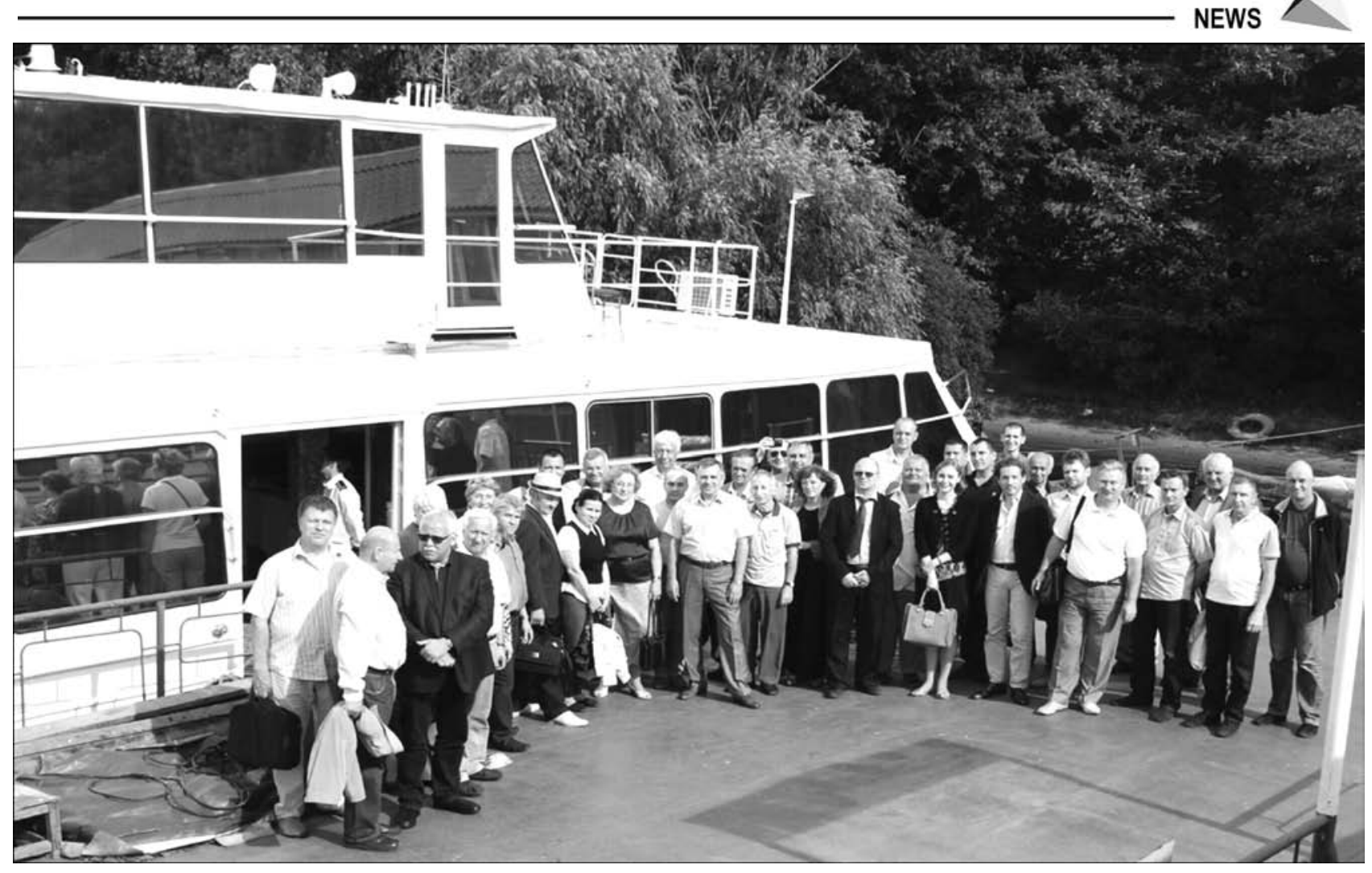

The Conference final: voyage along the Dnieper river

consumables and technologies of hardfacing of metals», headed by A.P. Zhudra (3 papers).

During the Conference the exhibition of materials, technologies and equipment for surfacing with samples of products of organizations-participants of the Conference was organized, where the developments were demonstrated of some PWI departments, PWI EDTB, PWI PPWE, as well as of companies TM.Veltek, Vitapolis, Migatech Industry, Navko-Tech, Plasma-Master, PlasmaTech, Fronius Ukraine, Frunze-Elektrod, Elna, ESAB Ukraine.

During exhibition it was possible to make subscription for books and journals in the field of welding and related technologies, published over the recent years, as well as to get familiar with the published collection «Surfacing. Technology. Materials. Equipment» (compiled by I.A. Ryabtsev, I.A. Kondratiev, E.F. Pereplyotchikov and Yu.M. Kuskov). Collection includes 119 articles of associates of the PWI Department «Physical-metallurgical processes of surfacing of wear- and heat-resistant steels», which generalizes and is structuring the many-year experience in the field of research and development of the new methods of surfacing, surfacing consumables, technologies of surfacing and design of surfacing equipment.
On June 16 the operating equipment was demonstrated at the facility of the PWI Inter-Industry Training and Certification Centre: CMT surfacing (Fronius Ukraine); plasma powder surfacing with demonstration of surfaced parts and series of manufactured plasmatrons for surfacing (PlasmaMaster); surfacing with pulsed feeding of electrode wire (PWI Department «Physicalmechanical investigations of weldability of structural steels»).

Over the period of the Conference, on June 16, the Meeting of specialists of enterprises-members of Association «Elektrod» and PWI was held. Discussed were the present situation of activity of the Association and trends in improvement of work and also the coming 25th jubilee since the day of its organizing and the conference on the occasion of its organizing in Rostov Veliky, RF, in 2016. During the Meeting the Agreement was signed about cooperation between the Society of Welders of Ukraine and Association «Elektrod».

The Conference was carried out in creative, friendly atmosphere and finalized by the voyage at the motor ship along the Dnieper river.

A. Zelnichenko, V. Lipodaev, PWI 


\title{
PATON PUBLISHING HOUSE
}

\author{
www.patonpublishinghouse.com
}

SUBSCRIPTION

The Patgobrinat

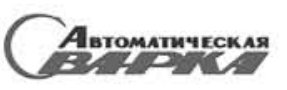

«The Paton Welding Journal» is Published Monthly Since 2000 in English, ISSN 0957-798X.

«Avtomaticheskaya Svarka» Journal (Automatic Welding) is Published

Monthly Since 1948 in Russian, ISSN 005-111X.

«The Paton Welding Journal» is Cover-to-Cover Translation of

Avtomaticheskaya Svarka» Journal into English.

If You are interested in making subscription directly via Editorial Board, fill, please, the coupon and send application by Fax or E-mail.

The cost of annual subscription via Editorial Board is $\$ 348$ for «The Paton Welding Journal» and $\$ 180$ for «Avtomaticheskaya Svarka» Journal.

«The Paton Welding Journal» can be also subscribed worldwide from catalogues subscription agency EBSO.

\author{
SUBSCRIPTION COUPON \\ Address for journal delivery \\ Term of subscription since \\ Name, initials \\ Affiliation \\ Position \\ Tel., Fax, E-mail
}

20

till

20

We offer the subscription all issues of the Journal in pdf format, starting from 2009.

The archives for 2009-2012 are free of charge on wrw.patonpublishinghouse.com site.
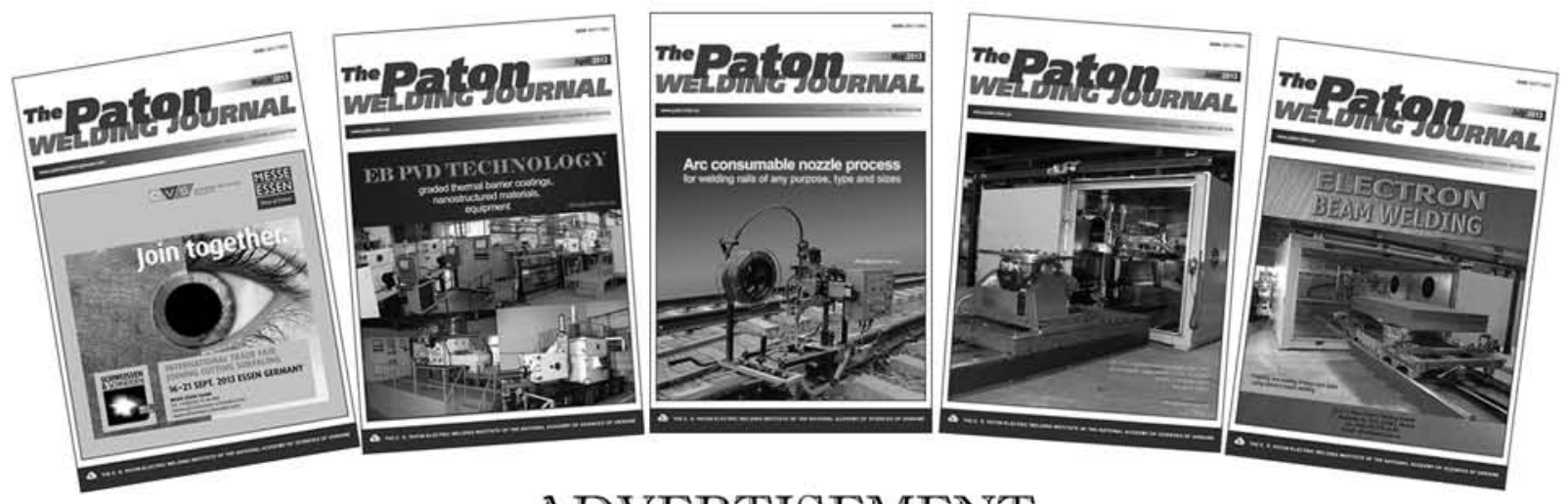

\section{ADVERTISEMENT}

in "Avtomaticheskaya Svarka" and "The Paton Welding Journal"

External cover, fully-colored:

First page of cover

$(190 \times 190 \mathrm{~mm})-\$ 700$

Second page of cover

$(200 \times 290 \mathrm{~mm})-\$ 550$

Third page of cover

$(200 \times 290 \mathrm{~mm})-\$ 500$

Fourth page of cover

$(200 \times 290 \mathrm{~mm})-\$ 600$

\author{
Internal cover, fully-colored: \\ First/second/third/fourth page \\ of cover $(200 \times 290 \mathrm{~mm})-\$ 400$ \\ Internal insert: \\ Fully-colored $(200 \times 290 \mathrm{~mm})-$ \\ $\$ 340$ \\ Fully-colored (double page A3) \\ $(400 \times 290 \mathrm{~mm})-\$ 500$
}

- Article in the form of advertising is $50 \%$ of the cost of advertising area

- When the sum of advertising contracts exceeds $\$ 1001$, a flexible system of discounts is envisaged

Size of journal after cutting is $200 \times 290 \mathrm{~mm}$

Editorial Board of Journal «Avtomaticheskaya Svarka» and «The Paton Welding Journal»

E.O. Paton Electric Welding Institute of the NAS of Ukraine

International Association \&Welding

11, Bozhenko Str., 03680, Kyiv, Ukraine

Tel.: (38044) 20060 16, 20082 77; Fax: (38044) 20082 77, 2008145

E-mail: journal@paton.kiev.ua; www.patonpublishinghouse.com 